\title{
On the contribution of MMP-2 and MMP-9 to the postnatal cerebellar corticogenesis
}

\author{
Albert E. Ayoub \\ West Virginia University
}

Follow this and additional works at: https://researchrepository.wvu.edu/etd

\section{Recommended Citation}

Ayoub, Albert E., "On the contribution of MMP-2 and MMP-9 to the postnatal cerebellar corticogenesis" (2003). Graduate Theses, Dissertations, and Problem Reports. 1939.

https://researchrepository.wvu.edu/etd/1939

This Dissertation is protected by copyright and/or related rights. It has been brought to you by the The Research Repository @ WVU with permission from the rights-holder(s). You are free to use this Dissertation in any way that is permitted by the copyright and related rights legislation that applies to your use. For other uses you must obtain permission from the rights-holder(s) directly, unless additional rights are indicated by a Creative Commons license in the record and/ or on the work itself. This Dissertation has been accepted for inclusion in WVU Graduate Theses, Dissertations, and Problem Reports collection by an authorized administrator of The Research Repository @ WVU.

For more information, please contact researchrepository@mail.wvu.edu. 


\title{
On the Contribution of MMP-2 and MMP-9 to the Postnatal Cerebellar Corticogenesis
}

\author{
Albert E. Ayoub \\ Dissertation submitted to the \\ School of Medicine \\ at West Virginia University \\ in partial fulfillment of the requirements \\ for the degree of
}

Doctor of Philosophy

Jia Luo, Ph.D., Chair

William A. Beresford, D. Phil.

Albert S. Berrebi, Ph.D.

James L. Culberson, Ph.D.

Richard C. Wiggins, Ph.D.

Department of Neurobiology and Anatomy

Morgantown, West Virginia

2003

Keywords: Bergmann glia, cerebellum, development, extracellular matrix, gelatinases, gelatinase inhibitor, granule neurons, migration, Purkinje neurons, matrix metalloproteinase 2, matrix metalloproteinase 9 


\title{
Abstract \\ On the Contribution of MMP-2 and MMP-9 to the Postnatal Cerebellar Corticogenesis
}

\begin{abstract}
Albert E. Ayoub
The development of the cerebellar cortex is dependent on orchestrated cell-cell, cell-matrix interactions, as well as intrinsic genetic programs. Matrix metalloproteinases (MMPs) are proteolytic enzymes that degrade ECM molecules and are involved in neuronal migration, process extension, and synaptic plasticity. The current study investigated (1) the developmental expression and activity of MMP-2 and MMP-9, and (2) the effect of blocking the activity of MMP-2 and MMP-9 by a specific inhibitor on the histogenesis of the cerebellar cortex. Cerebella were collected from rat pups every three days starting at postnatal day 3 (P3) until P25 - a period equivalent to the third gestational trimester in humans. Temporal analysis of MMP activity by gelatinase assay showed that both the active and latent forms were present in the developing cerebellum. The mRNA analysis by real-time quantitative PCR indicated that the expression pattern of MMP-2 and MMP-9 mRNA agreed with their gelatinase activity. In situ zymography was localized in the EGL, the PCL, and IGL. The EGL, Bergamnn glial fibers, and the PCL showed immunoreactivity for MMP-2, whereas MMP-9 immunoreactivity was detected only in PC and the EGL. Exposure of organotypic slices to a specific MMP2/MMP-9 inhibitor $(1.6,3.2$ or $6.4 \mu \mathrm{M})$ altered the activity of MMP-2 and 9 and caused a significant increase in the thickness of the EGL, and a decrease in migrating granule neurons in the molecular layer. Our study suggests that MMP-2 and MMP-9 play a role in the postnatal cerebellar histogenesis.
\end{abstract}




\section{Dedication}

To my family in Lebanon, to my wife

and

to the loving memory of my father

Elias I. Ayoub

who passed away December 25, 2001. 


\section{Acknowledgments}

Dr. Luo: thanks for being an excellent mentor. I appreciate the time you spent guiding me through our scientific inquiry. Thanks for being patient and available for discussions. Thanks to Dr. Luo's laboratory members, Dr. Cuiling Ma, Hong Lin, Zheng Li, Gang Chen, and Kimberly Bower for their friendship, help, and encouragement. I also thank Rebecca Kaplan for her assistance and help performing the real-time quantitave RT-PCR experiment. Last but not least, thanks to Dr. Aye for being a good colleague and friend.

Dr. Wiggins: Thanks for helping me understand the importance of balacing a reductionist and a holistic approach to the study of neuroscience. Thanks for your invaluable carrier guidance, help in various aspects of my project, and introducing me to developmental neuroscience.

Dr. Aric Agmon: I admire the scientist he is, his critical eye, and his willingness to share his knowledge. Dr. Agmon's lab has always been open to me to learn various techniques. I met good friends and colleagues in his lab, especially Cary Johnson, Jason Wells, and Xiaming Jin. Thanks to Dr. Agmon and Hang Hu for their assistance in my project, especially for teaching me how to prepare organotypic slice cultures.

Dr. Al Berrebi: I learned many things in his lab, especially the importance of team work and attention to details. Thanks for sharing your expertise in immunohistochemitry and your assistance with this project.

Dr. Beresford: He is simply a great teacher. Dr. Beresford is always helpful and ready to provide insight and guidance. I am glad I had the chance to learn from him. I am also very thankful for his help and suggestions in improving this manuscript.

Dr. Culberson: Thanks for teaching me neuroscience. I especially enjoyed learning from him the structure of the CNS, history of neuroscience, and the ethics of teaching medical neurobiology.

Dr. Salm: Thanks for getting me knee-deep in neuroscience. Her enthousiasm about neuroscience is contagious. My neuroscience career started as a short undergraduate research project in her Lab. It was enough to lure me into the study of the brain. Thanks for being a good mentor and a friend. I am happy I had the chance to work in her lab and meet Dr. Kraszpulski, Patricia Dickerson, Brent Lally, and the late Dr. Hawrylack.

I met wonderful colleagues, mentors, and teachers in the department, especially Dr. Dey, Dr. Konat, Dr. Reilly, Dr. Cilento, Dr. Walker, Dr Ressetar, and the late Dr. Overman. And many thanks to the staff members especially Lois Corbin, Suzie Martin, Jeff Altimus, Janice Shaw, Joyce Riffle, and Robert Bolyard 


\section{Table of Contents}

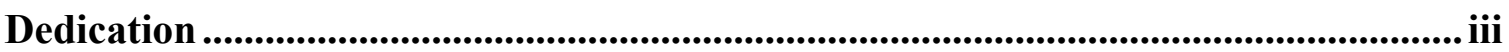

Acknowledgments ................................................................................................................. iv

Table of Contents ................................................................................................................. v

Index of Figures............................................................................................................................. vi

Index of Tables ................................................................................................................ vii

List of Abbreviations .............................................................................................................. viii

Chapter One: Introduction ............................................................................................................ 1

Chapter Two: Literature Review .......................................................................................... 6

A REVIEW OF THE STRUCTURE AND FUNCTION OF THE CEREBELLUM...................................................... 7

CEREBELLAR CORTICOGENESIS: WITH EMPHASIS ON THE ONTOGENESIS OF GRANULE NEURONS AND THE

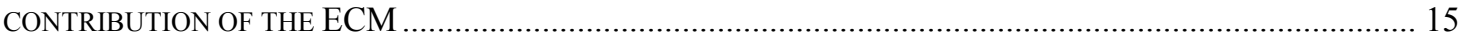

MATRIX METALLOPROTEINASES AND THE EXTRACELLULAR MATRIX IN THE CNS .............................. 31

Chapter Three: Expression of MMP-2 and MMP-9 and their role in the histogenesis of the postnatal cerebellar cortex ............................................................................................. 41

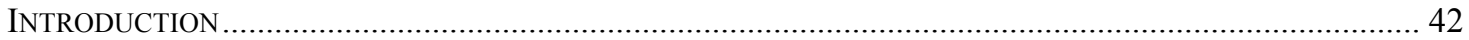

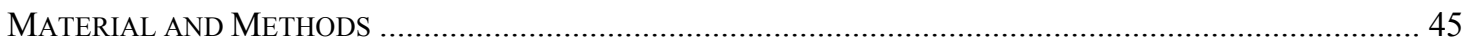

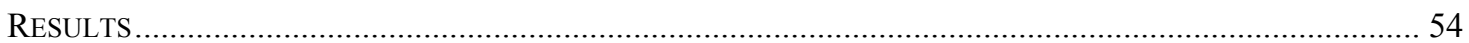

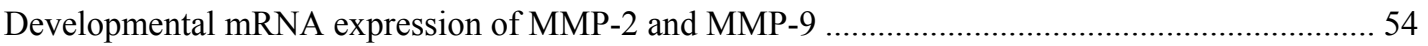

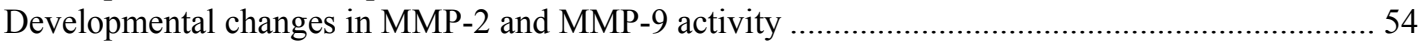

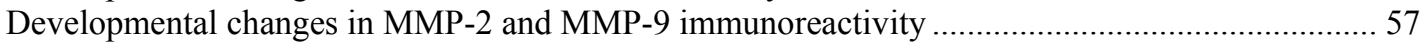

Effect of specific MMP-2 and MMP-9 inhibitor on cerebellar morphology ............................... 59

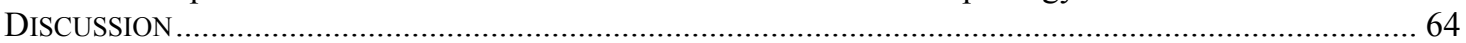

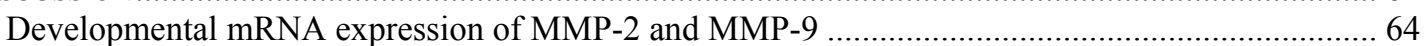

Developmental changes in MMP-2 and MMP-9 activity ............................................................6 66

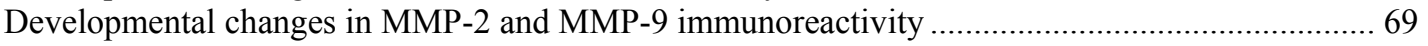

The effect of inhibiting gelatinases on cerebellar development in organotypic slice culture............. 71

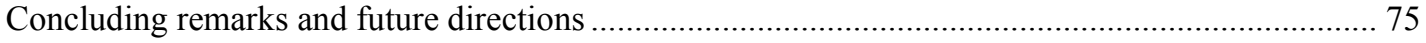

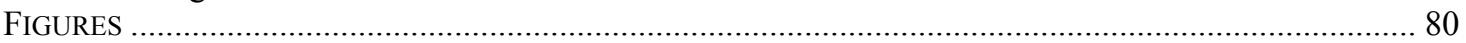

Reference List........................................................................................................................... 107

Appendix 1: Detailed experimental protocols ................................................................. 136

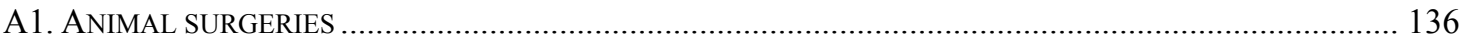

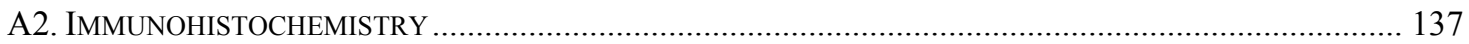

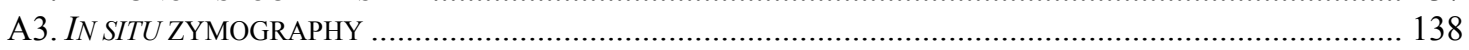

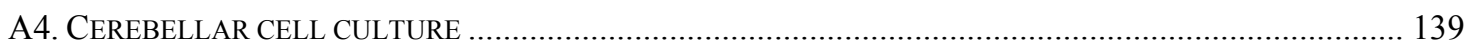

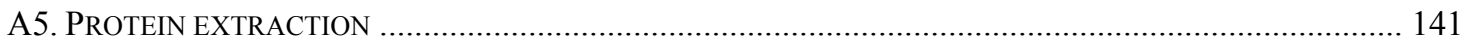

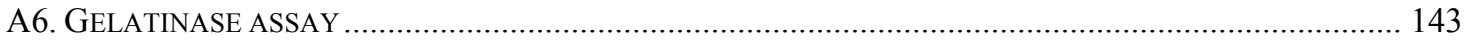

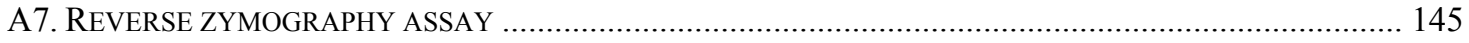

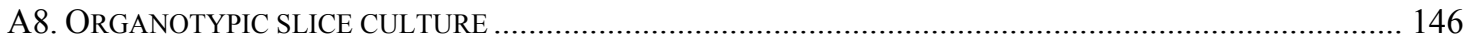

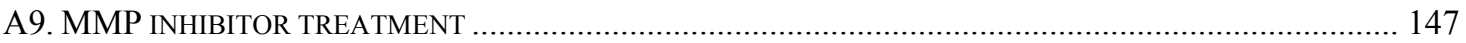

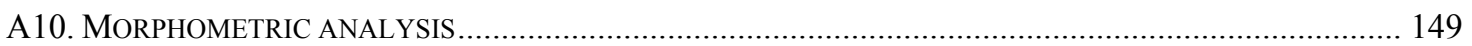

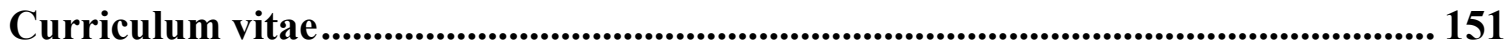




\section{Index of Figures}

Chapter One

Page

Figure 1.1

Formation of the cerebellar primordium 3

Chapter Two

Figure 2.1

Figure 2.2

Figure 2.3

Figure 2.4

Figure 2.5

Figure 2.6

Figure 2.7

An illustration of the major cerebellar pathways................ 9

Histology of the cerebellum................................ 10

Relationship between Bergamnn glia and Purkinje neurons....... 12

Cerebellar histogenesis.................................. 16

A schematic representation of the developmental stages of granule neurons by Ramon ý Cajal (1911)..................... 20

Structural domains of gelatinases.......................... 34

Activation of MMP-2 and MMP-9's gene expression.............36

Chapter Three

Figure 3.1

Figure 3.2

Figure 3.3

Figure 3.4

Figure 3.5

Figure 3.6

Figure 3.7

Figure 3.8

Figure 3.9

Figure 3.10

Real-time quantitative RT-PCR ........................... 72

Gelatinase activity in the cerebellar cortex between P3 and P25..73

In situ zymography in the developing cerbellum................ 74

Immunohistochemical expression of MMP-2 and MMP-9 ...... 75

Detailed view of MMP-2 immunohistochemistry.............. 79

Detailed view of MMP-9 immunohistochemistry ............ 81

Control sections for MMP-9 IHC from P15 rat cerebellum...... 83

Expression and activity of MMP-2 and MMP-9 in vitro.......... 84

The effect of inhibitor treatment on the activity of MM-2 and

MMP-9 in vitro............................................ 86

The effect of inhibitor treatment on cerebellar corticogenesis in

vitro................................................. 87

Appendix

$\begin{array}{llr}\text { Figure A.1 } & \text { Freezing slices for IHC and ISZ } & 126\end{array}$

$\begin{array}{lll}\text { Figure A.2 } & \text { Morphometric analysis in cerebellar sections }\end{array}$ 


\section{Index of Tables}

Chapter Three

Page

Table 3.1

Table 3.2

Slice culture treatment groups...........................53

Percent change in the thickness of the EGL after treatment with

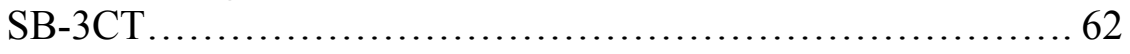

Table 3.3 Percent change in the number of migrating cells in the ML after treatment with SB-3CT............................... 63

Appendix

Table A.1

Protein concentration for gelatinase assay. 144 


\section{List of Abbreviations}

\begin{tabular}{|c|c|}
\hline $\mathrm{BC}$ & Basket cells \\
\hline BG & Bergmann glia \\
\hline BGF & Bergmann glial fiber \\
\hline $\mathrm{BL}$ & Basal lamina \\
\hline Cbl & Cerebellum \\
\hline CGN & Cerebellar granule neuron \\
\hline Ctx & Cortex \\
\hline $\mathrm{CF}$ & Climbing fibers \\
\hline dEGL & Deep external granule layer \\
\hline DIV & Days in vitro \\
\hline $\mathrm{ECM}$ & Extracellular matrix \\
\hline EGL & External granule layer \\
\hline $\mathrm{EtOH}$ & Ethanol \\
\hline $\mathrm{GC}$ & Golgi type II cells \\
\hline HSPG & Heparan sulfate proteoglycans \\
\hline Hip & Hippocampus \\
\hline $\mathrm{IHC}$ & Immunohistochemistry \\
\hline IGL & Internal granule layer \\
\hline ISZ & In situ zymography \\
\hline ML & Molecular layer \\
\hline MMP & Matrix Metalloproteinase \\
\hline O.C.T. & Optimum cutting temperature compound \\
\hline OSC & Organotypic slice culture \\
\hline $\mathrm{P}$ & Postnatal day \\
\hline PBS & Phosphate buffer saline \\
\hline PC & Purkinje cells \\
\hline PD & Purkinje cell dendrite \\
\hline PCL & Purkinje cell layer \\
\hline PF & Parallel fibers \\
\hline sEGL & Superfiacial external granule layer \\
\hline TX & Triton X-100 \\
\hline WM & White matter \\
\hline
\end{tabular}


Chapter One: Introduction 
The development of the cerebellar cortex involves the timely generation of different types of cells with a precise connection pattern that produces highly conserved tissue architecture. The cerebellum develops from the rhombic lip on the roof of the fourth ventricle. Cells in the cerebellum are generated from two germinal zones - the ventricular germinal zone and the external germinal layer (Figure 1.1). Precursor cells in the ventricular germinal zone generate cerebellar neurons and glial cells starting with Purkinje cells around embryonic day 11 in rodents and embryonic day 55 in humans (Gilthorpe et al., 2002; Yachnis and Rorke, 1999). Progenitors of granule neurons migrate from the rhombic lip and form a thin external germinal layer that generate granule neurons during the first two postnatal weeks in rodents and the last trimester of human fetal development. The organization of the cerebellar cortex and its development are dependent on a myriad of intrinsic and extrinsic factors. The orchestration of the activity of genes, gene products, interactions among cells, and between cells and the extracellular matrix is crucial for neurogenesis, migration, and differentiation. Each of these developmental processes is vulnerable to disruption. Numerous gene mutations and neurotoxic agents are known to cause developmental abnormalities in the cerebellum by interfering with these processes (Ferguson, 1996; Millen et al., 1999). Analysis of mutations, like reeler and weaver, and toxin-induced abnormalities, like exposure to lead and methylmercury (Howard and Mottet, 1986; Lorton and Anderson, 1986), helped uncover an array of molecular and genetic mechanisms that drive the development of the cerebellum.

The histogenesis of the internal granule layer has been extensively studied and is an excellent model to study neurogenesis, migration, process extension, and 
differentiation. Progenitor cells in the external granule layer proliferate rapidly then migrate radially towards the ventricular zone and form the internal granule layer. As they descend, they extend two apical processes forming the parallel fibers that synaptically connect to the dendritic spines of Purkinje neurons. Granule neurons migrate through an already formed molecular layer, past the Purkinje cell layer and stop before reaching the white matter. Bergmann glial processes help guide the migration of granule neurons through the molecular layer. Extensive development of Purkinje cell dendritic trees and maturation of Bergmann glial processes occur during the same period. The molecules involved in remodeling the extracellular matrix for migrating granule neurons and extending processes are not well understood.

Extracellular matrix-degrading enzymes, matrix metalloproteinases (MMP), have been studied in other systems and been shown to be involved in cell proliferation, process extension, migration and cancer metastasis. These enzymes are normally tightly regulated due to their potent proteolytic activity. Specific tissue inhibitors of matrix metalloproteinases (TIMPS) are expressed concomitantly with MMPs and regulate the activation of matrix metalloproteinases. Emerging evidence connects MMPs, especially MMP-2 and MMP-9, to events like normal brain development, tissue remodeling and various diseases and injuries affecting the central nervous system (Yong et al., 2001). For example, Vaillant et al (1999) showed that MMP-2 and MMP-9 are expressed in the cerebellum at postnatal days 10 and 15 . However, the functional contribution and developmental expression and temporal activity of MMP-2 and MMP-9 in the developing cerebellar cortex are not known. 


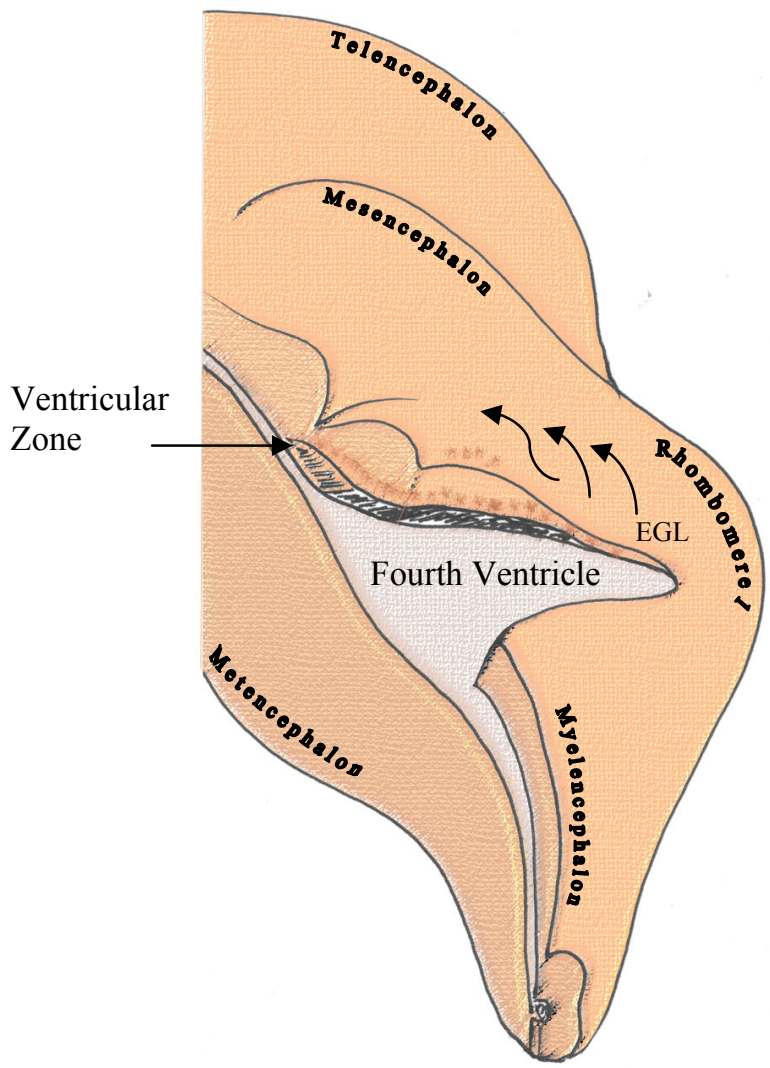

Figure 1.1 Formation of the cerebellar primordium. Progenitors of granule neurons migrate from the rhombic lip on the surface of the cerebellar primordium (curved arrows) and form the external granule layer (EGL) of Obersteiner.

The central hypothesis of this investigation is that MMP-2 and MMP-9 contribute to the development of the rat cerebellar cortex, with the implication that the disruption of MMP-2 and MMP-9's function would cause developmental abnormalities. The study tested the hypothesis by pursuing the following objectives: 1) localize and determine the temporal pattern of expression of MMP-2 and MMP-9 and their spatiotemporal activity in the developing cerebellum, 2) to determine whether blocking MMP-2 and MMP-9's activation by a specific inhibitor hinders the proliferation and migration of granule cells. In order to establish a developmental pattern for the expression of MMP-2 and MMP-9, 
we performed an immunohistochemical study, real-time quantitative RT-PCR, and zymographic analysis on tissue collected from neonatal rats every 3 days from postnatal day 3 until postnatal day 25. Finally, we investigated the effect of inhibition on MMP-2 and MMP-9 in an organotypic slice culture system. We measured the activity of these enzymes, the thickness of the external granule layer and the number of migrating cells in the molecular layer in thinly sectioned slices after exposure to a specific MMP-2/MMP-9 inhibitor. 
Chapter Two: Literature Review 


\section{A review of the structure and function of the cerebellum}

The cerebellum contributes significantly to planning and coordinating movement, maintaining muscle tone and equilibrium, and motor learning and plasticity. Among cerebellar dysfunctions, motor disorders like dysmetria, dysdiadochokinesia and hypotonia are most prevalent. Several developmental and genetic disorders riddle the cerebellum such as Joubert's syndrome (Yachnis and Rorke, 1999), Walker's lissencephaly and neu-laxova syndrome (Lyon et al., 1993). Ethyl alcohol consumption and exposure is also a major cause of damage to the cerebellum (Bendszus et al., 2001; Brodie, 2002; Tagliaferro et al., 2002; White et al., 2000a), especially during development (Bonthius et al., 1988; Bonthius and West, 1988; Cragg and Phillips, 1985; Olney et al., 2002; Pierce et al., 1999).

The cerebellum is located in the posterior cranial fossa below the dural tentorium cerebelli. The cerebellum constitutes part of the roof of the fourth ventricle. It lies behind the isthmus, the boundary between the midbrain and the hindbrain, and dorsal to the pons and medulla oblongata. The cerebellum is divided into a narrow medial portion called the vermis and two lateral hemispheres. Numerous transverse sulci create thin folia (leaflets) that extend over the entire external surface of the cerebellum (Conradi, 1985). Deeper fissures subdivide the surface of the cerebellum into lobules, which are grouped into three principal lobes -- anterior, posterolateral and flocculonodular. The flocculonodular lobe is the phylogenetically oldest part of the cerebellum and is called the archicerebellum. This division is primarily involved in maintaining equilibrium and is connected with the 
vestibular system. The second oldest division of the cerebellum is called the paleocerebellum and contains the anterior lobe. This part maintains muscle tone and coordinates limb movements. The posterolateral lobe is considered the neocerebellum and is responsible for coordinating fine movements (Altman and Bayer, 1997; Whiting and Barton, 2003; Dillon and Atkins, 1970; Parma, 1969; Nieuwenhuys, 1967).

In the cerebellum, white matter lies below the cortical mantle and encapsulates four pairs of deep cerebellar nuclei. From medial to lateral, they are called the fastigial, the globose, the emboliform, and the dentate (Korneliussen, 1968). These nuclei receive output from the cerebellar cortex and collaterals from climbing and mossy fibers. Cortical projections to the deep nuclei are all inhibitory, GABAergic neurons, which originate in Purkinje cells. The dentate, emboliform, and globose send projections via the superior cerebellar peduncle to the red nucleus, ventral lateral and ventral posterolateral nuclei of the thalamus, other thalamic nuclei, and the contralateral inferior olivary nucleus. Efferent fibers from the fastigial nucleus target contralateral brain stem nuclei, various nuclei in the reticular formation, motor neurons in the upper cervical spinal cord, bilateral vestibular nuclei, superior colliculus, and ventral lateral and ventral posterolateral nuclei of the thalamus (Figure 2.1) [for more details refer to (Kandel et al., 2000; Altman and Bayer, 1997)].

Three major pairs of fiber bundles connect the cerebellum to the rest of the nervous system. The superior cerebellar peduncle has cerebellar efferents to the thalamus, the red nucleus, vestibular nuclei, the reticular formation, the oculomotor nucleus, and contains a few afferent fibers from the spinal cord. The middle cerebellar peduncle contains efferents from contralateral pontine nuclei, while the inferior cerebellar peduncle 
links the cerebellum with the inferior olive, brain stem nuclei, vestibular nuclei and the spinal cord (Carpenter, 1991; Altman and Bayer, 1997; Hayle, 1973; Jansen, 1972; Ito, 1968; Eccles, 1967).

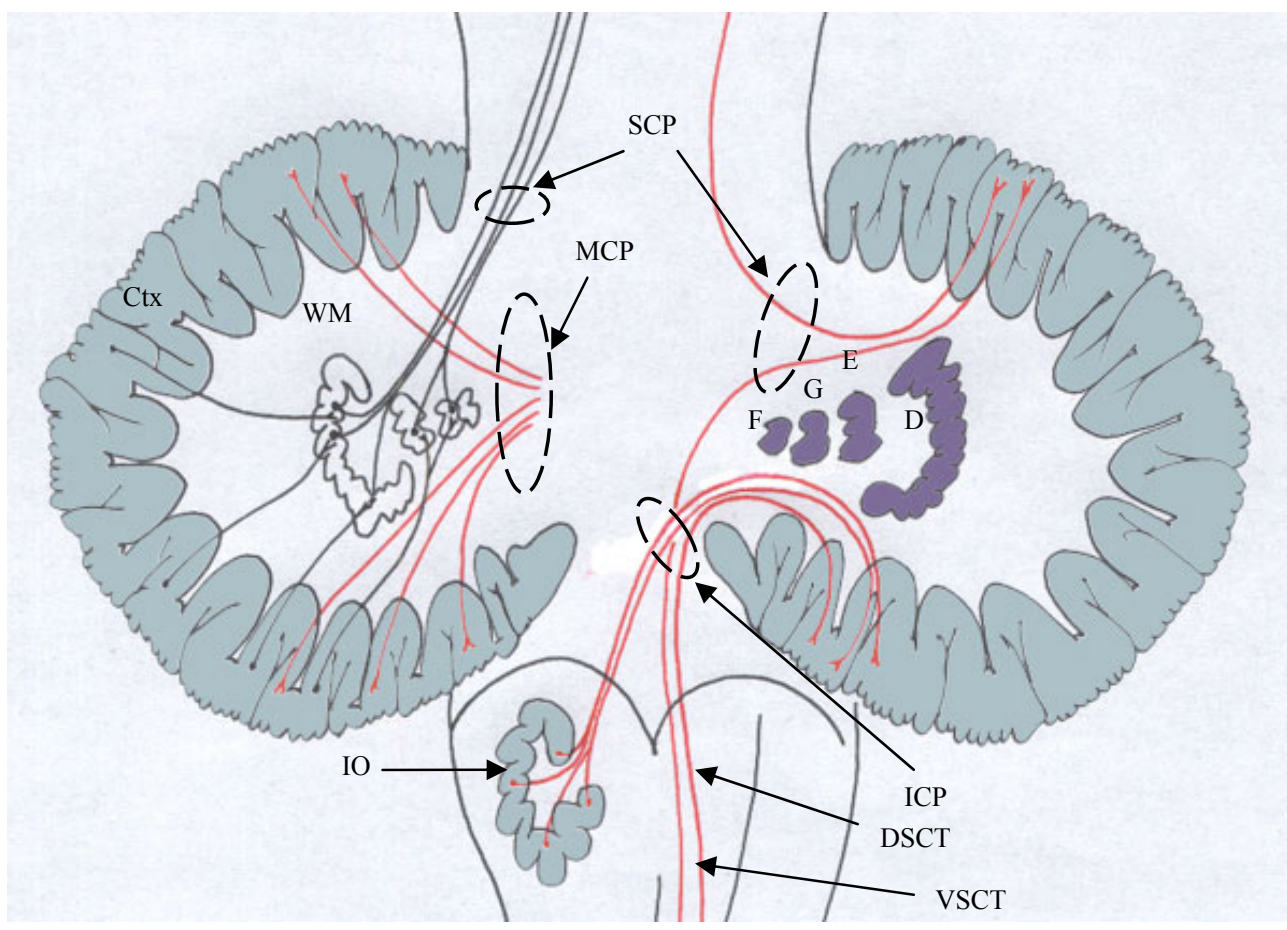

Figure 2.1 An illustration of the major cerebellar pathways. Refer to the text for description. (Ctx: cortex; D: dentate nucleus; DSCT: dorsal spinocerebellar tract; E: emboliform; F: fastigial; G: globose; ICP: inferior cerebellar peduncle; IO: inferior olive; MCP: middle cerebellar peduncle; SCP: superior cerebellar peduncle; VSCT: ventral spinocerebellar tract; WM: white matter) (adapted from Carpenter, 1991).

The organization of the cerebellar cortex is noticeably conserved among vertebrates, especially with regard to the connection pattern among cortical neurons (Lange, 1971; Lange, 1972; Nieuwenhuys, 1967). However, the ratio of granule neurons to Purkinje neurons increases with evolutionary advancement (Han and Bell, 2002; Glickstein and Voogd, 1995; Hayle, 1973; Schleifenbaum, 1973; Kanan, 1973; Hackethal, 1971; Shafranova, 1969). The mature cerebellar cortex contains an outermost 
molecular layer, a Purkinje cell layer, and an internal granule layer (Figure 2.2 A and B) (Obersteiner H, 1883; Addison, 1911; Cajal, 1909; Palay and Chan-Palay, 1974; Rakic and Sidman, 1970; Jansen, 1972; Hackethal, 1971).

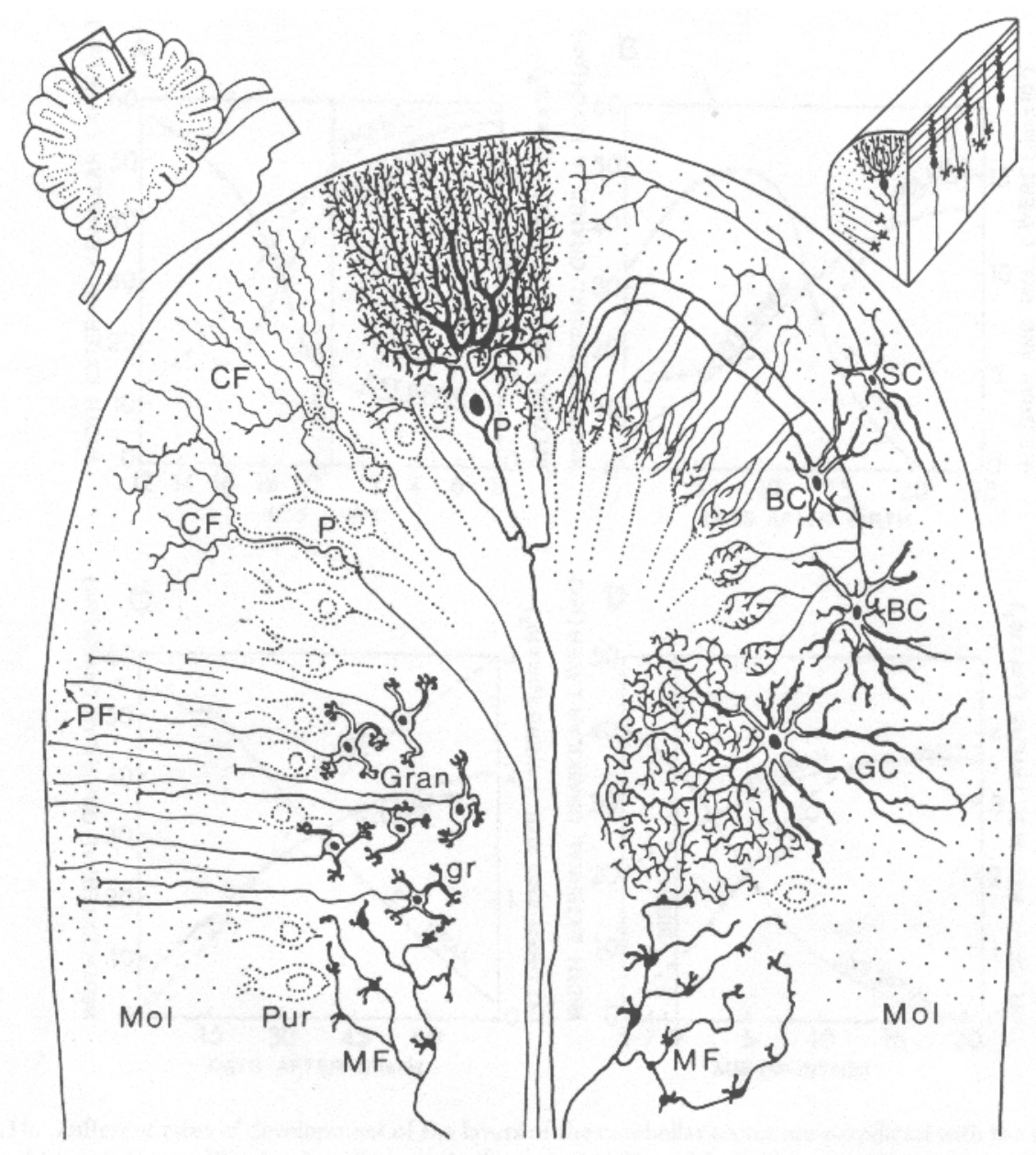

Figure 2.2 Histology of the cerebellum. An illustration of a cerebellar folium. Granule neurons extend parallel fibers along the long axis of the folium. They synapse with the dendrites of Purkinje cells. Also shown are BC: Basket cell; CF: Climbing fibers; GC: Golgi cell; gr: granule neuron; Gran: Internal granule layer; MF: Mossy Fibers; Mol: Molecular layer; Pur: Purkinje cell; PF: Parallel fiber; SC: Stellate Cell. [from:(Jacobson, 1991)].

The molecular layer in the adult animal contains stellate cells, basket cells, the unmyelinated parallel fibers of granule cells, a small population of astrocytes, Bergmann glia and the immense dendritic trees of Purkinje neurons (Cajal, 1909; Rakic, 1971; 
Goldowitz and Hamre, 1998). Several extracellular matrix molecules have been found in the granule and molecular layer, including chondroitin sulfate, laminin, versicans, cytotactin, tenascin-R, hyaluronic acid and hyaluronic acid-binding proteins, and thrombospondin (Bandtlow and Zimmermann, 2000; Bignami et al., 1993a; Bignami et al., 1993b; Grumet et al., 1985; Llano et al., 2000; Loeb and Fischbach, 1995; O'Shea et al., 1990). Mounting evidence suggest that these molecules play an important role in the formation of the cerebellum. For example, abnormal positoning of neurons and glia in the cerebellum and cerebral cortex is observed in animals suffering from a mutation to the extracellular protein reelin (Bignami and Dahl, 1974; Yuasa et al., 1993).

Purkinje neurons are the first neurons to reach in the cerebellar cortex right below the thin external germinal layer of Obersteiner, where they aggregate in a three to fourcell layer (Athias, 1897; Yuasa et al., 1991). After birth in rodents, Purkinje cells progressively begin to align in a one-cell layer and their dendrites start to grow from small bifurcated stumps into branched dendritic trees (Addison, 1911; Altman and Bayer, 1985). As the dendritic trees begin to receive parallel fibers from migrating granule cells, they grow and begin to flatten in a plane perpendicular to the long axis of the folium. In the adult, the Purkinje cell layer has a single row of Purkinje cell somata. The dendrites of Purkinje cells receive climbing fibers arising in the contralateral inferior olive and axodendritic excitatory connections from parallel fibers. Purkinje cells synthesize $\gamma$ aminobutyric acid as a neurotransmitter and their axons constitute the only output of the cerebellar cortex. Purkinje cells express a variety of molecules including the calciumbinding protein calbindin $\mathrm{D} 28 \mathrm{k}$, the $\mathrm{NgCAM}$-binding protein $\mathrm{FAR}-2$, and the cell 
adhesion molecule Tenascin-R (Amenta et al., 1994; Plagge et al., 2001; Woodworth et al., 2002).

Bergmann glia, also called Golgi epithelial cells, have their cell bodies surrounding the Purkinje cell somata (Shiga et al., 1983; Reichenbach et al., 1995). Bergmann glial cells extend processes through the molecular layer to reach the pial surface. These processes are believed to help guide the migration of granule neurons during development. Bergmann glial fibers persist into adulthood and their membranes become closely apposed to Purkinje cell dendritic spines (Figure 2.3) (Castejon, 1990; Spacek, 1985). Several groups studied the relationship between Bergmann glia and Purkinje cells, which led to the proposition that Bergmann glia help with the metabolic demands of Purkinje cells. For example, the enzyme 3PGDH, which is required for the biosynthesis of several membrane proteins, nucleotides, and the neuroactive peptide glycine is expressed in Bergmann glia, but not in Purkinje cells (Yamasaki et al., 2001). Furthermore, Bergmann glia express the $\mathrm{Ca}^{2+}$-permeable AMPA-type glutamate receptor (Iino et al., 2001). This receptor is indispensable for the removal of glutamate released at synaptic clefts between climbing fibers and Purkinje cells. Mounting evidence suggests that Bergmann glia in the adult cerebellum fulfill a role similar to that of astrocytes (Yamasaki et al., 2001; Iino et al., 2001; Seil, 2001; Yuasa et al., 1996; Hatten, 1984; Castejon, 1990). 


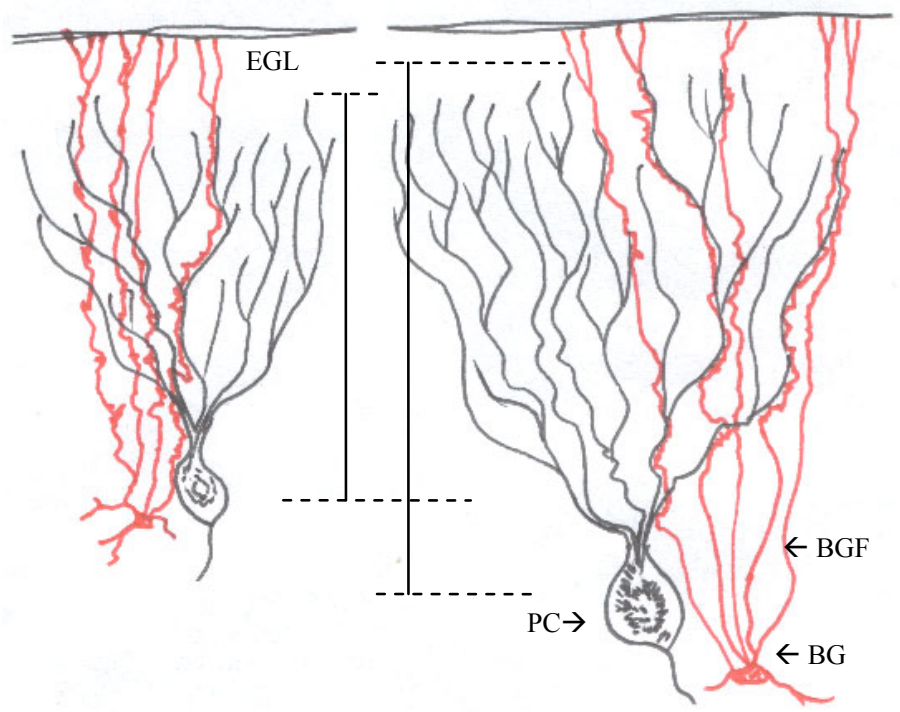

Figure 2.3 Relationship between Bergmann glia and Purkinje neurons. A Drawing depicting the relationship of Bergmann glia to Purkinje cells in the rat cerebellar cortex. In the second and third postnatal weeks, the external granule layer diminishes in thickness due to cell migration and cell death. As Purkinje cells mature and their dendritic trees grow, Bergmann glial processes increase their coverage of Purkinje dendrites and begin to fulfill a role similar to that of astrocytes. PC: Purkinje cell; BG: Bergmann Glia; BGF: Bergmann Glial fibers; EGL: external granule layer.

Granule neurons are tightly packed in the internal granule layer. These neurons form the parallel fibers that comprise most of the molecular layer in the adult animal. Parallel fibers run in a parallel direction to the long axis of the folium. In this configuration they run in a perpendicular path to the dendritic trees of Purkinje cells (O'Leary et al., 1968). In humans, more than 400,000 parallel fibers are thought to intersect and synapse with each Purkinje cell dendritic tree (Jansen, 1972). Parallel fibers also make excitatory synapses with the dendrites of stellate cells, basket cells, and Golgi type II neurons (see below). Lugaro cells are located just below the Purkinje cell layer and send their process upward into the molecular layer, where they connect with basket cells and stellate cells (Melik-Musyan and Fanardzhyan, 1998; Laine and Axelrad, 1998). 
Another type of interneurons in the internal granule layer is the unipolar Brush cells. These receive excitatory collaterals from mossy fibers and synapse with granule neurons in the internal granule layer (Dino et al., 2000a; Dino et al., 2000b). Golgi cells are dispersed among the granule neurons in the internal granule layer and in much smaller numbers. Their axons meet with the claw-like axonal endings of granule neurons and the terminal endings of mossy fibers The intersection of the three axonal endings is ensheathed by a glial capsule to form a glomerulus (O'Leary et al., 1968; Mugnaini and Forstronen, 1967; Eccles et al., 1967). Several hypothesis [reviewed in (Kandel et al., 2000)] have been proposed to explain the countless computations performed by the cerebellar circuitry, which permit the coordination of muscle movement and the maintenance of balance. Most importantly, the development of these circuits is essential to proper motor movements, which if disturbed can siginificantly affect the functioning of the organism as a whole. 


\section{Cerebellar corticogenesis: with emphasis on the ontogenesis of granule neurons and the contribution of the ECM}

The development of the cerebellar cortex has been extensively described in several species by Obersteiner (1883), Cajal (1911), Addison (1911), and Miale and Sidman (1961) to name but a few. The formation of the cerebellar primordium starts around embryonic day 55 in human fetuses and embryonic day 11 in rodents (Sidman and Rakic, 1973; Altman and Bayer, 1985) and continues until the postnatal period. The ventricular germinal zone at the edges of the rhombic lip, between rhombomere 1 and 2 , generates the precursors of deep cerebellar neurons as a first wave, followed by the generation of the precursors of Purkinje cells and of Bergmann glia (Figure 2.4). The latter two types populate the mantle layer. Golgi type II neurons, basket cells, and stellate cells are generated afterwards. Golgi type II neurons settle in the internal granule layer, whereas the basket cells and stellate cells settle in the molecular layer. Astrocytes and oligodendrocytes are generated later during the development.

A restricted region in the ventricular zone of the rhombic lip generates precursors that form the external granule layer of Obersteiner. Neuroblasts migrate dorsomedially on the surface of the cerebellar anlage and form the one-layer-thick external germinal zone (Gilthorpe et al., 2002). This layer generates the mature granule neurons that populate the internal granule layer. Purkinje neurons are generated long before granule neurons. Purkinje cells first aggregate to form a thick layer below the external germinal zone. By the time granule neurons start to migrate, Purkinje cells have already aligned themselves 
in a single-cell layer. In newborn rats, the dendritic tree of Purkinje cells is limited to a few branches.

The differentiation and growth spurt of the Purkinje dendritic trees occur during the period of migration of granule neurons (Addison, 1911; Altman, 1972a; Zecevic and Rakic, 1976), which takes place between postnatal day 4 (P4) and P20 in the rat, and between the 4th fetal month and the end of the 1st postnatal year in humans. The relationship between the growth of the Purkinje dendritic tree, and the migration of granule neurons and the formation of parallel fibers was noted by Cajal (Cajal, 1909), who proposed an interdependence between these cells. Indeed, destruction of the external granule layer, as in x-irradiated neonatal rats, results in underdeveloped Purkinje dendrites (Altman et al., 1969b; Altman et al., 1969a); whereas the destruction of Purkinje neurons causes a comparable loss of granule neurons. Purkinje neuron somata receive synapses from climbing fibers from the contralateral inferior olive. In human fetuses, these fibers initially aggregate in a cell-free layer called the lamina dissecans before contacting Purkinje neurons. As the Purkinje dendritic trees grow and branch, climbing fibers start to synapse with the apical dendrites (Rakic and Sidman, 1970). Later during development, basket cells extend processes and surround Purkinje somata with an array of fibers that resemble baskets.

The lamina dissecans is a thin acellular layer composed of cytoplasmic outgrowths from immature Purkinje cells and granule neurons. Axonal endings of mossy fibers and climbing fibers also contribute to this layer. This layer appears in the 


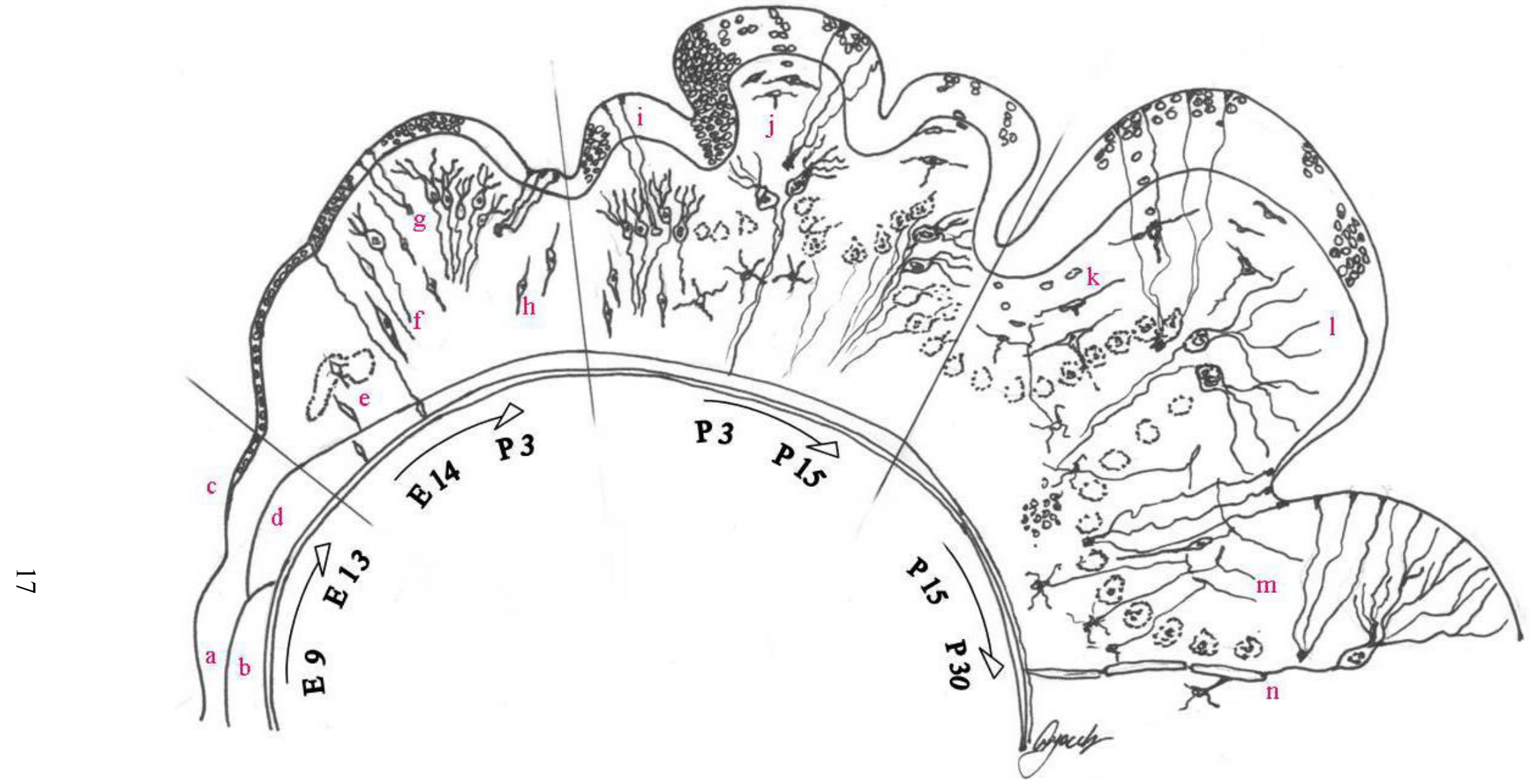

Figure 2.4 Cerebellar histogenesis. Starting at embryonic day 9 (E9), the cerebellar primordium is composed of a marginal layer (a) and a mantle layer (b). By E13, precursor cells in the internal germinal zone (d) start generating cerebellar cells, and cells from the edge of the rhombic lip migrate to the surface of the cerebellar anlage and form the external germinal layer of Obersteiner (c). Between E14 and P3, immature neurons migrate to form deep cerebellar nuclei (e) followed by Purkinje neurons (f) and Bergmann glia (g). Around the time of birth, interneurons (h) -- Golgi type II, stellate, and basket cells -- settle in the cerebellar cortex. By P3, the EGL increases in thickness due to proliferating progenitor cells (i). During the same period, Purkinje neurons line up and form a one-layer thick Purkinje cell layer. Postmitotic granule neurons start to migrate by P6 (j, k) and descend through the molecular layer and settle in the IGL. Granule neurons extend parallel fibers $(\mathrm{k})$ as their nuclei translocate centipitally. They maintain close association with Bergmann glial fibers. Purkinje cell dendrites mature (1) as they receive synaptic contacts from granule neurons. By postnatal day 20, the EGL disappears and granule neurons form the internal granule layer. The development of the cerebellar cortex is near completion as myelination begins $(n)$. 
developing human fetus by week 21 and disappears by week 30 (Rakic and Sidman, 1970). This layer has been demonstrated in cetaceans (blue whale) (Korneliussen, 1967) and is thought to exist in primates, but not in other vertebrates. Rakic and Sidman (1970) proposed that afferent fibers occupy and form this layer during their wait to receive their targets. It is possible that afferent fibers are supplied with trophic support that prevents their degeneration for several weeks, as well as a "stop" signal that halts their progress before reaching the Purkinje cell layer. The mechanisms and signals that might contribute to the formation of this layer are unknown.

Bergmann glia, also called Golgi epithelial cells, were described by Bergmann (1857), Golgi (1885), Athias (1897), Cajal (1911) and later by Miale and Sidman (1961), Gobel (1967), Mugnaini (1967), Rakic (1971), Palay and Chan-Palay (1974) and others. These cells are generated early during development in the ventricular zone and take on a radial orientation. A small number of these cells move to the mantle layer by embryonic day 14 in the mouse, as described from in situ hybridization, and immunohistochemistry for tenascin and the glutamate transporter GLAST (Bartsch et al., 1992; Yuasa, 1996; Yamada et al., 2000; Yamada and Watanabe, 2002). Once in the mantle layer, they extend long fibers that terminate as conical end-feet that make contact with the pial surface. These cells form a dense layer below the Purkinje cell layer, and after birth move to position themselves among the Purkinje cells. During the first two postnatal weeks in the rat, Bergmann glial cells appear to continue their proliferation (Das, 1976). Furthermore, they continue to form a scaffold through their processes that facilitate the migration of granule neurons (Das et al., 1974; Das, 1976). Immature granule neurons start to differentiate and migrate centripetally in a close association with the Bergmann 
glial fibers (Rakic, 1971). In electron microscopy, the membranes of glial fibers appear tightly attached to the spindle-shaped migrating neurons. Evidence presented from in vitro experiments and time-lapse video microscopy suggests that a mechanism more complex than just sliding is in effect in these migratory granule neurons (Edmondson and Hatten, 1987; Hatten M, 1990). Intracellular cytoskeletal organization is evident by the formation of a shell of microtubules that extends to the tip of the leading process and allows for vesicle trafficking. Furthermore, cortical actin wraps the nucleus and extends into the filopodia and the leading process. Migrating neurons form temporary junctions, called "interstitial densities", with the glial fiber (Gregory et al., 1988). The connecting densities associate closely with the microtubular system and seem to differ from desmosomes seen in stationary neurons. During the first twenty postnatal days, Bergmann glia increase their membrane appositions with developing Purkinje dendrites. The surface in contact with Purkinje dendrites and budding spines appears more complex and dense than the surface in contact with migrating granule neurons. Bergmann fibers extend GLAST-positive digitations that progressively cover Purkinje cell dendrites (Yamada et al., 2000). Following the cessation of granule neuron migration, Bergmann glia gradually assume a role similar to that of protoplasmic astrocytes (Spacek, 1985).

The formation of the internal granule layer from the external germinal zone was initially described using the Golgi impregnation method (Obersteiner H, 1883; Addison, 1911; Cajal, 1909). Further support emerged in the mid 1960s with the use of autoradiography (Miale I and Sidman R, 1961; Hanaway J, 1967; Altman, 1972a). Even though some evidence suggests that Golgi cells and basket cells, as well as granule neurons, are generated from the external granule layer (Hausmann et al., 1985), recent 
evidence suggests otherwise. Clonal analysis using retroviral probes in chicks and rats allowed the determination of detailed lineage maps and provided additional support for the hypothesis that only granule neurons originate in the EGL (Ryder and Cepko, 1994; Zhang and Goldman, 1996b; Zhang and Goldman, 1996a). Ryder and Cepko (1994), followed later by Zhang and Goldman (1996), injected retroviruses carrying the $\beta$ Galactosidase gene in the developing cerebellum at various ages and provided direct evidence for the origin of granule neurons. Injections in the EGL labeled progenitor cells that matured to become granule neurons only, whereas injections in the white matter labeled glial cells, basket, stellate and Golgi neurons. It is now accepted that neurons in the cerebellar cortex are generated from two germinal zones via opposing modes of migration. An outward migration from the ventricular zone generates all the neurons and glia of the cerebellar cortex, except the granule neurons. The later neurons are generated in the external germinal layer and migrate inwardly to populate the internal granule layer.

Ramon ý Cajal (1911) treated the developmental stages of granule cells in great length and tallied the knowledge learned from his contemporaries. According to Cajal, the maturation of granule neurons encompasses four developmental phases (Figure 2.5). The outermost zone in the external granule layer (of Obersteiner) contains proliferating undifferentiated progenitor cells. The deeper zone of the external granule layer contains fusiform bipolar cells that extend tangential parallel processes. These cells are postmitotic and pre-migratory. Progressively these cells descend into the plexiform or molecular layer. The third phase, the Radial Bipolar Stage, contains cells with fully extended processes. A dendrite protrudes from the cell body and extends centripetally towards the Purkinje cell layer. The nucleus translocates downward following the leading tip of the 
dendrite until it reaches the internal granule layer. Thus, the parallel fibers or axons of granule cells are fully developed by the time the cells reach their destination. When granule cells pass the Purkinje cell layer, their leading dendrite is resorbed and replaced with several thin dendrites that emanate from their perikarya in all directions. Only three or four of these dendrites develop varicosities as they start receiving mossy fiber rosettes. These dendritic varicosities eventually develop into claw-like digitations.

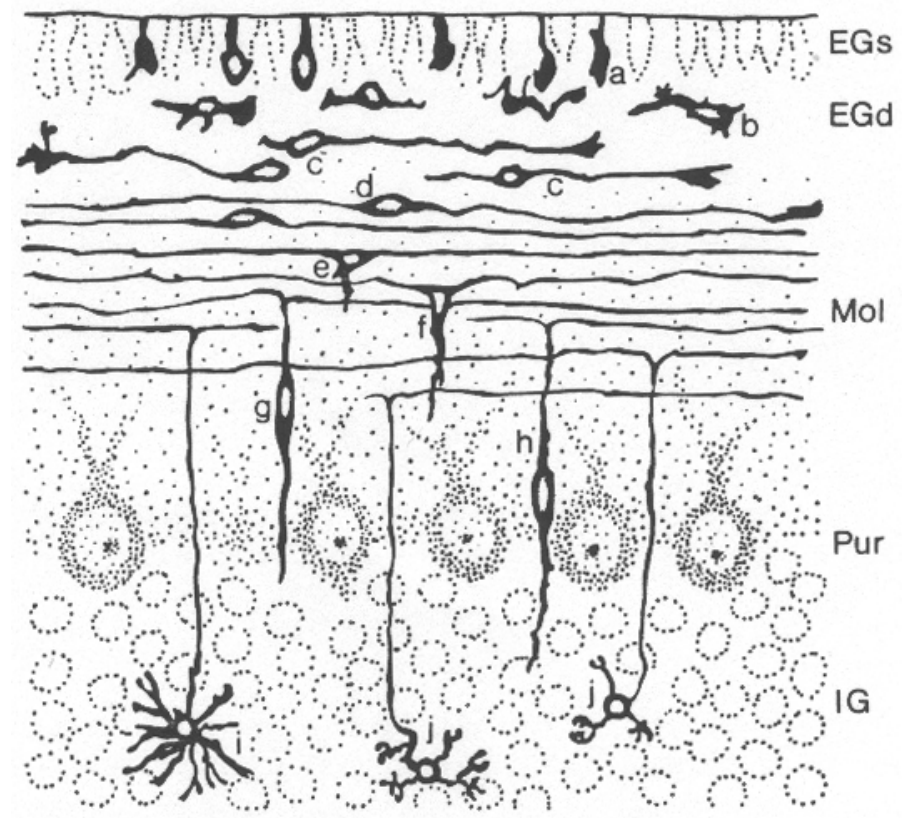

Figure 2.5 A schematic representation of the developmental stages of granule neurons by Ramon ý Cajal (1911). Progenitor cells proliferate rapidly in the EGs. Daughter cells assume a pre-migratory phenotype (c) in the EGd and start growing parallel processes. As granule neurons move through the molecular layer (d), they extend their parallel process and make synaptic contacts with Purkinje cell dendrites. A leading process extends from the forward tip of the granule cell $(\mathrm{e}, \mathrm{f})$ and crawls towards the internal granule layer. The nucleus translocates down $(\mathrm{g}, \mathrm{h})$, past the Purkinje cell layer and settles in the internal granule layer. The cell differentiates further and grows clawlike dendrites that receive mossy fibers $(i, j)$. Abbreviation: EGs, superficial external granule layer; EGd, deep external granule layer; Mol, molecular layer; Pur, Purkinje cell layer; IG, internal granule layer. 
The advent of molecular biology has helped shed light on the molecular machinery that drives this process. An internal genetic clock has been proposed to dictate the migration of granule neurons (Trenkner et al., 1984; Zagon et al., 1985; Komuro and Rakic, 1995). Indeed, there is growing evidence in support for an intrinsic genetic program with the potential to maneuver the migrating granule neurons in a time and age dependent manner (Komuro and Rakic, 1995; Komuro and Rakic, 1998; Komuro et al., 2001). Recently, Yacubova and Komuro (2002) showed in an elegantly designed set of experiments that cultured granule neurons exhibit sequential alterations in morphology and migratory behavior in the absence of ECM signaling (Yacubova and Komuro, 2002). The observed movements, however, did not perfectly mimic those normally observed in vivo, which suggests a role for extracellular signals and cell-cell interactions. Hausmann and Sievers (1985) showed that granule neurons in vivo maintain contact with the basal lamina during their proliferative phase. They observed that proliferating cells in the superficial EGL make contact with the basal lamina through their soma or with short radial processes from embryonic day 16 until postnatal day 17 (Hausmann and Sievers, 1985). Growing evidence supports a role for the extracellular matrix and extracellular signaling in addition to the innate genetic program. For example, Hager et al (1995) reported that granule neurons in organotypic cerebellar slices can migrate centripetally with or without contact with glial elements (Hager et al., 1995). A follow-up study by the same group showed the involvement of the extracellular molecule laminin in the migration process. Blocking the activity of laminin with a specific antibody against the B2 chain of laminin in living cerebellar slices inhibited neuronal migration (Liesi et al., 
1995). Additionally, laminin interacts and enhances the mitogenic effect of Sonic hedgehog (Shh) signaling on proliferating granule neurons in vitro (Pons et al., 2001).

The proliferation of granule progenitors in the sEGL has been shown to be induced by Purkinje cells through Shh signaling (Wallace, 1999). Secreted Shh causes the progenitor cells in the sEGL to upregulate the transcription factors Gli1 and Gli2 (Dahmane and Altaba, 1999), a mechanism that promotes proliferation and inhibits differentiation (Rowitch et al., 1999). ECM molecules like HSPG, laminin and vitronectin, regulate the response of granule progenitors to Shh. HSPG and laminin enhance Shh-induced proliferation of granule progenitors (Pons et al., 2001; Rubin et al., 2002), whereas vitronectin induces cell-cycle exit and differentiation (Wechsler-Reya, 2001). Vitronectin stimulates differentiation through the c-AMP/CREB signaling cascade (Pons et al., 2001; Wechsler-Reya, 2001).

We are just beginning to understand the role that interactions with the extracellular environment play in the shaping of the nervous system. The extracellular matrix is a product of its inhabitants and seems to affect their behavior dramatically. Several extracellular molecules emerged as modulators of cell behavior like laminin, proteoglycans, integrins, reelin, tenascin, cytotactin, hyaluronic acid and matrix degrading enzymes (Grumet et al., 1985; Werz and Schachner, 1988; Bignami et al., 1993a; Pires Neto et al., 1999; Bandtlow and Zimmermann, 2000; Pesheva and Probstmeier, 2000; Schwartz, 2001; Del Bigio et al., 1999). Proteoglycans are large glycoproteins that form a main component of the extracellular matrix in all tissues including the brain. Some proteoglycans, like neurocan, versican v2, brevican and neuroglycan, are secreted exclusively in the CNS by neurons or glial cells. Others are 
available in other tissues like syndecans, NG2, agrins and testicans. These molecules bind to a plethora of molecules including growth factors, cell surface molecules, adhesive and repellent molecules, and other constituents of the ECM such as laminin, tenascin, fibronectin and thrombospondin (Bandtlow and Zimmermann, 2000; Bruckner and Grosche, 2001; Ohtsuka et al., 2000; Oohira, 2001; Sobel, 2001). The distribution pattern of proteoglycans (e.g. glypican 1 and NG2) during development points to their direct involvement in neurogenesis and gliogenesis, axonal pathfinding and differentiation.

Some ECM molecules, like hyaluronic acid, went unnoticed for a long time because they readily dissolve during tissue preparation. Hyaluronic acid exerts its influence partly through hyaluronic-acid-binding proteins (HA-BP) like versicans, aggrecans, and the glial HA-BP (Bignami et al., 1993a; Bignami et al., 1993b). ECM molecules bind adhesive and repellant molecules and modulate their function. For example, Ng-CAM and cytotactin are expressed in migrating granule cells and glial cells respectively (Chuong et al., 1987). Anti-Ng-CAM antibodies arrest migratory granule neurons in the external granule layer, whereas anti-cytotactin antibodies arrest granule neurons in the molecular layer. The adhesive function of Ng-CAM and cytotactin is promoted by chondroitin sulfate proteoglycans, but inhibited by heparin and heparan sulfate (Milev et al., 1995; Werz and Schachner, 1988; Hoffman et al., 1988). Conversely, in peripheral nerves and DRG neurons, chondroitin sulfate proteoglycans inhibit laminin-stimulated neurite growth (Zuo et al., 1998). This effect can be reversed in vitro by the addition of recombinant MMP-2, a matrix-degrading enzyme also thought to be expressed in the cerebellar cortex. Another example is netrin-1 which acts as an 
attractant to growth cones and changes to repulsion when it binds laminin-1 (Hopker et al., 1999). Another adhesion molecule, astrotactin 1, is expressed in migrating neurons in the cerebellum. This molecule is involved in the formation of temporary junctions between the leading process of migrating neurons and glial cells (Adams et al., 2002; Zheng et al., 1996). In vitro assays show that blocking astrotactin with specific antibodies caused a significant $60 \%$ decrease in the migration rate of granule neurons (Fishell and Hatten, 1991).

Thrombospondin (TSP), is a trimeric glycoprotein that is expressed at the neuromuscular junction and around synapses in the retina and the adult cerebellum (Arber and Caroni, 1995). Thrombospondin is first apparent in the rhombic lip and contributes to the formation of the external germinal zone (O'Shea et al., 1990). TSP appear to be involved in the initial interactions between leading axons of granule cells and Bergmann glial cells, to promote neurite outgrowth and help mediate the migration of granule cells across the molecular layer in explants of neonatal cerebellum. Activation of cellular events by TSP-1 is thought to involve the extracellular receptor Integrin alpha 3 beta 1 (DeFreitas et al., 1995). Studies on the function of thrombospondins in neovascularization and tumor metastasis show that TSP-1 upregulates the matrix degrading enzyme MMP-9 (Albo et al., 2002; Qian et al., 1997). The intermediate steps may include signaling via cell surface receptors like integrins but are not clear at the present time.

The effect of several soluble and insoluble ECM molecules is exerted through the integrin family of cell surface receptors. Integrins have extracellular domains that bind extracellular molecules, transmembrane domains, and an intracellular domain involved in 
cell signaling (Damsky and Werb, 1992; Schwartz, 2001). The binding of integrins to the ECM is relatively weak and allows for rapid formation and dissociation of contacts, which are necessary processes in cell migration. Integrins associate with growth factor receptors and are thought to modulate and potentiate their downstream signaling (Eliceiri, 2001; Martin et al., 2002). Binding of integrins to ECM molecules, like fibronectin and laminin, results in the rapid phosphorylation of FAK (focal adhesion kinase) and Src proteins (nonreceptor protein-tyrosin kinases). Phosphorylation of the SH2 domain of FAK induces the PI-3K signaling pathway and recruits the Grb2-Sos complex, which activates the Ras-ERK-MAP kinase signaling cascade. More than 20 proteins, including vinculin and myosin II, are thought to associate with the cytoplasmic domain of integrins. These molecules help trigger the reorganization of the actin cytoskeleton and the formation of stress fibers in motile cells. Motility requires the dissociation of connections between integrins and their ECM ligands. This process is facilitated by de-adhesive molecules like disintegrins, ADAMs (a disintegrin and metalloproteinase), and ADAMTSs (ADAM with thrombospondin repeats). Disintegrins have binding motifs that block the interactions with ECM molecules and can sequester matrix metalloproteinases that degrade the ECM (Shrimali and Reddy, 2000; Wu et al., 2003). ADAMs are membrane-anchored disintegrins that catalyze the breakdown of ECM and membrane molecules in the vicinity of the cell surface (Huang et al., 2003; Fourie et al., 2003). ADAMTS have a structure similar to ADAMs except they have thrombospondin-1 like repeats (Tang, 2001). Proteolytic cleavage of extracellular domains allows the cell to control the activity of membrane receptors and release factors. For example, the ADAM 
member TACE (TNF- $\alpha$ converting enzyme) can release the inflammatory cytokine TNF$\alpha$ from the cell surface (Moss and Lambert, 2002).

Autocrine and paracrine diffusible factors like neurotrophins and cytokines have been shown to be involved in various aspects of CNS development. In the cerebellar cortex, neurotrophins promote cell differentiation, proliferation, and inhibit cell death (Vaudry et al., 2003). IGF-1 (insulin-like growth factor 1) is secreted by Purkinje cells and exerts such a trophic effect on granule cells. IGF-1 triggers the phosphoinositide 3kinase (PI-3k), which phosphorylates Akt and upregulates survival signaling (D'Mello et al., 1993; Bonthius et al., 2003). Glutamate released at synapses also activates the PI3k/Akt pathway and enhances the survival of differentiating cells. On the other hand, glutamate has an opposite effect on mature granule neurons; glutamate can activate the p38-Rb, which in turn activates caspase-3 death signaling (Felici et al., 1989). Some cytokines like TGF- $\beta$ and TNF- $\alpha$ act as death signals by activating the JNK-p53 pathway, which results in the activation of caspase- 3 and the initiation of cell death. Bone morphogenic proteins -- BMP-4, 6 and 7 - are also members of the TGF- $\beta$ family, are expressed in the postnatal cerebellum and are thought to promote differentiation (Ming et al., 2002; Yabe et al., 2002; Alder et al., 1999). BMP binding to cell surface receptors induces the phosphorylation of smad 1 and its association to smad-4. The smad $1 / \operatorname{smad} 4$ complex translocates to the nucleus activating genes involved in cell differentiation (Angley et al., 2003).

The growth factor Neuregulin, secreted by neurons in the cerebellum (Chen et al., 1994), affects their migration, and induces the maturation of glial radial process (Ozaki et al., 1998; Rio et al., 1997) and the formation of synapses between mossy fibers and 
granule neurons (Ozaki et al., 2000). Blocking the interaction of neuregulin with its receptor erbB4 in vitro causes impairment in the development of glial radial fibers and the migration of granule neurons. Furthermore, differential expression of the neuregulin receptors -- erbB-1, -2, -3, -4 and NRG beta-1-- by granule neurons and other cells in the cerebellum may promote proliferation or differentiation. The receptors erbB-2 and -1 are not normally expressed in the EGL. The erbB-3 receptor is observed in postmitotic cells, whereas erbB-4 is thought to inhibit differentiation (Pinkas-Kramarski et al., 1997). In medulloblastoma, a tumor of the EGL, a deregulated expression of the erbB-2 receptor, which is normally absent in the EGL, and the erbB4/NRG beta-1 is thought to promote tumorigenesis and metastasis (Gilbertson et al., 1998).

Neurotrophins have varying effects on granule neurons in the cerebellum depending on their developmental stage. BDNF, NT-4 and NT-5 promote the survival of immature granule progenitors (Yacubova and Komuro, 2003; Dieni and Rees, 2002; Borghesani et al., 2002; Carter et al., 2002). The PI-3k pathway, via the PLC- $\gamma$ and the SHC-Ras-Raf pathway, mediates the trophic effect of BDNF, NT-4, and NT-5. The latter two pathways activate the MAPK cascade, which results in the phosphorylation of transcription factors in the nucleus and the initiation of gene translation. On the other hand, NT-3 seems to promote cell cycle exit and the differentiation of granule cells (Seabold et al., 1998; Condorelli et al., 1998; Maisonpierre et al., 1990). In various cases, it is becoming apparent that neurotrophin signaling in vivo is enhanced by integrin signaling, thus affecting the organization of the cytoskeleton, cell motility, cell cycle regulation, as well as survival and differentiation (Mills et al., 2003; Martin et al., 2002) . 
A considerable understanding of the morphogenesis of the cerebellar cortex and the interdependence of cells has been learned from studies of mutant mice. To date, about fifty mutations have been identified that result in aberant development and a spectrum of clinical deficits. A comprehensive review of mutations affecting the cerebellum is beyond the scope of this discussion [reviewed in (Sotelo, 1990; Goffinet, 1990; Katsuhiko et al., 1984; Sidman, 1983; Caviness, Jr. and Rakic, 1978; Landis and Landis, 1978)]. Of particular interest is the mutation affecting the extracellular protein reelin in reeler mice (D'Arcangelo et al., 1997). Reeler mutants have abnormal patterning and neuronal positioning in laminated structures of the CNS, including the cerebral cortex, hippocampus, the dorsal cochlear nucleus, the inferior olivary complex, and the cerebellar cortex. Purkinje neurons in the cerebellum of reeler mice are ectopically located and reduced in number (Yuasa et al., 1993; Heckroth et al., 1989), and so are granule neurons and Bergmann glia (Terashima et al., 1985; Bignami and Dahl, 1974). Despite the disorderly arrangement of cells in the cerebellar cortex, the synaptic connections appear normal between synaptic partners.

Reelin is expressed in pioneering neurons and forms an integral part of the cortical matrix (cortical plate) (Tissir et al., 2002). Reelin binds the membrane receptors VLDLR (very-low-density lipoprotein) and ApoER2 (apolipoprotein E receptor type 2), which phosphorylate the cytoplasmic protein Dab1 (disabled-1) and trigger presentlyunknown signaling cascades (Rice et al., 1998; Howell et al., 1997). Interestingly, mutations affecting the genes of both receptors VLDLR and ApoER2, as well as the cytoplasmic protein Dab1, cause abnormalities similar to those observed in reelin mutant mice (Trommsdorff et al., 1999; Ohshima et al., 2001). The sequencing of genes and 
identification of gene products of the reeler and other cerebellar mutants, like the weaver mutant, will provide additional insight about the mechanisms contributing to the histogenesis of the cerebellar cortex.

The cerebellar cortex is a marvelous processing powerhouse that easily outpaces any available manmade superprocessor. The microstructure of the cerebellum has been known since the beginning of the twentieth century, but the molecular machinery that pieces it together is largely unknown. Evidence is accumulating in support for both an intrinsic genetic machinery, as well as intercellular and intracellular signaling molecules. New work is unraveling the role of extracellular-matrix molecules and the mechanisms cells use to degrade and reconstruct the extracellular matrix. For a developing cerebellar cortex, remodeling the extracellular matrix is a balance between proteolysis and synthesis that facilitates cell migration and process extension, yet holds all cellular elements together. Close proximity allows for intercellular communication and triggers more downstream events, events that culminate in the formation of the highly specialized circuits of the cerebellar cortex. 


\section{Matrix metalloproteinases and the extracellular matrix in the CNS}

The extracellular matrix contributes to the integrity of the CNS, although not as extensively as other tissues like bone and cartilage. The extracellular matrix contains invaluable structural and signaling molecules needed for proliferation and differentiation, but too rigid and invariable a matrix would hinder developmental and homeostatic mechanisms like cell migration, neurite extension, and synaptic plasticity. Fortunately, the same cells that secrete extracellular matrix proteins secrete proteolytic enzymes that degrade them. This allows for tissue remodeling around extending neurites and filopodia, permitting the establishment of new connections as well as cell motility. As one can envision, the proteolytic activity of matrix-degrading enzymes has to be precisely controlled such that the enzyme is active only in front of growth cones, for example, and not at sites of attachment with the basal lamina. Matrix metalloproteinases are zincdependent endopeptidases that degrade all extracellular molecules. Their activity is regulated at various levels by activators and inhibitors. Over 24 MMPs have been classified to date and seven have been found to be expressed in the nervous system. The expression of MMP-1 (Agapova et al., 2001; Schutz et al., 2002), MMP-2 (Costa et al., 2002; Rosenberg et al., 2001), MMP-3 (Vaillant et al., 1999; Oh et al., 1999), MMP-7 (Rosenberg et al., 2001; Conant et al., 1999), MMP-9 (Conant et al., 1999; Tanney et al., 1998), MT1-MMP (Tanney et al., 1998; Agapova et al., 2001), MT5-MMP (SekineAizawa et al., 2001; Llano et al., 1999) and their inhibitors, TIMP-1 through 4, have been observed in normal CNS development and in pathological conditions. The expression of MMPs in the CNS does not appear to be cell-specific but function-specific. For example, 
glial cells as well as neurons in various regions of the CNS express MMP-2 and MMP-9 during process or neurite outgrowth (Costa et al., 2002; Ferguson and Muir, 2000; Oh et al., 1999; Uhm et al., 1998).

Numerous studies found that abnormal expression (over- or under-expression) and uncontrolled activity of MMPs accompanies various CNS pathologies like Alzheimer's disease, aneurisms, ischemia/reperfusion, multiple sclerosis, meningioencephalitis, disruption of the blood-brain barrier, and Wallerian degeneration (Khuth et al., 2001; Vecil et al., 2000; Yoshiyama et al., 2000; Leib et al., 2000; Azeh et al., 1998; Planas et al., 2000; Clark et al., 1997; Gokaslan et al., 1998; Liuzzi et al., 2000; Fujimura et al., 1999; Rosenberg et al., 1996; Matsuura et al., 2000; Rosenberg et al., 1998; Lim et al., 1997; Hughes et al., 2002; Maquoi et al., 2002). Outside the nervous system, MMPs have been studied extensively in bone remodeling, nephrogenesis, implantation and human fetal development, lung tissue and lung cancer, spermatogenesis, tumor invasion and viral infections like HIV-1 (Huppertz et al., 1998; Tanney et al., 1998; Bord et al., 1999; Kanwar et al., 1999; Furuya et al., 2000; Vliagoftis et al., 2000; Ghorpade et al., 2001; Marchenko et al., 2001; Bischof et al., 2002; Schutz et al., 2002; Hunter and Spector, 2003; Baumgart et al., 2002; Buchman-Shaked et al., 2002).

With few exceptions, all MMPs described to date share conserved structural domains, including an $\mathrm{N}$-terminal signal peptide, a propeptide region, a catalytic domain that contains the $\mathrm{Zn}^{2+}$ binding site, fibronectin repeats, a short hinge region, and $\mathrm{C}$ terminal hemopexin-like repeats (Becker et al., 1995; Bode et al., 1993; Hayashita-Kinoh et al., 2001; Sekine-Aizawa et al., 2001). MMPs differ mostly in their content of hemopexin-like and fibronectin repeats, with MMP-7 lacking all repeats and MMP-9 
having the most (Figure 2.6) (Dhanaraj et al., 1996; Van Wart and Birkedal-Hansen, 1990).

The signal peptide is a hydrophobic region with about 25 residues. This sequence targets the enzyme for secretion and is cleaved before activation. Between the signal peptide and the catalytic domain is a propeptide region. The propeptide forms $3 \alpha$-helices that contain about 80 residues and a highly conserved "Cystein switch" sequence PRCGVPD. Removal of the cystein residue activates the enzymes (Springman et al., 1990; Vallee and Auld, 1990). The attachment of the propeptide region is essential in keeping the enzyme in an inactive state (Fisher et al., 2002). The importance of the propeptide region to maintaining latency was determined by mutational studies for several MMPs (Murphy et al., 1999). The presence of 20 residues at the C- and N-termini proved crucial to the function of the propeptide; enzymatic or mutational removal of these sequences cause autoactivation of the enzyme (Freimark et al., 1994). The integrity of the propeptide region is also essential in binding tissue inhibitors of MMPs (TIMP) and the subsequent activation of MMPs (Pavlaki et al., 2002; Cao et al., 1998).

The catalytic domain is highly conserved among MMPs and contains the zincbinding sequence HEXGHXXGXXHS (Bode et al., 1994; Willenbrock et al., 1995). Of special importance are the histidines in this sequence because their disturbance by point mutations inactivates the catalytic domain (Windsor et al., 1994). A second $\mathrm{Zn}^{2+}$ is found in some MMPs but its importance is uncertain at this point. Downstream from the catalytic $\mathrm{Zn}^{2+}$ is a $\mathrm{Ca}^{2+}$ molecule that binds flanking His and Asp and is thought to help stabilize the structure (Bode et al., 1994; Willenbrock et al., 1995). The catalytic domain of gelatinases (MMP-2 and MMP-9) contains 3 tandem fibronectin inserts. These repeats 
fold into double stranded antiparallel $\beta$-sheets (Clark and Cawston, 1989; Lowry et al., 1992; Overall, 2002) and are thought to allow cooperative binding to substrates (Banyai et al., 1994).

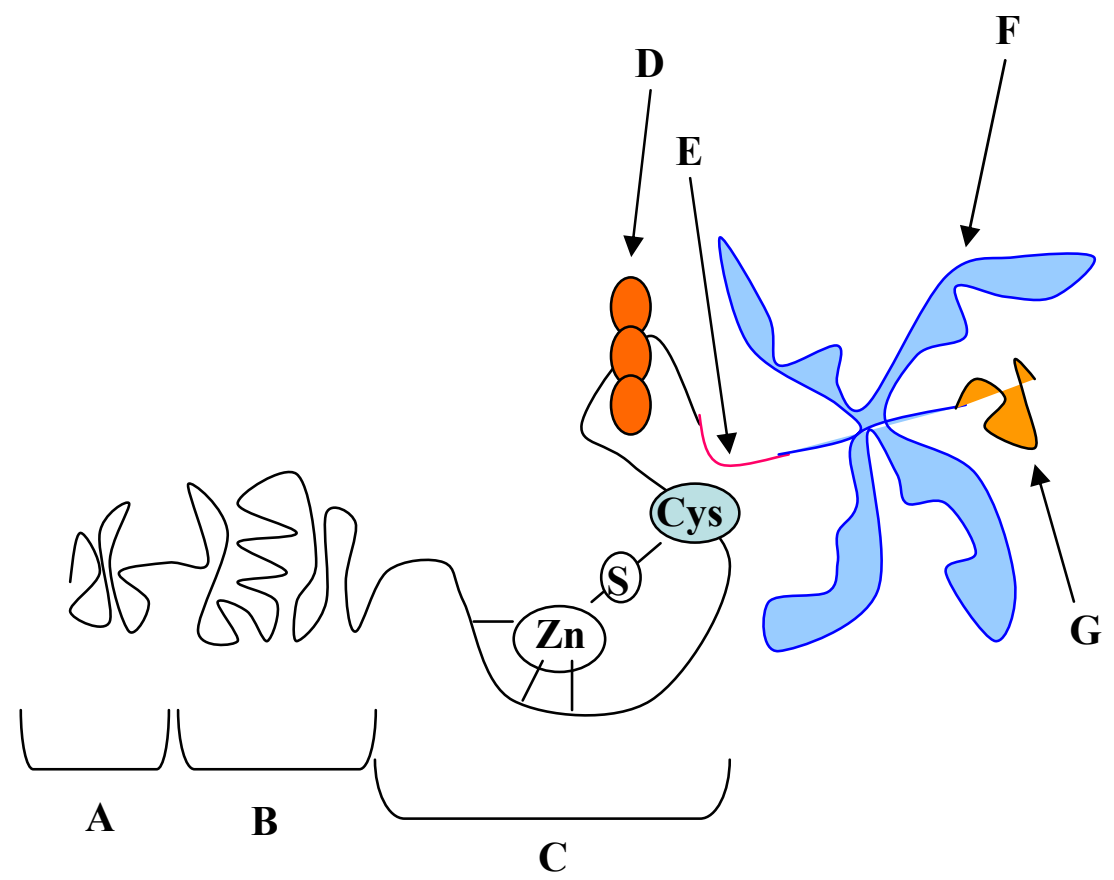

Figure 2.6 Structural domains of gelatinases. MMP-2 and MMP-9 are among the largest MMPs. They contain a signal peptide (A), a pro-domain (B), a catalytic domain (C), Fibronectin-repeats (D), a linker domain (E), and hemopexin-repeats (F). Other MMPs may lack the fibronectin-repeats and the hemopexin-repeats, while membrane-tethered MMPs have an additional hydrophobic domain $(\mathrm{G})$.

Following the catalytic domain is a hinge region of variable length that connects to the C-terminal hemopexin repeats. The structure of the hemopexin domain was resolved by X-ray crystallography and is arranged like a four-blade propeller structure with $4 \beta$-sheets ( $\mathrm{Li}$ et al., 1995; Libson et al., 1995). This domain allows the binding to substrates like collagen I and II, TIMPs, and heparin (Allan et al., 1991; Crabbe et al., 1993). An additional highly hydrophobic N-terminal region is found in membrane 
tethered MMPs, e.g. MT1-MMP, and allows the enzyme to attach to the plasma membrane (Okumura et al., 1997; Sato et al., 1996).

From expression to activation, MMPs are tightly regulated to prevent deleterious effects. Several signal transduction cascades have been implicated in activating MMP gene expression including the ERK-MAP kinase, PI-3 kinase, PKC, and p38 pathways (Wang et al., 2002; Hussain et al., 2002; White et al., 2000b). Mounting evidence suggests that these pathways induce homo- and heterodimerization of c-fos and c-jun, members of the proto-oncogene family, which form the intranuclear transcription activator protein AP1 (Illman et al., 2001; Sato et al., 2002). Binding sites for AP1 are found in the promoter sequence of most MMPs. Moreover, most MMPs have binding sites for other nuclear factors like NFאB, Smad, and Ets (Hall et al., 2003; Eberhardt et al., 2002). In addition to MMPs, tissue inhibitors of MMPs (TIMPs) seem to be regulated by the same factors. For example, inhibition of AP1 binding by specific inhibitors suppresses the expression of MMP-1 and MMP-9 and increases the expression of TIMP-1 (Sato et al., 2002). The gene expression of TIMP-1 is also induced by TGF- $\beta 1$ by binding AP1, while concomittent interaction of Smads with the AP1 binding site on the MMP-1 promotor region represses the later's gene expression (Hall et al., 2003). In a mouse model for hydrocephalus resulting from the overexpression of TGF $\beta 1$, a recent study found abnormally high expression of TIMP-1 and a simultaneous decrease in the expression of MMP-9 (Zechel et al., 2002). Conversely, multiple cytokines could interact and increase the expression and activation of MMP-9. In human skin keratinocytes, for example, TGF $\beta 1$ and TNF $\alpha$ bind to TGF $\beta$-RE (TGF $\beta 1$ response element) and NFאB binding site and induce increased MMP-9 expression (Han et al., 2001). Similarly, in malignant 
gliomas and transformed keratinocytes, TGF- $\beta$ is thought to induce the expression of MMP-9 (Santibanez et al., 2002; Platten et al., 2001). In human breast cancer cells, heuregulin- $\beta 1$, a growth factor that promotes the survival of breast cancer cells, induces the expression of MMP-9 through the ERK-MAPK, PKC, and p38 signal transduction pathways. However, the downstream signaling molecules and transcription factors leading to the activation of MMP-9 gene expression are yet to be identified. Furthermore, our knowledge of the regulation of gene expression of MMPs and their inhibitors is still in its early stages.

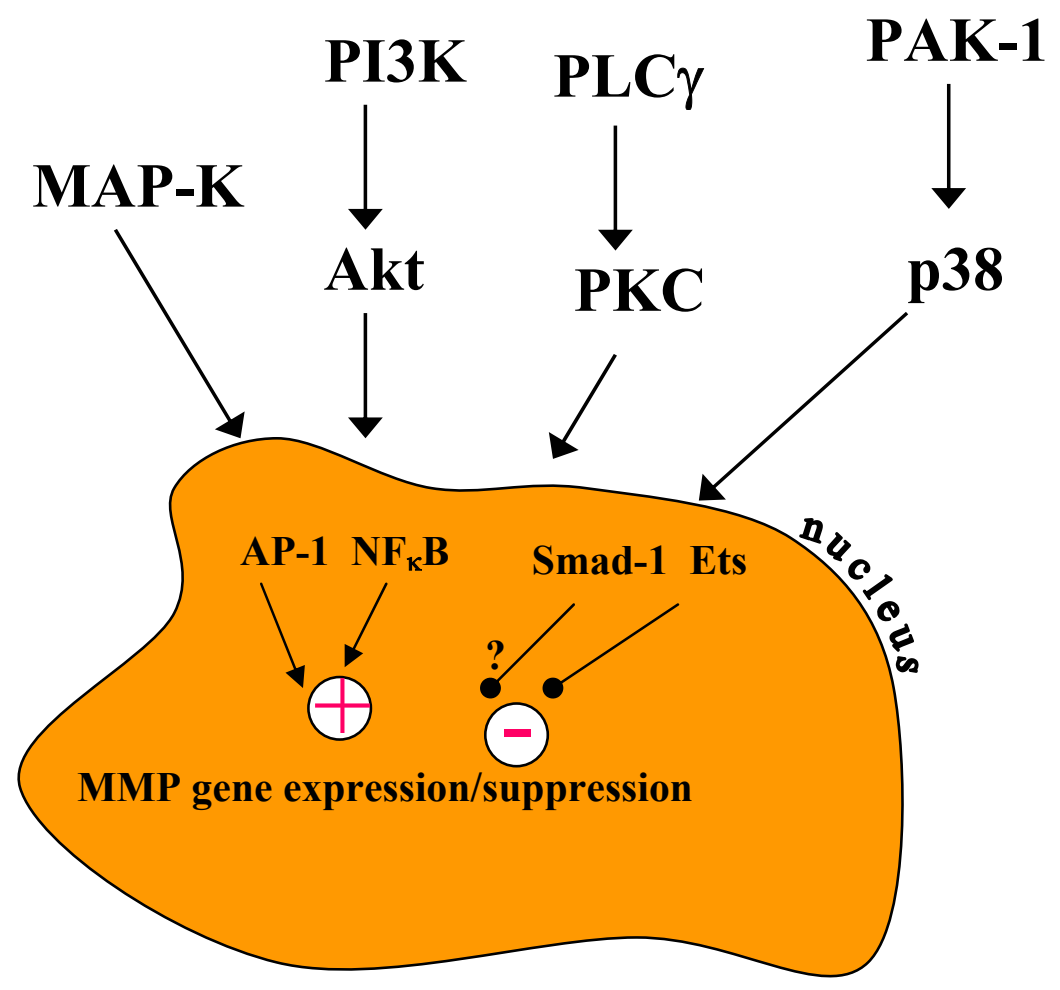

Figure 2.7 Activation of MMP-2 and MMP-9's gene expression. Several signal transduction pathways modulate the expression of MMP-2 and MMP-9, and the simultaneous release of TIMP-1 and TIMP-2.

Once secreted, MMPs are activated by a variety of coumpounds including organomercurial, phorbolesters, SDS, reactive oxygen species like $\mathrm{HOCl}^{-}, \mathrm{H}_{2} \mathrm{O}_{2}, \mathrm{ONOO}^{-}$, 
acidic $\mathrm{pH}$, and other proteinases (Birkedal-Hansen and Taylor, 1982; Okada et al., 1992; Owens et al., 1997; Saari et al., 1990; Sopata and Wize, 1979). The activation step invariably involves the cleavage of the $\mathrm{Zn}^{2+}$--Cys bond, which makes the catalytic domain free to interact with substrates (Springman et al., 1990). MMPs are activated on the cell surface by membrane tethered MMPs, like MT1-MMP, by furin and plasmin, and by stepwise activation of other MMPs (Fillmore et al., 2001; Gveric et al., 2001; Makowski and Ramsby, 1998; Murphy et al., 1999; Nagase, 1997). For example, proMMP-2 is activated on the cell surface by MMP-1, plasmin, and MT1-MMP. The tissue inhibitor TIMP-2 binds pro-MMP-2 and presents it to MT1-MMP (Maquoi et al., 2000). This reaction is dependent on stochiometric concentrations of TIMP-2. Furin and plasmin also activate MT1-MMP (Monea et al., 2002; Sato et al., 1996), which cleaves the prodomain of pro-MMP-2. A similar process for the activation of pro-MMP-2 is mediated by integrin $\alpha(\mathrm{v}) \beta(3)$, which binds pro-MMP-2 and presents it to TIMP- 2 and MT1-MMP (Hofmann et al., 2000a; Hofmann et al., 2000b). After the activation of MMP-2, the MT1-MMP/TIMP-2 complex is quickly internalized and degraded inside lysosomes and endosomes (Jiang et al., 2001).

Pro-MMP-9 is activated by trypsin, plasmin, cathepsin G, and chymotrypsin (Morodomi et al., 1992). Other MMPs, like MMP-1 (Sang et al., 1995), MMP-2 (Fridman et al., 1995), MMP-3 (Goldberg et al., 1992), MMP-7 (Imai et al., 1995), MMP-10 (Nakamura et al., 1998), and MMP-13 (Knauper et al., 1997) cleave the prodomain of MMP-9 and generate an $\sim 82 \mathrm{kDa}$ active zymogen. MMP-9 autolysis can also occur in vivo and results in smaller 80 and $67 \mathrm{kDa}$ active zymogens (Fillmore et al., 2001; Fridman et al., 1995; Makowski and Ramsby, 1998; Murphy et al., 1999; Nagase, 
1997). The generation of smaller fragments eventually deactivates the enzyme. Activation of pro-MMP-9 proceeds in a stepwise fashion through other MMPs (Ogata et al., 1992) and requires the dissociation of TIMP-1 - a necessary step for activation (Itoh and Nagase, 1995). The stepwise mode of activation allows the formation of active intermediates and a greater control over the degradation of ECM molecules (Suzuki et al., 1995).

Abnormal activation or secretion of MMPs is invariably associated with CNS pathologies. The functions of MMP-9, MMP-1, and MMP-3 have been shown to be disturbed in human brains affected with Alzheimer's disease (AD). A study on postmortem tissue from Alzheimer's patients, found MMP-9 in pyramidal neurons in the hippocampus, but not in granule neurons and glia (Backstrom et al., 1996). Active MMP9 can degrade $\beta$-amyloid proteins in vitro, but accumulates in a latent form around $\beta$ amyloid plaques in tissue collected from Alzheimer's patients. A similar observation was made in canine brains with $\beta$-amyloid plaques (Lim et al., 1997), which supports the proposition that accumulation of $\beta$-amyloid proteins is partly due to insufficient activation of MMP-9. A recent study investigating the distribution of MMP-9 and uPA (urokinase plaminogen activator), an activator of pro-MMP-9, in postmortem tissue collected from Alzheimer's and vascular dementia patients revealed a segregation in the expression pattern (Asahina et al., 2001). In Alzheimer's tissue, MMP-9 colocalised in neurons, senile plaques and the vascular wall whereas uPA was found only in the vascular wall. On the other hand, MMP-9 and uPA were colocalized to the vascular wall in vascular dementia tissue. MMP-3 also has reduced expression around senile plaques (Yoshiyama et al., 2000). Whether MMP-3 contributes to the pathology of AD, or not, is 
contingent on MMP-3's ability to degrade $\beta$-amyloid proteins, which is not known at the present time. In contrast to MMP-9, MMP-1 expression in AD tissue is elevated compared to normal tissue especially around capillaries (Leake et al., 2000), which suggests a role in damaging the blood-brain barrier (BBB).

Elevated levels of MMP-9 have been reported in studies of transient focal ischemia (Clark et al., 1997; Fujimura et al., 1999; Planas et al., 2000). Increased expression of MMP-9 is first seen after 4 hrs of the ischemic insult, and is sustained for almost 4 days. MMP-2 expression showed a delayed response in that it increases after 4 days of the ischemic injury (Heo et al., 1999; Planas et al., 2001). The rise in the expression of the active MMP-9 is believed to contribute to the damage caused to the blood-brain barrier and myelin membranes. Several components of the BBB, like laminin, and a major component of the myelin membrane, myelin basic protein, are degraded by MMP-9. Interestingly, MMP-9 knock-out mice show reduced damage after ischemic and traumatic brain injuries compared to wild type mice (Wang et al., 2000; Asahi et al., 2001). Administration of the broad spectrum MMP inhibitor batimastat (BB94) significantly decreased the damage caused by ischemic injury in wild type mice, but not in MMP-9 knockouts (Asahi et al., 2000). The use of BB-94 also reduces hemorrhagic volumes, a known complication with the administration of tPA in ischemic and embolic injuries (Lapchak et al., 2000; Sumii and Lo, 2002). Moreover, in clinical studies of stroke patients, MMP-9 plasma levels proved to be a reliable predictor of hemorrhagic infarcts and parenchymal hematomas (Montaner et al., 2001; Castellanos et al., 2003). 
Increased MMPs', especially MMP-9, activity and expression are also seen in inflammatory demyelination and malignant gliomas (Rosenberg et al., 1996; VanMeter et al., 2001; Yong et al., 2001). Secretion of matrix degrading enzymes by invading immune cells is thought to exacerbate the damage to the ECM and myelin in MS (Sobel, 2001; Sobel and Ahmed, 2001). Malignant and metastatic brain tumors invariably show increased expression of MMPs, which are believed to facilitate tumorogenic invasion and subsequent vascularization (Fillmore et al., 2001; Sameshima et al., 2000; Friedberg et al., 1998). Therapies based on MMP inhibition are under development but have to overcome the problems that plagued early therapies for stroke, arthritis, MS and cancer (Marder and Greenwald, 2003; Scappaticci, 2003; Fingleton, 2003; Zheng et al., 2003). One of the hurdles is the redundancy of MMPs and their wide spectrum of substrates and functions. A successful therapeutic approach minimizes damage cause by overexpression of certain MMPs, like gelatinases, without interfering with the homeostatic function of other MMPs. Significant advances have been made in designing specific inhibitors or "suicide substrates" that exhibit high affinity and specificity (Brown et al., 2000; Kleifeld et al., 2001). A better understanding of the mechanism of action of MMPs and their distribution is of utmost importance in order to design therapies that are more effective. 
Chapter Three: Expression of MMP-2 and MMP-9 and their role in the histogenesis of the postnatal cerebellar cortex 


\section{Introduction}

Matrix metalloproteinases 2 and 9 belong to the metalloendopeptidase family and are known to catalyze the degradation of ECM proteins including collagens, proteoglycans, fibronectin, and elastin (Chandler et al., 1997; Huppertz et al., 1998). Excess MMP production and activation is thought to be a key feature of several CNS pathologies. For example, remodeling of dendritic trees in the hippocampus is accompanied by an increased expression of gelatinases in a model of temporal lobe epilepsy (Szklarczyk et al., 2002; Zhang et al., 1998). MMP-9 has also been shown to be involved in the pathogenesis of Alzheimer's disease (Asahina et al., 2001; Backstrom et al., 1996; Lim et al., 1997), ischemic injuries (Fujimura et al., 1999; Planas et al., 2001) and Multiple Sclerosis (Lee et al., 1999; Yushchenko et al., 2000). Accumulating evidence suggests that MMP-2 and MMP-9 are involved in normal developmental processes as the differentiation of neurons and glia (Agapova et al., 2001; FrolichsthalSchoeller et al., 1999), migration, and process extension by oligodendrocytes during development (Oh et al., 1999; Uhm et al., 1998; Vu and Werb, 2000). In the peripheral nervous system, neurite extension over Schwann cell basal lamina is thought to be facilitated by MMP-2 and MMP-9 (Ferguson and Muir, 2000). MMP-2 and MMP-9 have been shown to be expressed in the developing cerebellum (Vaillant et al., 1999). The expression of MMP-2 and MMP-9 coincided with the formation of the internal granule layer and the maturation of neurons and glia but the nature of their contribution is not understood. 
During the first three postnatal weeks, the cerebellar cortex of the rat is the stage for major developmental changes. The postnatal histogenesis of the cerebellar cortex has been described by Obersteiner (1883), Cajal (1911), Addison (1911), Mugnaini and Forstronen (1967), and several others. Progenitors of granule cells proliferate rapidly in the EGL between P3 and P9 and start their migration towards the internal granule layer by P6. Proliferating granule neurons maintain their contact with the basal lamina (Hausmann and Sievers, 1985). Migrating neurons extend parallel fibers that make synaptic contact with Purkinje dendrites. Granule cells have to pass through an already developed molecular layer, past the Purkinje cell layer, to reach their final destination in the IGL. This tortuous journey is facilitated by the interactions between granule cells and Bergmann glial fibers (Rakic, 1971). During the same period the dendritic trees of Purkinje neurons grow extensively as they synapse with parallel fibers (Addison, 1911; Zecevic and Rakic, 1976). Purkinje cells also interact with neighboring Bergmann glial fibers (Riquelme et al., 2002; Seil, 2001). Between P7 and P21 in rats, Purkinje dendrites become increasingly ensheathed by Bergmann glial processes and membranous digitations (Seil, 2001; Yamada and Watanabe, 2002). These events are known to involve various ECM molecules including hyaluronic acid, versicans, tenascin-R, laminin, proteoglycans and others (Aspberg et al., 1995; Bignami et al., 1993a; Mendis et al., 1994; Thelen et al., 2002; Tucker et al., 1994). These molecules have adhesive or repulsive properties that permit migration, process extension, and plasticity of neuronal and glial elements. Moreover, many of these extracellular proteins are substrates for MMP-2 and MMP-9 (Chandler et al., 1997; Schutz et al., 2002). 
The important role of MMPs in the regulation of interaction between cells and the ECM enticed us to test the hypothesis that MMP-2 and MMP-9 contribute to postnatal cerebellar histogenesis. To better understand the developmental pattern of expression and the distribution of gelatinases, we performed realtime quantitative RT-PCR, in situ zymographic analysis, and immunohistochemistry on cerebellar tissue from pups at the postnatal age of 3 until P25. We investigated the contribution of these gelatinases to the developmental events that shape the cerebellar cortex by determining the effect of a specific gelatinase inhibitor on MMP-2 and MMP-9's activity in cerebellar organotypic slice culture. 


\section{Materials and Methods}

Animal surgeries. We used four Sprague Dawley rat pups from the postnatal age of 3 (P3), P6, P9, P12, P15, P18, P21 and P25 for each experiment. Animals were housed and bred in an ACUC-accredited animal facility at West Virginia University Health Sciences Center. All animal protocols complied with the Society for Neuroscience guidelines for animal care and use. For the immunohistochemistry experiments, animals were anesthetized with sodium pentobarbitol $(150 \mathrm{mg} / \mathrm{kg}$ body weight $)$ then perfused intracardially with $4 \%$ paraformaldehyde. Brains were dissected and post-fixed in the same solution for $12 \mathrm{hrs}$ at $4^{\circ} \mathrm{C}$, cryprotected in $30 \%$ sucrose solution for 3 additional days, then embedded in O.C.T. compound (Optimum Cutting Temperature; Cat.\# 25608930, VWR, Westchester, PA) and frozen on powdered dry ice. For the remaining procedures, brains were dissected and immediately frozen in liquid nitrogen. Tissue collected was stored at $-80^{\circ} \mathrm{C}$ until further processing.

Real-time Quantitative PCR. The cerebellum was dissected under a dissecting scope and immediately frozen in liquid nitrogen. For comparision purposes, cortical tissue from the cerebrum was dissected from the same animals by making a shallow tangential cut through the sagittal plane. Total RNA was extracted using TRIZOL reagent according to the protocol provided by the manufacturer (Life Technologies, Grand Island, NY). The solution was then treated with DNAse I (Ambion Inc., Austin, TX) for 30 minutes at $37^{\circ} \mathrm{C}$. DNAse I was inactivated and removed from the reaction with the addition of DNAse inactivation reagent (Ambion). RNA concentration was determined by spectrophotometric analysis at $\mathrm{A}_{260}$ and $\mathrm{A}_{280}$ using a DU 640 Spectrophotometer 
(Beckman Coulter Inc., Fullerton, CA). Oligonucleotide primers and Taqman probes for rat MMPs were designed using Primer Express Software (Perkin-Elmer, Boston, MA) and were synthesized by Perkin-Elmer. Primer and probe sequences $\left(5^{\prime}-3^{\prime}\right)$ were as follows: MMP-2 forward primer, CCCATGAAGCCTTGTTTACCAT; MMP-2 reverse primer, CTGGAAGCGGAACGGAAA; MMP-2 probe, 6FAM-CAATGCTGATGGAC AGCCCTGCA-TAMRA. MMP-9 forward primer, CGTGGCCTACGTGACCTATGA; MMP-9 reverse primer, GCACCGCTGAAGCAAAAGA; MMP-9 probe, 6FAMCTCCTGCAGTGCCCTTGAaCTAagGCT-TAMRA; Primers and probes for rat $18 \mathrm{~S}$ were purchased from Perkin-Elmer. Real-Time quantitative TaqMan PCR analysis was used to determine the relative levels of MMP-2 and MMP-9 mRNA. RT-PCR and TaqMan PCR were performed according to the manufacturer's instructions (PE Biosystems, TaqMan Gold RT-PCR protocol and TaqMan Universal PCR Master Mix). Sequence-specific amplification was detected with an increase fluorescence signal of the reporter dye FAM during the amplification cycle. Amplification of the gene for rat $18 \mathrm{~S}$ was performed in the same reaction on all samples tested as an internal control for variations in RNA amounts. Levels of the different mRNAs were subsequently normalized to $18 \mathrm{~S}$ mRNA levels, and were represented as fold difference of various postnatal ages against age of day 3 .

Culture of cerebellar granule neurons. Dissociated cerebellar cell culture were used to ascertain the presence of and determine the probable source of gelatinases in the cerebellum. Cerebellar granule neurons and glial cells were isolated from P4 rat cerebella, cultured, and then assayed for gelatinase activity. Primary cultures of CGNs and glial cells were generated as previously described (Luo et al., 2001; Li et al., 2001). 
Briefly, the cerebellum was dissected out and quickly placed in a $2 \mathrm{ml}$ conical tube filled with $1 \mathrm{H}$ buffer (50 $\mathrm{ml}$ EBSS, $0.125 \mathrm{~g}$ Glucose, $0.15 \mathrm{~g}$ BSA, $0.5 \mathrm{ml}$ of $3.82 \%$ $\mathrm{MgSO}_{4}, 7 \mathrm{H}_{2} \mathrm{O}$ ). All tissue was finely chopped with a razor blade on a glass slide and moved to a $50 \mathrm{ml}$ conical tube full of solution A $(0.1 \mathrm{ml}$ of $25 \mathrm{mg} / \mathrm{ml}$ trypsin, $9.9 \mathrm{ml} 1 \mathrm{H}$ buffer). After vigorous shaking, the tube was placed in the incubator/shaker at $37^{\circ} \mathrm{C}$ for 15 min to allow ample time for trypsinization. Next, solution $\mathrm{C}$ was added $(9.78 \mathrm{ml} 1 \mathrm{H}$, $160 \mu \mathrm{l}$ of $4 \mathrm{mg} / \mathrm{ml}$ trypsin inhibitor, $30 \mu \mathrm{l}$ of $200 \mathrm{U} / \mathrm{ml}$ DNAse and $30 \mu \mathrm{l}$ of $3.82 \%$ $\mathrm{MgSO}_{4}, 7 \mathrm{H} 2 \mathrm{O}$ ) and centrifuged the mixture at $1000 \mathrm{rpm}$ for 5 minutes. After removing the supernatant, trypsin inhibitors (buffer B: $8.6 \mathrm{ml} \mathrm{1H,} 1 \mathrm{ml} \mathrm{of} 4 \mathrm{mg} / \mathrm{ml}$ trypsin inhibitor, $0.2 \mathrm{ml}$ of $200 \mathrm{U} / \mathrm{ml}$ DNAse, $0.2 \mathrm{ml}$ of $3.82 \% \mathrm{MgSO}_{4}, 7 \mathrm{H}_{2} \mathrm{O}$ ) was added to the tube, swirled the mixture thoroughly and left to settle for $5 \mathrm{~min}$. The supernatant was transferred to a $15 \mathrm{ml}$ tube, combined gently with solution $\mathrm{D}(9.8 \mathrm{ml} 1 \mathrm{H}, 400 \mathrm{mg} \mathrm{BSA}$, and $0.2 \mathrm{ml} \mathrm{3.82 \%} \mathrm{MgSO}_{4}, 7 \mathrm{H}_{2} \mathrm{O}$ ), and the mixture was spun down for $5 \mathrm{~min}$ at $2000 \mathrm{rpm}$. The solution was discarded again and the pellet, which contained CGNs, was suspended in culture media and plated over PDL-coated culture dishes. For glial culture, the pellet was transferred to a flat culture bottle with $10 \mathrm{ml}$ DMEM and incubated for the same period. After 48 hrs, cultured Cells and and their conditioned media were collected in separate tubes and processed for gelatinase assay.

Organotypic slice culture. Organotypic slice cultures were prepared from postnatal day 5 cerebella. The animals were numbed on ice for several minutes, and then the cerebellum was rapidly extracted and immersed in oxygenated-ACSF (artificial cerebrospinal fluid). Cerebella were sectioned at $500 \mu \mathrm{m}$ thickness in the parasagital plane with a Vibraslicer (WPI, Sarasota, FL). Slices were cultured on collagen-coated 
Nucleopore membrane (Millipore, Bedford, MA) at the interface between air and culture medium according to the method of Kunimoto and Suzuki (1997) and Tanaka et al. (1994), with minor modifications (Jin et al., 2001). Two slices were placed on every membrane, and four membranes in each sterile six-well culture plate, each over $1 \mathrm{ml}$ of culture media. Culture media was changed every two days and $24 \mathrm{hrs}$ before each harvest. The slices were incubated at $37^{\circ} \mathrm{C}$ and $5 \% \mathrm{CO}_{2}$ atmosphere.

Gelatinase Assay. Zymographic analysis was performed on proteins extracted from freshly frozen tissue, cerebellar granule neuronal cultures, mixed glial cultures, and conditioned media from cerebellar organotypic slice cultures. Cerebella were dissected out from P3 to P25 rat pups and quickly frozen in liquid nitrogen. Proteins were extracted as described earlier (Li et al., 2001). Samples were collected from three animals at each time point and three cell culture replications, and gelatinase assays were repeated 5 times for each sample. In the case of in vitro preparations, culture media containing secreted proteins were collected in addition to the cell lysates. The concentration of proteins in extracts was determined by a Lowry assay then equal amounts of protein were loaded in the electrophoretic gel. The gel was prepared with substrate $(1 \mathrm{mg} / \mathrm{ml}$ gelatin) copolymerized with $10 \%$ SDS-polyacrylamide. Equal volumes $(25 \mu \mathrm{l})$ of the proteins were prepared with RIPA buffer and 4x non-reducing sample buffer. All samples were kept on ice during the whole procedure until loaded in the gel to minimize denaturation of proteins and enzymes. After $3 \mathrm{hrs}$ of electrophoresis, gels were washed with $2.5 \%$ Triton X-100 for $30 \mathrm{~min}$ at room temperature, then with a rinse buffer (50mM Tris-HCL $\mathrm{pH} 7.4,0.1 \mathrm{M} \mathrm{NaCl}, 2.5 \%$ Triton-100) for an additional $60 \mathrm{~min}$, followed by an overnight incubation at $37^{\circ} \mathrm{C}$ in reaction buffer $(50 \mathrm{mM}$ Tris-HCL pH7.4, $10 \mathrm{mM} \mathrm{CaCl} 2)$. Gels were 
then stained with a solution of Coomassie blue $(0.5 \%$ Coomassie blue R in $45 \% \mathrm{MeOH}$, $10 \%$ acetic acid) for $60 \mathrm{~min}$, then de-stained in a solution of $10 \% \mathrm{MeOH}$ and $10 \%$ acetic acid until the digested bands are clear. To further ascertain equal loading in gels, we cut the top $2 \mathrm{~cm}$ from each gel and stained it with Coomassie blue for $5 \mathrm{~min}$. Gels were photographed on a trans-illuminator using a Sony CCD Camera and digitally captured and processed using the Eagle Sight ${ }^{\circledR}$ Software (Stratagene). Densitometric quantification of the digested bands was performed on FluorChem SA (Alpha Innotech Corp., San Leandro, CA) and graphed using MS Excel (Microsoft Corp., Seattle, WA). Densitometry measurements were collected after calibration for background intensity and loading controls, and then data were analyzed using SigmaSTAT statistical software (SPSS Inc., Chicago, IL; see statistical analysis for more details).

Reverse Zymography. The levels of gelatinase inhibitors in tissue affect the availability and effectiveness of MMP-2 and MMP-9 in digesting ECM molecules. Reverse zymographic analysis was performed on protein extracts to monitor for the presence of gelatinase inhibitors. Briefly, the experiment proceeds in a similar fashion to the gelatinase assay, except that a $12 \%$ SDS-polyacrylamide gel (containing $1 \mathrm{mg} / \mathrm{ml}$ Gelatin) was prepared with a mixture of pro-MMP-2 and pro-MMP-9, which were activated with APMA (p-Aminophenylmercuric Acetate) following manufacturer instructions (Cat.\# 444213, 444231, 164610; Calbiochem, San Diego, CA). This procedure uncovered bands of gelatinase inhibitors, TIMP-1 and TIMP-2, where the added enzyme did not digest the gelatin. Loading controls and densitometry were preformed as described for the gelatinase assay. 
In situ zymography. Brains were embedded and frozen in O.C.T. compound directly after the dissection and without fixation. Specimens were sectioned using a cryostat at $20 \mu \mathrm{m}$ thickness, then stored at $-20^{\circ} \mathrm{C}$ until stained. All slides were incubated in a solution containing $0.05 \mathrm{M}$ Tris- $\mathrm{HCl}, 0.15 \mathrm{M} \mathrm{NaCl}, 5 \mathrm{mM} \mathrm{CaCl}_{2}, 0.2 \mathrm{mM} \mathrm{NaN}_{3}(\mathrm{pH}$ 7.6) and $40 \mu \mathrm{g} / \mathrm{ml}$ of FITC-labeled gelatin (Molecular Probes, Eugene, OR), on a shaker at $37^{\circ} \mathrm{C}$ for $24 \mathrm{hrs}$. Slides were coverslipped with Vectashield mounting media after blotting excess fluids, and without any rinses. This technique allowed endogenous gelatinases to digest the gelatin producing a fluorescent reaction product, which was detected using conventional fluorescent microscopy as in Oh et al (1999). We preincubated control sections in $20 \mathrm{mM}$ EDTA for $1 \mathrm{hr}$, or $4 \%$ formaldehyde for $10 \mathrm{~min}$, to determine the specificity of the enzymatic activity (Mook et al., 2003). We detected the fluorescence with excitation at 460-500 $\mathrm{nm}$ and emission at 512-542. Slides were imaged on an Olympus AX70 microscope (Olympus America Inc., Melville, NY) equipped with a Spot 2e digital camera (Diagnostic Inst. Inc., Sterling Heights, MI). Camera settings, including optical gain, exposure, and brightness control were the same for captured images. Pictures were imported directly into Adobe Photoshop 5.5 (Adobe Systems Inc., San Jose, CA) for cropping and labeling.

Immunohistochemistry. Brains were sectioned parasagitally on a LEICA cryostat at $12 \mu \mathrm{m}$ final thickness and collected on superfrost plus slides (Fisher); they were then stored at $-20^{\circ} \mathrm{C}$ until processing. Sections representing all experimental ages and controls were stained at the same time to minimize variability. Slides were rinsed and cleared in $25 \%$ ethanol solution for 5 min to remove excess tissue freezing compound. This step was followed by 5 min rinse in $\mathrm{ddH}_{2} \mathrm{O}$ and $10 \mathrm{~min}$ in PBS containing $0.1 \%$ 
Triton-X 100. Slides were incubated in primary antibodies against MMP-2, MMP-9 (all goat-anti-rat; sc-6838, sc-6840; Santa Cruz Biotech. Inc., Santa Cruz, CA) diluted 1:1000 in PBS with 1\% normal horse serum (Wagner et al., 2003). Primary antibodies against GFAP and Calbindin (mouse anti-rat; Sigma G3893 and C9848) were prepared at a final dilution of 1:1000 and 1:3000 respectively. After 24 hours at $4^{\circ} \mathrm{C}$, slides were placed at room temperature for $15 \mathrm{~min}$ to equilibrate, and rinsed 3 times in PBS for a total of 30 min. Slides were then incubated in FITC-labeled anti goat secondary antibody or FITClabeled anti-mouse (1:200 in PBS; Zymed Laboratories Inc, South San Francisco, CA) for $2 \mathrm{hrs}$ at room temperature. The nucleic acid stain TOTO-3 iodide (T-3604, Molecular Probes, Eugene, OR) was diluted with the secondary antibody at a final concentration of $1 \mu \mathrm{g} / \mathrm{ml}$. After three rinses in PBS, slides were covered with Vectashield (Vector labs) solution and coverslipped. We processed negative control sections, by omitting the primary antibody, with every batch of stain. Furthermore, to test the specificity of the primary antibodies, we incubated sections with MMP-2 antibody preabsorbed with the specific blocking peptide (sc-6838p, Santa Cruz Biotech), and with MMP-9 antibody preabsorbed with MMP-9 blocking peptide (sc-6840p). All immunohistochemically prepared slides were imaged using a Zeiss LSM 510 confocal microscope (Carl Zeiss Imaging Inc., Thornwood, NY). The same settings for filters, pinhole size, stack size and resolution, were used for all captured images. All images were cropped and labeled using Adobe Photoshop 5.5.

Treatment with gelatinase inhibitor. Organotypic slices were prepared from P5 pups, as described earlier, and treated with a selective MMP-2/MMP-9 inhibitor (1.6 $\mu \mathrm{M}$, $3.2 \mu \mathrm{M}$ and $6.4 \mu \mathrm{M}$; SB-3CT; 80512-564; VWR) or without inhibitor (Controls) diluted 
in culture media for $24 \mathrm{hrs}, 4$ days in vitro (DIV), 7DIV, and 10DIV. This gelatinase inhibitor functions as a substrate analogue, and binds with specificity and high affinity to the enzyme active site $(\mathrm{Ki}=13.9 \mathrm{nM}$ for MMP-2; $\mathrm{Ki}=600 \mathrm{nM}$ for MMP-9) (Brown et al., 2000; Kleifeld et al., 2001; Rosenblum et al., 2003). We collected slices after 1DIV, 4DIV, 7DIV, and 10DIV (table 3.1).

Treatment

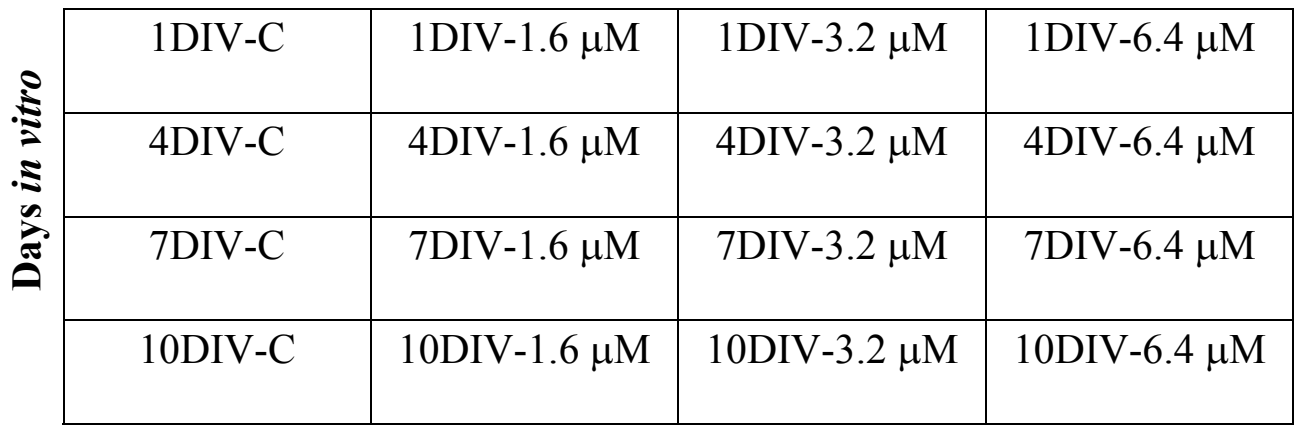

Table 3.1 Slice culture treatment groups. Serial slices were distributed in four treatment groups and incubated for 1, 4, 7 and 10 days in vitro. Slices were treated with SB-3CT at increasing concentrations for the entire culture period. We collected the culture media for gelatin zymography and the slices were sectioned for immunohistochemistry and in situ zymography.

For each treatment group and time point, we collected the culture media, since it contains secreted proteins, and stored it at $-80^{\circ} \mathrm{C}$ until further processing with gelatin zymography. The slices were embedded in O.C.T. compound and frozen at $-20^{\circ} \mathrm{C}$ between 2 glass slides on a flat metal block (Haydar et al., 1999). This procedure helped us maintain the slices flat and allowed us to section the slices thinner for immmunohistochemistry and in situ zymography.

Morphometric analysis. several parameters were monitored to assess the effect of MMP inhibitor on the histogenesis of the cerebellar cortex in organotypic slices ( $n=6$ per treatment group). The thickness of the EGL was measured and the number of granule 
cells in the molecular layer was counted. Measurements were taken from three lobes in every section. Lobes were assigned by systematic random sampling. Sampling areas $(325.7 \mu \mathrm{m} \times 325.7 \mu \mathrm{m})$ were predefined and equivalent in all treatment groups to minimize variability. Three lines were drawn to define the EGL and the ML. We measured the thickness of the EGL as the minimum distance between tangents to the lines defining the EGL and counted the number of cells with migrating morphology (fusiform somata) in the ML (see Appendix A10 for an example).

Statistical analysis. Parametric data were analyzed data by an ANOVA followed by post-hoc Tukey's t-test comparisons between groups when appropriate, using SigmaSTAT statistical software (SPSS Inc.). Bartlett's statistic was used to identify nonparametric data, which were analyzed with a Kruskal-Wallis test followed by Dunn's multiple comparisons. 


\section{Results}

\section{Developmental mRNA expression of MMP-2 and MMP-9}

The gene expression of MMP-2 and MMP-9 is modulated by a variety of factors expressed during development including growth factors, cytokines, and ECM molecules ( $\mathrm{Vu}$ and Werb, 2000). We measured the relative mRNA expression of MMP-2 and MMP-9 in cerebella and tissue from cerebral corteces of rat pups from P3 to P25. As measured by real-time quantitative PCR MMP-2 mRNA decreased by $40 \%$ between P3 and P6, and by an additional $20 \%$ between P6 and P25 (Figure 3.1A). In comparision, MMP-2 expression in the cerebral cortex gradually deceased from P3 to P25 (Figure 3.1B). The expression of MMP-9 in the cerebellar cortex decreased by 3-fold from P3 to P6 and remained constant thereafter (Figure 3.1A). In comparision, the mRNA expression of MMP-9 in cereberal tissue increased dramatically after postnatal day 12 and continued to rise until postnatal day 25 (Figure 3.1B). Since tissue were dissected from the same animals, prepared, and analysed at the same time to reduce variability, then the observed changes are specific to each of theses cortical areas.

\section{Developmental changes in MMP-2 and MMP-9 activity}

Matrix metalloproteinases are secreted as inactive enzymes into the extracellular matrix (Corcoran et al., 1995). Their activation is the last step in a highly controlled process and is needed to start their proteolytic activity (Murphy et al., 1999; Nagase, 
1997). It is thus important to distinguish between the levels of pro-enzyme and the proteolytically active enzyme. To determine the spatiotemporal levels of activation of MMP-2 and MMP-9 in the cerebellar cortex between P3 and P25, we performed a zymographic assay on protein extracts from freshly frozen tissue, on cultured cerebellar granule neurons (CGN) and on glial cell cultures prepared from same-age cerebella. This was followed by an in situ zymographic assay on freshly frozen cryostat sections. We were able to detect bands of pro-MMP-2 at $72 \mathrm{kDa}$ and weaker bands of active MMP-2 at $68 \mathrm{kDa}$. The gelatinase activity showed a progressive decrease in the concentration of pro-MMP-2 from P3 until P15 (Figure 3.2A, G). Since zymographic assays are sensitive enough to detect picogram amounts of gelatinases (Troeberg and Nagase, 2003), then the weak MMP-2 activity suggests a limited tissue-spread and a focused role for MMP-2. As for MMP-9's expression, the predominant form before P12 is the active form (Figure 3.2B, H). After P12, the latent pro-MMP-9 increased in proportion while the overall expression profile of MMP-9 (active and latent) started to decrease. We also measured the activity of the tissue inhibitors of MMPs, TIMP-1 and TIMP-2, by reverse zymography. We detected TIMP-2 (21 kDa), but not TIMP-1 (28 kDa), in the reverse zymographic assay (Figure $3.2 \mathrm{C}$, I). TIMP-2 binds to and controls the activity of MMP2. The activity of TIMP-2 increased between P3 and P9 and leveled afterwards.

To determine the source of the gelatinolytic activity in the cerebellum, we performed a gelatinase assay on conditioned media and cell lysate from cultured cerebellar granule neurons (CGN) and glial cells prepared from P4 cerebella. In culture, CGN showed high activity for pro-MMP-2 (72kDa), two active fragments of MMP-2 at $68 \mathrm{kDa}$ and $65 \mathrm{kDa}$, as well as pro-MMP-9 $(92 \mathrm{kDa})$ and the active MMP-9 at $80 \mathrm{kDa}$ 
(Figure 3.2E). In glial culture, we detected pro-MMP-2 and MMP-2 (68 and $65 \mathrm{kDa}$ ), and a relatively weaker band of pro-MMP-9 (Figure 3.2F).

We performed an in situ zymography assay on frozen cerebellar slices from P3 to P25, which allowed us to visualize the distribution of active forms of the gelatinases. Even though this method is sensitive to minute amounts of the gelatinases, it does not offer the high resolution achieved with immunohistochemical methods. In order to detect developmental changes, we used the same optical settings to capture all images. Briefly, we took $20 \mu \mathrm{m}$ cryostat sections from fresh-frozen brains from P3 to P25. After $24 \mathrm{hr}$ incubation with FITC-quenched gelatin, we detected fluorescence in areas of the sections where active MMPs cleaved gelatin. In the cerebellum, the fluorescence was mostly present in the EGL, the Purkinje cell layer and the IGL (Figure 3.3). The fluorescence in the pial basal lamina and the EGL was more intense than in the ML and the white matter. From P3 to P15, the distribution of gelatinase activity changed to include more of the internal granule layer and not just the EGL and PCL. During the same period, we observed a progressive decrease in proteolytic activity limited to the cerebellar cortex. Gelatinase activity was still detectable in the same sections in the hippocampal formation at P15 (Figure 3.3A) and persisted beyond P21 (not shown). We processed control sections as described by Mook et al. (2003) to ascertain the specificity of the fluorescent signal. Briefly, we incubated sections with gelatin-DQ ${ }^{\circledR}$ (Molecular Probes) as a substrate after blocking the gelatinase activity with $20 \mathrm{mM}$ EDTA or $4 \%$ formaldehyde. Sections treated with EDTA and formaldehyde showed greatly reduced fluorescence (Figure 3.3B). 


\section{Developmental changes in MMP-2 and MMP-9 immunoreactivity}

To determine the distribution of MMP-2 and MMP-9, we performed immunohistochemical staining on serial sections from the cerebellum. Briefly, for this experiment, fixed tissue was sectioned in the sagittal plane at $12 \mu \mathrm{m}$ thickness and probed for MMP-2 and MMP-9 with specific antibodies, followed by FITC-tagged secondary and counterstained with TOTO-3 iodide, a fluorescent nucleic-acid binding dye. Sections were imaged using a LSM510 confocal microscope under the same optical settings (see methods) and optical stacks were later collapsed into one image. In cerebellar sections, staining with TOTO-3 was noticeably more intense in the cytoplasm of Purkinje cells than in their nuclei (Figure 3.4). TOTO-3 iodide binds with specificity to nucleic acids, nuclear DNA and cytoplasmic RNA, which may have contributed to the cytoplasmic staining in Purkinje neurons. This diffuse staining seems more noticeable in cells with higher cytoplasmic RNA content and bigger somata (Boutonnat et al., 2000; Suzuki et al., 1997). Sections of similar age groups were also stained for Calbindin D28k, which stains Purkinje neurons in the cerebellum. We detected calbindin immunoreactivity in Purkinje cell bodies, dendritic trees, and axons (Figure 3.4). We also stained sections with antiGFAP antibody, which is expressed in Bergmann glia in the cerebellar cortex and astrocytes in the white matter (Levitt and Rakic, 1980; Dahl and Bignami, 1973). The immunoreactivity of GFAP increased in the first postnatal week and was stable afterwards. Bergmann glial endfeet stained intensly with GFAP, whereas Bergmann fibers stained more intensly as they approached the EGL. Immunostaining was present in perikarya (although less numerous in our sections) and absent in short bushy lamellate expansions seen in silver impregnation preparations; a comparable pattern was reported 
by other authors (for details see Levitt and Rakic, 1980). Artifacts and weaker stain were noticeable in some speciments and might be due to the age of animals, the condition of the tissue, and other conditions. However, the use of GFAP and calbindin allowed us to compare the cellular sources of MMP-2 and MMP-9, and tentatively identify cellular elements. Double or triple stain for GFAP, calbindin, and MMP (-2 or -9$)$, would have presented better cellular identification; however, we were unable to preserve the integrity of the tissue and get consistant results using this approach.

We detected MMP-2 immunoreactivity in Purkinje somata and initial dendritic trunks, in radial fibers resembling Bergmann glial fibers and in the EGL (Figure 3.4 - 5). MMP-2 immunoreactivity was strongly reduced in Bergmann glial fibers after P12 and in Purkinje cells after P15. Immunoreactivity of MMP-9 staining coincided with Purkinje neurons and the EGL (Figure 3.4 - 6). Diffuse staining was also noticeable around the Purkinje dendrites, which indicates the detection of MMP-9 in the extracellular space. MMP-9 staining in Purkinje cells was below detection after P18. Figures 3.5 and 3.6 show representative fields from sections treated with MMP-2 and MMP-9 antibodies at higher magnification. We processed negative control sections, where we omitted the primary antibody, with every batch of stain. To further ascertain the specificity of the antibodies, we incubated sections with the primary antibody pre-absorbed with the corresponding specific blocking peptide. Figure 3.7 shows representative control sections from P15 stained with MMP-9 antibody pre-absorbed with increasing dilution of MMP-9 blocking peptide (Santa Cruz Biotech). As can be noticed, the immunoreactivity increased as the concentration of the blocking peptide was reduced in relation to the antibody from 1:10, 1:20, 1:50, and was comparable to full antibody staining when we 
omitted the blocking peptide (0:1). Similar results were observed with MMP-2 preabsorbed with the MMP-2 blocking peptide (not shown).

\section{Effect of specific MMP-2 and MMP-9 inhibitor on cerebellar morphology}

We used organotypic slice cultures from cerebella of P5 rat pups. This technique has proved very useful in studying the developmental mechanisms in cerebellar cortex without sacrificing the role of the ECM and intercellular communication (Haydar et al., 1999). We cultured cerebellar slices for 1 day (1DIV = 1 day in vitro), 4DIV, 7DIV, and 10 DIV as described earlier (Jin et al., 2001; Tanaka et al., 1994). At each time point, serial slices were divided in four groups, three of which received treatment with a selective MMP-2/MMP-9 inhibitor (SB-3CT) at increasing concentrations (1.6, 3.2 and $6.4 \mu \mathrm{M})$ and a control group. This inhibitor was shown to bind specifically to MMP-2 and MMP-9 in a manner similar to TIMP-1 and TIMP-2 (Kleifeld et al., 2001). At the end of the treatment period (24hrs, 4 days, 7 days, and 10 days) we collected and stored the culture media, which contains secreted enzymes, and the slices at $-80^{\circ} \mathrm{C}$. We performed a zymographic assay on the culture media and in situ zymography on sectioned slices. We also sectioned and stained cerebellar slices to quantify the effect of inhibitor treatment on the histogenesis of the cerebellar cortex.

We processed alternate serial sections with immunohistochemistry for MMP-2, MMP-9, Calbindin D28K, and GFAP, and with in situ zymography from treatment groups and controls. The immunoreactivity of MMP-2 and MMP-9 followed an expression pattern similar to that observed in vivo. Figure 3.8 (A, B, C, and D) shows sample sections from control slices at 7DIV immunostained for MMP-2, MMP-9, 
Calbindin D28k and GFAP. Figure 3.8 (E and F) shows a sample from sections processed for in situ zymography taken from adjacent slices at 7 days in vitro. The distribution of the gelatinase activity in the section in (F) treated with $3.4 \mu \mathrm{M}$ SB-3CT was reduced and less uniform compared to the section in (E), which was taken from the adjacent control slice and imaged under the same optical settings. We observed a similar pattern of reduced and irregular activity in other slices exposed to SB-3CT at other concentrations.

We performed a zymographic assay on the culture media collected from inihibitor treated slices and controls (Figure 3.9A-F). The concentration of proteins in conditioned media was determined by a Lowry assay and the same amount of proteins was loaded in all wells (see methods). A progressive decrease in gelatinase activity, similar to the expression pattern detected in vivo, was measured for both MMP-2 and MMP-9 in control slices at all time points (Figure 3.9 A and F). Treatment with the specific inhibitor SB-3CT was accompanied by a progressive decrease in gelatinase activity. At 7 DIV and 10DIV (Figure 3.9 B, E, F), the activity of MMP-2 was still detectable, whereas the activity of MMP-9 was drastically reduced. To acetain equal loading in the gels, we cut and stained the top $2 \mathrm{~cm}$ of each gel, after electrophoresis and without incubation, with coomassie blue for $5 \mathrm{~min}$.

To assess the effect of MMP-2/MMP9 inhibitor treatment on the development of the cerebellum, we measured the thickness of the EGL before and after inhibitor treatment (Table 3.2; Figure 3.10 A). The EGL is composed of a dense population of cells between the pial basal lamina and the molecular layer, which provides a convenient method to delineate its outer and inner boundaries. This method has been successfully used to assess the effect of exogenous compounds on the proliferative activity of 
progenitors and migratory activity of immature postmitotic neurons (Ohmori et al., 1999; Doughty et al., 1998). To minimize error and bias, we chose the counting fields by systematic random sampling. All fields were equivalent in dimension $(325.7 \mu \mathrm{m} \times 325.7$ $\mu \mathrm{m})$ at $20 \mathrm{x}$ magnification regardless of age and treatment conditions. Treatment with inhibitor caused a significant dose-dependent increase in the thickness of the EGL compared to controls at 1DIV 1.6 $\mu \mathrm{M}, 3.2 \mu \mathrm{M}, 6.4 \mu \mathrm{M}\left(\mathrm{F}_{(3,53)}=38.42\right.$; all $\left.\mathrm{p}<0.001\right)$, and 4DIV $3.2 \mu \mathrm{M}\left(\mathrm{F}_{(3,53)}=11.84 ; \mathrm{p}<0.01\right)$ and $6.4 \mu \mathrm{M}(\mathrm{p}<0.001)$. At 7DIV, the thickness of EGL was significantly thicker in 7DIV $1.6 \mu \mathrm{M}$, 7DIV $3.2 \mu \mathrm{M}$, and 7DIV $6.4 \mu \mathrm{M}\left(\mathrm{F}_{(3,53)}\right.$ $=112.5$; all $\mathrm{p}<0.001)$. At $10 \mathrm{DIV}$, slices treated with $1.6 \mu \mathrm{M}$ and $3.2 \mu \mathrm{M}$ inhibitor had significantly thicker EGL $\left(\mathrm{F}_{(3,53)}=368.0 ; \mathrm{p}<0.001\right)$; while slices treated with $6.4 \mu \mathrm{M}$ inhibitor had a significantly thinner EGL $(\mathrm{p}<0.001)$.

Percent difference compared to control slices

\begin{tabular}{|c|c|c|c|}
\hline & $\begin{array}{c}1.6 \mu \mathrm{M} \text { Inhibitor } \\
( \pm \mathrm{SEM})\end{array}$ & $\begin{array}{c}3.2 \mu \mathrm{M} \text { Inhibitor } \\
( \pm \mathrm{SEM})\end{array}$ & $\begin{array}{c}6.4 \mu \mathrm{M} \text { Inhibitor } \\
( \pm \mathrm{SEM})\end{array}$ \\
\hline $1 \mathrm{DIV}$ & $+14.1 \%( \pm 1.66)$ & $+26.2 \%( \pm 0.98)$ & $+30.4 \%( \pm 0.67)$ \\
\hline 4DIV & $+8.2 \%( \pm 2.37)$ & $+17.1 \%( \pm 1.58)$ & $+24.2 \%( \pm 1.61)$ \\
\hline 7DIV & $+58.6 \%( \pm 0.73)$ & $+42.3 \%( \pm 1.31)$ & $+22.8 \%( \pm 0.61)$ \\
\hline 10DIV & $+17.4 \%( \pm 0.36)$ & $+11 \%( \pm 0.32)$ & $-30.9 \%( \pm 0.35)$ \\
\hline
\end{tabular}

Table 3.2 Percent change in the thickness of EGL after treatment with SB-3CT. Comparision of the average percent change in the thickness of the EGL in treated slices compared to in-group controls. 
We also counted the number of fusiform-shaped cells, presumed granule cells, in the molecular layer (Table 3.3; Figure 3.10 B). We limited our counting to cells with round or fusiform nuclei smaller than $7.5 \mu \mathrm{m}$ in diameter to exclude the bigger nuclei of other interneurons. The number of fusiform-shaped granule cells in the molecular layer was also affected by the inhibitor treatment. There was a dose-dependent decrease in the number of migrating cells in all treatment groups.

Percent difference compared to control slices

\begin{tabular}{|c|c|c|c|}
\hline & $\begin{array}{c}1.6 \mu \mathrm{M} \text { Inhibitor } \\
( \pm \mathrm{SEM})\end{array}$ & $\begin{array}{c}3.2 \mu \mathrm{M} \text { Inhibitor } \\
( \pm \mathrm{SEM})\end{array}$ & $\begin{array}{c}6.4 \mu \mathrm{M} \text { Inhibitor } \\
( \pm \mathrm{SEM})\end{array}$ \\
\hline & $-2.5 \%( \pm 1.99)$ & $-16.4 \%( \pm 1.92)$ & $-22.3 \%( \pm 1.71)$ \\
\hline $4 \mathrm{DIV}$ & $-17.4 \%( \pm 2.56)$ & $-27.3 \%( \pm 1.52)$ & $-46.6 \%( \pm 1.08)$ \\
\hline $7 \mathrm{DIV}$ & $-19.9 \%( \pm 1.68)$ & $-28.5 \%( \pm 1.47)$ & $-62.1 \%( \pm 0.96)$ \\
\hline $10 \mathrm{DIV}$ & $-28.8 \%( \pm 1.06)$ & $-48.7 \%( \pm 1.14)$ & $-72.1 \%( \pm 0.83)$ \\
\hline
\end{tabular}

Table 3.3 Percent change in the number of migrating cells in the ML after treatment with SB-3CT. Comparision of the average percent change in the number of migrating granule neurons in the ML in treated slices compared to in-group controls.

The effect was significant in 1DIV $3.2 \mu \mathrm{M}\left(\mathrm{F}_{(3,53)}=7.348 ; \mathrm{p}<0.05\right), 4 \mathrm{DIV} 1.6 \mu \mathrm{M}\left(\mathrm{F}_{(3,53)}\right.$ $=38.31 ; \mathrm{p}<0.01)$, and highly significant $(\mathrm{p}<0.001)$ in $1 \mathrm{DIV} 6.4 \mu \mathrm{M}, 4 \mathrm{DIV} 3.2 \mu \mathrm{M}, 4 \mathrm{DIV}$ $6.4 \mu \mathrm{M}, 7 \mathrm{DIV} 1.6 \mu \mathrm{M}\left(\mathrm{F}_{(3,53)}=65.82\right)$, 7DIV 3.2 $\mu \mathrm{M}, 7 \mathrm{DIV} 6.4 \mu \mathrm{M}, 10 \mathrm{DIV} 1.6 \mu \mathrm{M}$ $\left(\mathrm{F}_{(3,53)}=129.8\right), 10 \mathrm{DIV} 3.2 \mu \mathrm{M}$, and 10DIV $6.4 \mu \mathrm{M}$ respectively. Blocking the activity of gelatinases caused an increase in the thickness of the EGL and a decrease in the number of granule neurons in the ML. These results are indicative of either altered 
proliferation of progenitor cells in the EGL, altered initiation of migration of immature CGNs from the EGL, or disrupted migration through the ML. 


\section{Discussion}

We examined the expression, activity, and contribution of the matrix metalloproteinases 2 and 9 in the postnatal rat cerebellar cortex using a variety of experimental approaches. Temporal patterns of expression and activity pointed to the involvement of MMP-2 and MMP-9 in the cellular events that shape the cerebellar cortex. During the first two postnatal weeks, granule neurons complete their migration from the external granule layer to the internal granule layer. Before the end of the second postnatal week, the rate of granule cell migration significantly decreases while other cerebellar interneurons, stellate, Golgi, and basket cells complete their maturation (Altman, 1972a; Altman, 1972b). This period is also important for the maturation of Bergmann glial fibers and the growth of Purkinje cell dendritic trees (Seil, 2001; Zecevic and Rakic, 1976).

\section{Developmental mRNA expression of MMP-2 and MMP-9}

We determined the level of mRNA expression in the cerebellar cortex by realtime quantitative RT-PCR (Figure 3.1). The level of MMP-2 mRNA expression in the cerebellar cortex decreased sharply between P3 and P6 and more gradually between P6 and P25. In the cereberal cortex during the same period, MMP-2 mRNA progressively declined from P3 until P25. The transcript levels of MMP-9 remained unchanged between P6 and P25 after an initial decrease from P3 to P6. In comparision, the level of 
MMP-9 mRNA expression increased significantly in cerebral tissue from P6 to P25. During this period in the rat neocortex, dendritic trees of cortical neurons are expanding and axons are beginning to acquire a myeling sheath. Both, dendritic remodeling and process extension of oligodendrocytes, are known to involve gelatinases (Oh et al., 1999; Szklarczyk et al., 2002; Uhm et al., 1998). The mRNA expression for MMP-9 was previously studied by Vaillant et al. (1999). They observed MMP-9 mRNA in the cerebellum at P10 and P15 by in situ hybridization; however, they did not detect MMP2's mRNA. Their observations in the cerebellum at P10 and P15 are in accordance with our data, except that we detected a preceding decrease between P3 and P6. The decline in MMP-9's mRNA may have an impact on the level of pro-MMP-9 and, subsequently, the active MMP-9 available for the degradation of ECM proteins. Other regulatory mechanisms may be at play as well, especially the possibility that MMP-9 is controlled post-transcriptionally or post-translationally. Modulation and expression of the transcript of gelatinases, MMP-2 and MMP-9, can occur on a localized level, within a cell type or cell layer, and not at the organ level. Studies on gliomas, astrocytomas, and other metastatic brain tumors give ample support for this proposition (Raithatha et al., 2000; Vince et al., 1999; Lampert et al., 1998). In these studies, gelatinase transcripts were detectable only within cancerous tissue and not in the surrounding normal tissue. Evidence from these studies and other work on lung, liver, skin, and ovarian cancers links this expression to migration, invasiveness, and to neovascularization (Gokaslan et al., 1998; Platten et al., 2001; Furuya et al., 2000; Hah and Lee, 2003; Rooprai and McCormick, 1997). 


\section{Developmental changes in MMP-2 and MMP-9 activity}

The physiological roles of MMP-2 and MMP-9 are dependent on the availability of the latent enzymes and their subsequent activation ( $\mathrm{Vu}$ and Werb, 2000). We examined the gelatinase activity of MMP-2 and MMP-9 in the cerebellar cortex from rat pups and found that the activity gradually decreases in the first 25 postnatal days (Figure 3.2 A-D, G-I). The gelatinase activity of MMP-2 decreased progressively from P3 until P18 and was constant afterwards. Vaillant et al. (1999) reported gelatinase assays for only three time points (P10, P15 and adult) with somewhat different results. Even though Vaillant and colleagues reported a constant level of MMP-2 throughout development, close inspection of their results suggest a modest decrease between P10 and P15; however, no quantitative data was reported to clarify this discrepancy. In the current study, we studied eight time points covering the period from birth to P25. Furthermore, to address differences with published results (Vaillant et al. 1999), we performed densitometric analysis on zymographic gels $(n=5$ per time point), which supported our observations (Figure 3.2 A, G). MMP-2 activity gradually decreased between P3 and P18 and stabilized afterwards.

During the same period, reverse zymography assays showed constitutive activity for TIMP-2 (21 kDa) between P9 and P25, after an initial slow increase between P3 and P9 ( $p<0.05$; Figure 3.2 C, I). This suggests that the activity of MMP-2 is being controlled at yet another level. In fact, TIMP-2 binds and inhibits MMP-2 (Nagase, 1997), and functions as an adaptor protein between pro-MMP-2 and its activators, MT-MMPs. High levels of TIMP-2 saturate all the binding sites on MT-MMPs (membrane tethered MMPs) and block the activation of MMP-2, whereas low levels favor binding and activation 
(Murphy et al., 1999). The availability of TIMP-2, which may limit the activation of proMMP-2, combined with a progressive decrease in MMP-2's gelatinase activity suggests a more significant developmental role for MMP-2 in the first postnatal week than in the second and third postnatal weeks.

As for MMP-9 (Figure 3.2 B, H), the active form was predominant between P3 and P12. The proportion of the latent form increased on and after P12, however, the total MMP-9 activity (latent and active) gradually decreased after P18. These data suggest a switch in the available form of MMP-9; the active enzyme was predominant until P9, while the latent form increased afterwards. Vaillant et al. (1999) reported a parallel pattern, with MMP-9's activity strong at P10 but hardly noticeable at P15 and in adults. Quantitative analysis of our gels by densitometry supports our qualitative observations $(\mathrm{p}<0.05$; Figure $3.2 \mathrm{H})$. In reverse zymographic assays, we did not detect TIMP-1 (28 $\mathrm{kDa}$ ), which normally binds to and inhibits MMP-9. The absence of the inhibitor TIMP-1 and the availability of the catalytically active form of MMP-9 suggest the involvement of MMP-9 in the biochemical and cellular events between P3 and P15, and a declining role afterwards. The activity of these enzymes persists longer than their RNA message, which supports the idea of translational, post-translational or post-transcriptional regulation of the activity and expression of MMP-2 and MMP-9.

To determine the potential source of MMP-2 and MMP-9 activity in the developing cerebellum, we isolated and cultured CGNs from P4 cerebella. After 48 hrs in culture, we performed a zymographic analysis on the conditioned media, which contained secreted proteins (Figure 3.2 E). We also performed a zymographic analysis on conditioned media from glial cultures isolated and cultured from same age cerebella. 
Both CGNs and glial cells in vitro expressed pro-MMP-2 (72 kDa) and MMP-2 (68 kDa and $65 \mathrm{kDa}$ ). On the other hand, pro-MMP-9 and MMP-9 expression was more prominent in CGNs than glial cells. This suggests that granule neurons and glial cells are a potential source of gelatinases in the developing cerebellar cortex, with CGNs expressing both MMP-2 and MMP-9.

We used an in situ zymography assay to determine the spatial distribution of active gelatinases (Figure 3.3). This technique has been successfully used to study the distribution pattern and changes of gelatinases in the developing and adult nervous system (Oh et al., 1999; Szklarczyk et al., 2002). In cerebellar sections, the distribution of gelatinase activity in the cerebellar cortex gradually increased between P3 and P12. Initially the activity was present in the EGL and basal lamina. Between P9 and P12, the distribution of gelatinase activity progressively increased to include the Purkinje cell layer and the IGL. By P15, however, the gelatinase activity decreased to a minimal level in all layers of the cerebellar cortex. In contrast, gelatinase activity in the hippocampal formation was still detectable at P15 in the same section (Figure 3.3), demonstrating that the decrease in activity was localized to the cerebellum. This decrease in activity from P12 to P15, as detected with in situ zymography, mirrors the pattern observed in gelatinase assays (previous section). Several studies have documented the contribution of gelatinase activity to retinal development, but none have examined the cerebellum. In the retina, MMP-2 and MMP-9 activity was observed in Müller cells, which form a "scaffold" structure like Bergmann glia, in growing neurites and growth cones, in the retinal pigment epithelium and the ECM surrounding photoreceptors (Limb et al., 2002; Padgett et al., 1997; Sheffield et al., 1994). There is strong evidence for the participation 
of gelatinases in synapse formation (Taishi et al., 2001), differentiation (ChambautGuerin et al., 2000), migration through glial scars (Muir et al., 2002) and tumor metastasis (Rooprai and McCormick, 1997). In the cerebellum, during the first three postnatal weeks, three of these processes (synapse formation, differentiation, and migration) are underway. Granule neurons are migrating from the EGL to the IGL, they are forming connections with Golgi cells and mossy fibers, and PCs, interneurons and glia are still differentiating (Altman, 1972a; Sotelo, 1990). In situ gelatinase activity is enhanced within the EGL, PCL, and the IGL, which suggests a role for MMP-2 and MMP-9 in some of these critical cellular events.

\section{Developmental changes in MMP-2 and MMP-9 immunoreactivity}

Inspection of the expression of MMP-2 and MMP-9, over time, by immunohistochemistry helped us understand the distribution of the enzymes relative to cells and cell layers (Figure 3.4-6). Staining with a polyclonal antibody against MMP-2 coincided with the Purkinje cell layer, especially the soma and proximal dendritic trunks of PCs. This pattern was different from the immunoreactivity detected by calbindin D28k, which as expected labeled entire PCs including their dendrites. MMP-2 immunoreactivity was also associated with radial processes that strongly resemble Bergmann glial fibers in size, location, and arrangement. Moreover, staining for MMP-2 was present in the EGL. Staining for MMP-2 decreased below detection level at P15. Vaillant et al. (1999) observed MMP-2 immunoreactivity in the PCL, but not in the EGL or ML. This difference is probably due to several factors including the specificity of the 
antibody we used (Santa Cruz), which recognizes the C-terminal domain common to both pro-MMP-2 and MMP-2. We performed several controls to ascertain the specificity of the antibody including negative controls, pre-absorption with a specific MMP-2 blocking peptide (data not shown), and by western blot analysis (Dr. Luo, unpublished data). The specificity of this antibody has been independently confirmed and successfully used by other authors (Wagner et al., 2003). Furthermore, CGN and glial cultures (Figure 3.2 E, F) showed strong gelatinase activity for MMP-2, which further supports our observations. Several developmental events occur during this period, including the migration of granule neurons and the extension of parallel fibers, the maturation of Bergmann glial fibers, and the ensheathment of Purkinje cell bodies by glial processes (Yamada and Watanabe, 2002; Altman, 1972a; Altman, 1972b). The expression of MMP-2 in the EGL, Bergmann glial fibers, and the Purkinje cell layer suggests the involvement of MMP-2 in these developmental events.

MMP-9 immunoreactivity was most intense in the EGL and in the Purkinje cells. Side by side comparision of MMP-9's immunoreactivity to calbindin immunostaining, revealed a difference in the distribution. Whereas calbindin stained the entire Purkinje cell, MMP-9 was distributed in somata and dentrites but did not extend to smaller dendrites and spines. Furthermore, punctate staining for MMP-9 could be observed in the immediate pericellular space surrounding PCs. Similar punctate immunoreactivity for MMP-9 and other MMPs have been reported in trophoblasts of the human placenta and in malignant gliomas (Huppertz et al., 1998; Rooprai et al., 1998). MMP-9 has been shown to contribute to process extension of oligodendrocytes, to neurite extension, and dendritic remodeling in the hippocampus (Oh et al., 1999; Pittman and Williams, 1989; Uhm et al., 
1998; Zhang et al., 1998). Diffuse and punctate staining around the dendrites (Figure 3.6) suggests a role in the degradation of ECM around extending neurites or synapse formation. The pattern of expression of MMP-9 also may suggest a role in the maturation of Purkinje cells and the branching and expansion of their dendritic trees.

\section{The effect of inhibiting gelatinases on cerebellar development in organotypic slice culture}

We next tried to demonstrate possible effects of diminishing MMP-2 and MMP-9 on the histogenesis of the cerebellar cortex by exposing cerebellar slices to a selective MMP-2/MMP-9 inhibitor (Figure 3.8-10). Organotypic slice culture has been successfully used to study the development of the cerebellar cortex (Hager et al., 1995; Kunimoto and Suzuki, 1997). The cytoarchitecture of the cerebellar cortex is maintained (Tanaka et al., 1994; Bruckner and Grosche, 2001), even in organotypic slices prepared from P8 pups and cultured for 11 days in vitro (Takacs and Metzger, 2002). In our experiments, sections from cerebellar slices showed a developmental pattern that is comparable to what we observed in vivo (Figure 8A-C). Several experimental modifications seemed to improve the integrity of cultured slices like replacing the culture media every $48 \mathrm{hrs}$ instead of $36 \mathrm{hrs}$, adding $10 \mu \mathrm{l}$ of culture media on top of the slice, and placing slices side by side on the filter insert. The inhibitor we used (SB-3CT, VWR) has been shown to mimic the binding of TIMP-1 and TIMP-2 (Kleifeld et al., 2001). In situ zymography in sectioned cerebellar slices showed abberant activity in slices treated with the gelatinase inhibitor compared to controls (Figure 7E and F). This altered 
gelatinase activity was most noticeable in the EGL and the IGL. We used two parameters to quantify the effects of MMP-2 and MMP-9 inhibitor on cerebellar cortical histogenesis in organotypic (Figure 3.10A and B). First, we measured the thickness of the EGL, which is an indirect indicator of the density of granule cells in the EGL. Secondly, we counted the number of small fusiform cells, presumed to be migrating granule neurons, in the ML. The first parameter pertains to the proliferative activity of progenitor cells and the rate of CGN exodus from the EGL. Combining this information with the number of migratory profiles allows us to assess the effect of inhibiting the function of gelatinases. A decrease in the thickness of the EGL could be due to lenghthening of the cell cycle or an increase in the rate of migration. The first condition leads to a decrease in the number of migrating profiles, while the second leads to a transient increase followed by a decrease due to reduction of the premigratory population in the deep EGL. An increase in the thickness of the EGL would indicate shortening of the cell cycle or a decrease in the rate of migration. Shortening the cell cycle will increase the packing density of cells and thickness of the EGL without affecting the number of migratory profiles in the ML, while a decrease in the number of migrating cells in the ML would be due to a decrease in the rate of migration.

Inhibitor treatment resulted in a significant dose-dependent increase in the thickness of the EGL in slices cultured for 1 day (1DIV) and 10DIV compared to untreated controls. The number of fusiform cells in the ML, presumed to be migrating, decreased significantly in a dose dependent fashion in all treatment groups compared to controls. We speculate that the increase in the thickness of the EGL can be explained by an increase in the number of cells unable to start migration, whereas the decrease in 
thickness at 10 DIV may be due to an increase in cell death, particularly in the postmitotic-premigratory population. A similar decrease in the thickness of the EGL was observed in cerebellar slices treated with methylmercury, which inhibited neuronal migration and caused an increase in pyknotic nuclei in the deep EGL as identified by BrdU pulse labeling and TUNEL (Kunimoto and Suzuki, 1997). Kunimoto and colleagues proposed that the retardation of migration may cause an increase in naturally occurring cell death that is thought to reduce the number of granule neurons (Wood et al., 1993).

The reduction in the number of migrating cells in the ML and the increase in thickness of the EGL was accompanied by a time- and dose-dependent decrease in gelatinase activity detected in cerebellar slices (Figure 9A-F). These data support the proposition that MMP-2 and MMP-9 may contribute to the migration of CGNs. The concentration of inhibitor we used $(1.6 \mu \mathrm{M}-6.4 \mu \mathrm{M})$, has been shown to have minimal effect on other MMPs (Brown et al., 2000) and on the viability of cells in vitro (Fingleton, 2003; Rosenblum et al., 2003). Other issues remain to be clarified about the effect of inhibitor treatment. It is not clear whether the decrease in migratory cell number is due to the decrease in the rate of migration, or is secondary to a decrease in the ability of postmitotic neurons to initiate migration. Gelatinases have been shown in other systems to promote cell motility and tumor metastasis (Gokaslan et al., 1998; Tokuraku et al., 1995). Gelatinase inhibitors has been shown to reduce the migration of Langerhans cells, skin dendritic cells (Ratzinger et al., 2002), and the migration of vascular smooth muscle cells (Pross et al., 2002). Although inhibitor treatment did not completely stop the migration of granule neurons, it decreased it significantly. Since the development of the 
cerebellar cortex is dependent on intact interactions and normal development of its cellular constituents, then a role for gelatinases is strongly supported.

Disturbing the development of granule neurons, by mutations or toxic compounds, is known to cause stunting of Purkinje dendrites and damage to Bergmann glia; disrupting the development of Purkinje neurons can have even gravier consequences (Ferguson, 1996; Bignami and Dahl, 1974; Adams et al., 2002; Altman and Anderson, 1972; Llinas et al., 1973). The pattern of immunoreactivity of MMP-2 localizes around fusiform-shaped cells in the ML, presumably migrating granule neurons, and around granule neurons in the deep EGL, which supports a role in migration. MMP-2 immunorectivity was also detetcted in Bergamnn glial fibers. Additionally, purified CGNs and glial cells from P4 cerebella had strong MMP-2 expression. Temporary "interstitial densities" have been shown to attach migrating granule neurons to BG fibers (Gregory et al., 1988). We speculate that Bergmann glia and/or granule neurons secrete MMP-2 to dissolve these densities and allow for further advancement of cells or processes. Gelatinases have been shown to facilitate the migration of gliomas (Uhm et al., 1996), and of oligodendrocyte progenitors in vitro on an an astrocytic ECM by degrading temporary cell attachments (Uhm et al., 1998; Oh and Yong, 1996).

We detected MMP-9 activity in purified CGNs, and immunoreactivity in the EGL and in Purkinje cell dendrites. This expression pattern indicates a role for MMP-9 in the migration of CGNs and in the growth of Purkinje cell dendrites. We speculate that the effect on migrating cells may be secondary to impeding the growth of Purkinje dendritic trees. This could be resolved by measuring the growth of Purkinje dendritic trees in treated slices compared to control slices. Damage to Purkinje cells by X-irradiation or 
mutations is known to cause reduction in granule neuron numbers (Altman et al., 1969b; Bradley and Berry, 1978). Another possibility is that the inhibition of gelatinases reduced the ability of cells to degrade the ECM, which might have resulted in an increase in the packing density of cells in the EGL. Furthermore, the expression pattern in the EGL suggest a role for MMP-2 and MMP-9 in neurogenesis; a function suggested for MMP-9 (Canete et al., 1995) but not for MMP-2. These possibilities, however, will require experimental evaluation.

\section{Concluding remarks and future directions}

Several studies reported the absence of MMP-2 transcript in normal adult tissue and elevated mRNA levels only in malignant tissue (Raithatha et al., 2000; Vince et al., 1999; Lampert et al., 1998). The decrease in MMP-2 mRNA from developmental levels to adult levels has been reported to occur before birth (Casasco et al., 1995). Our data suggest that this decrease occurs postnatally in rats (Figure 3.1). Transcript levels of MMP-2 in the cerebellar and cerebral cortex declined progressively between P3 and P25. The possibility remains that MMP-2's transcripts are expressed locally in certain cells, which could be verified by in situ hybridization. Furthermore, new technologies like laser capture microdissection (LCM, Acturus) or laser microdissection and pressure catapulting (LMPC, Carl Zeiss Inc.) allow the dissection of cells or small regions of tissue for RNA or DNA analysis. These techniques would allow the study of the expression of MMP-2 and MMP-9 by RT-PCR in cortical tissue, cortical layers, and in specific cell populations. 
MMP-9 transcript showed an increase during the first two postnatal weeks in cerebral tissue, which consistently contained parts of the corpus callosum. The contribution of MMP-9 to process extension of oligodendrocytes and to myelination, have been previously proposed (Oh et al., 1999; Uhm et al., 1998). Myelination in the corpus callosum increases during the second postnatal week, but is delayed until after postnatal day 25 in the cerebellum (Wiggins, 1986; Raval-Fernandes and Rome, 1998; Hamano et al., 1998). Therefore, the increase in MMP-9 mRNA in cortical tissue may be partly due to the increase in myelination. If this speculation were true, we would expect to observe an increase in MMP-9 mRNA in the cerebellum after P25. A progressive decrease to adult MMP-9 mRNA levels would be expected as myelination subsides. Another possibility is that MMP-9 contributes to dendritic growth and plasticity. Evidence presented by Szklarczyk and colleagues (2002) suggests a role for MMP-9 in these functions in the adult nervous system but whether MMP-9 fulfills the same function during development remains to be explored.

Genetic manipulations of the expression of MMPs provided ample knowledge about the mechanisms of activation and the consequences of abnormal expression. Knock-out studies of individual MMPs show no lethal mutants, which was attributed to the redundancy of MMPs and their broad spectrum of substrates (Shapiro, 1998). Overexpression of MMPs, such as MMP-2 and MMP-9, has been shown to contribute to the degradation of myelin and the BBB in MS, cancer metastasis, and other diseases (Beliveau et al., 1999; Wang et al., 2000; Yong et al., 1998). On the other hand, reduced expression and activation of MMPs has been linked with several brain pathologies especially Alzheimer's disease (Asahina et al., 2001; Yong et al., 2001). Evidence from a 
variety of experimental approaches suggests that pathologies arise from the disruption of more than one MMP, particularly MMPs like MMP-2 and MMP-9 that degrade common substrates. Inhibition of gelatinases has been shown to limit the extension of retinal growth cones by stopping the formation of filopodial processes (Sheffield et al., 1994). Outside the nervous system, the inhibition of gelatinases has been shown to reduce the migration of Langerhans cells, skin dendritic cells, and vascular smooth muscle cells (Pross et al., 2002). Furthermore, synthetic inhibitors of gelatinases have been successfully used to limit the metastasis of tumors in animal models, and are potential candidates for treating invasive tumors in humans (Brown et al., 2000; Marder and Greenwald, 2003; Rooprai and McCormick, 1997).

The defects we observed in cerebellar slices after inhibitor exposure are probably due to the combined inhibition of MMP-2 and MMP-9. MMP-9 knock-out mice do not exhibit significant abnormalities in the development of the cerebellum (Shapiro, 1997). Gelatinases are similar to other MMPs in that they are zinc-dependent enzymes. Abnormalities in the development of the cerebellar cortex have been described in zincdeficient mice (Dvergsten et al., 1983). The damage to the cerebellar cortex, especially in the number of granule neurons and the thickness of EGL, was more severe in zincdeficient pups than in undernourished pair-fed pups. Toxic compounds are also known to damage the cerebellum during development (Antonio et al., 2002; Nielsen et al., 2003; Stoltenburg-Didinger et al., 1990). In rodents, in vitro and in vivo exposure of the cerebellum to methylmerucy, an animal model for Minamata disease, causes a severe decrease in the number of migrating granule neurons as seen in our study (Howard and Mottet, 1986; Kunimoto and Suzuki, 1997; Sager et al., 1982). Mercuric coumpounds 
modulate the activity of MMPs, especially MMP-2 and MMP-9. Some organic mercurial coumpounds are known to induce gelatinase activity, whereas mercuric salts suppress the activity of gelatinases (de Souza et al., 2000; Sopata and Wize, 1979). The damage caused by a zinc-defiency and exposure to methylmercury involves a myriad of molecules, most of which are unknown. The damage, nevertheless, could possibly be due, at least in part, to disruption of the activity of MMPs.

Sereral additional aspects of these results need to be addressed, especially the role of gelatinases in the extension of parallel fibers. MMP-9 contributes to process extension of oligodendrocytes and to neurite outgrowth in the retina (Letourneau et al., 1992; Uhm et al., 1998; Ferguson and Muir, 2000; Buttery and ffrench-Constant, 2001). We did not observe immunoreactivity for MMP-9 in association with parallel fibers. This might be due to our use of the parasagittal plane in all sections. As a result, our slices were all perpendicular to the direction of parallel fibers. The proposition that gelatinases contribute to the extension of parallel fibers might be addressed experimentally by performing immunohistochemitry for gelatinases on frontal sections. Furthermore, depositing small particles of DiI on the surface of the EGL, followed by immunohistochemistry for gelatinases in the frontal plane, would permit the validation of this proposition. We also observed MMP-2 and MMP-9 expression in the EGL and treatment with the MMP-2/MMP-9 inhibitor caused an increase in the thickness of the EGL. The increase in thickness could be due to an increase in proliferation, a decrease in migration, a decrease in cell death, or a combined effect. These possibilities are addressable by a variety of available techniques including the determination of the growth fraction (population of actively cycling cells) by BrdU labeling of proliferating 
cells and determining the percentage of newborn BrdU-positive neurons that migrate after treatment with the gelatinase inhibitor. Furthermore, immunostaining of migrating ganule neurons with doublecortin will reduce the errors associated with the morphometric analysis. Determining the amount of cell death by TUNEL staining will help us assess the possible neurotoxic effect of blocking gelatinase activity on the cerebellar cortex. Furthermore, MMP-2 activity and expression coincided with EGL and fusiform-shaped cells, resembling migrating granule neurons, in the ML (Figure 3.5). Whether MMP-2 contributes to the migration of progenitor neurons, between E14 and E17, from the rhombic lip to the EGL is yet to be determined.

Matrix metalloproteinases, especially MMP-2 and MMP-9, have emerged as key contributors to several homeostatic mechanisms, including process extension and cell migration. These processes are essential to the formation of the cerebellar cortex and the normal development of the nervous system. More research is needed to clarify how these matrix-degrading enzymes are controlled and coordinated to serve such complex situations. The investigation of the contribution of gelatinases to earlier events in cerebellar corticogenesis are also important, especially the migration of progenitor cells from the rhombic lip to populate the EGL, and the migration of immature Purkinje neurons and deep cerebellar neurons from the ventricular zone. 
Figures 
A

Relative mRNA in the developing cerebellar cortex

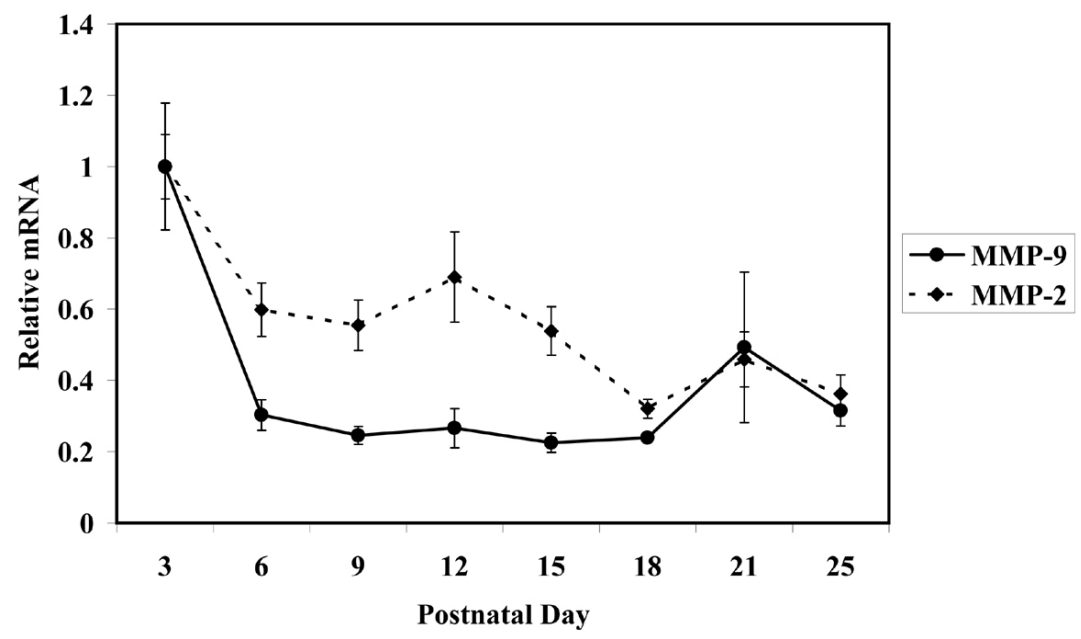

$\mathrm{B}$

Relative mRNA in the postnatal cerebral cortex

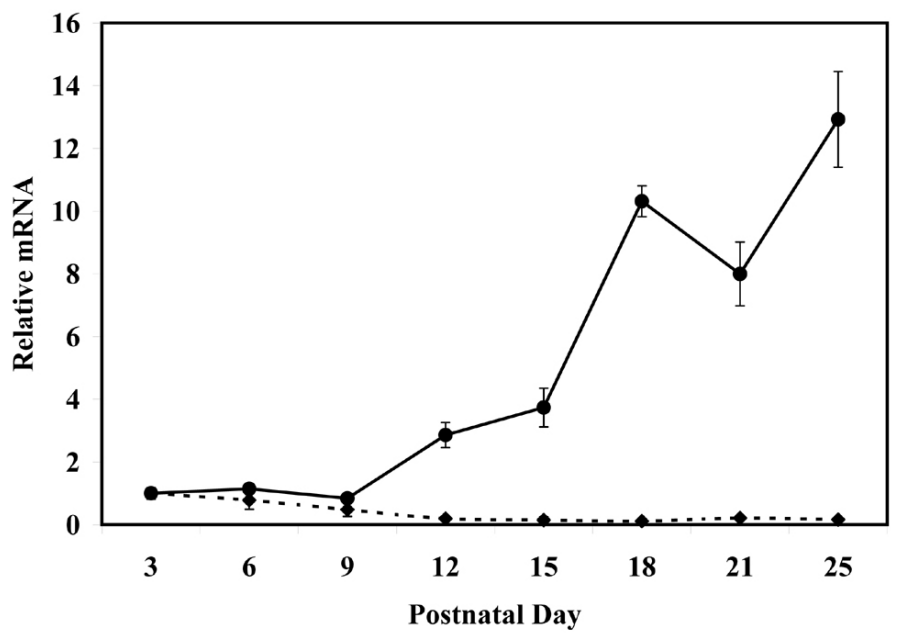

Figure 3.1 Real-time quantitative RT-PCR. A) The relative level of MMP-2 and MMP-9 mRNA in the cerebellar cortex (top graph) gradually decreased from P3 to P25. B) The expression pattern was different for MMP-9 but not for MMP-2 in the cerebral cortex (see text for details; Bars: $\pm \mathrm{SD}$ ). 
Figure 3.2 Gelatinase activity in the cerebellar cortex between P3 and P25. The cerebellum was dissected from rat pups at P3 until P25 and proteins were extracted from the tissue. Gelatin zymography showed digested bands of (A) pro-MMP-2 $(72 \mathrm{kDa})$ and MMP-2 (68 kDa); (B) pro-MMP-9 (92 kDa) and MMP-9 (82 kDa). We also performed a reverse zymographic assay to determine the presence of the gelatinase inhibitors TIMP-1 $(28 \mathrm{kDa})$ and TIMP-2 $(21 \mathrm{kDa})$ in tissue extracts. Only TIMP-2 activity was present between P3 and P25 (C). As a loading control, we cut the top $2 \mathrm{~cm}$ of every gel following the electrophoresis and stain it with Coomassie blue stain for $5 \mathrm{~min}$, which revealed bands of loaded proteins (D). We also performed gelatinase assay on cerebellar granule neurons (E) and mixed glial cells cultured from P4 cerebella (F). Gels were quantified with a densitometric analysis. (G) Shows densitometry for MMP-2, (H) shows densitometry for MMP-9, and (I) shows densitometry for TIMP-2. Experiments were repeated 3 times and gels were repeated 5 times (densitometry in arbitrary units; bars: \pm SEM).
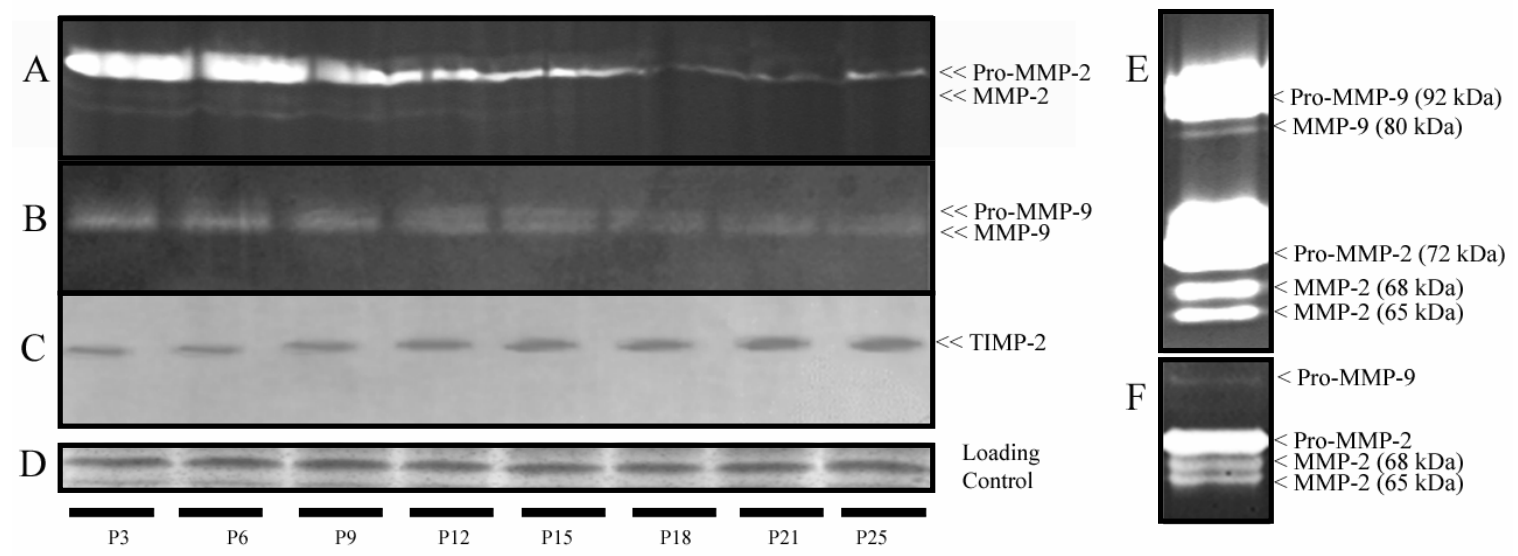
Densitometric analysis for MMP-2

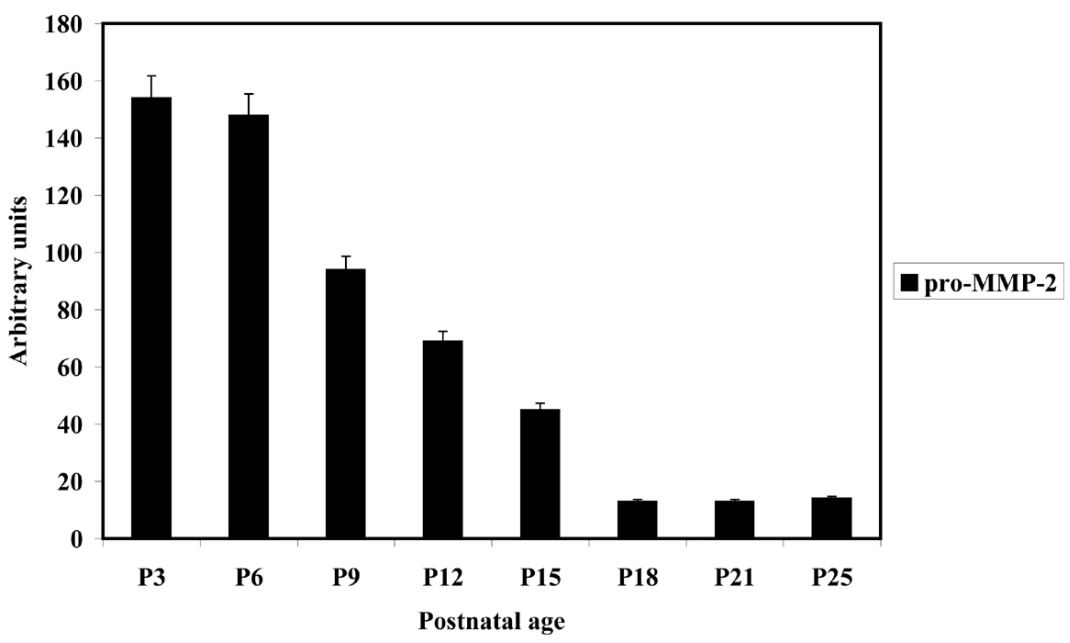

$\mathrm{H}$

Densitometric analysis for MMP-9

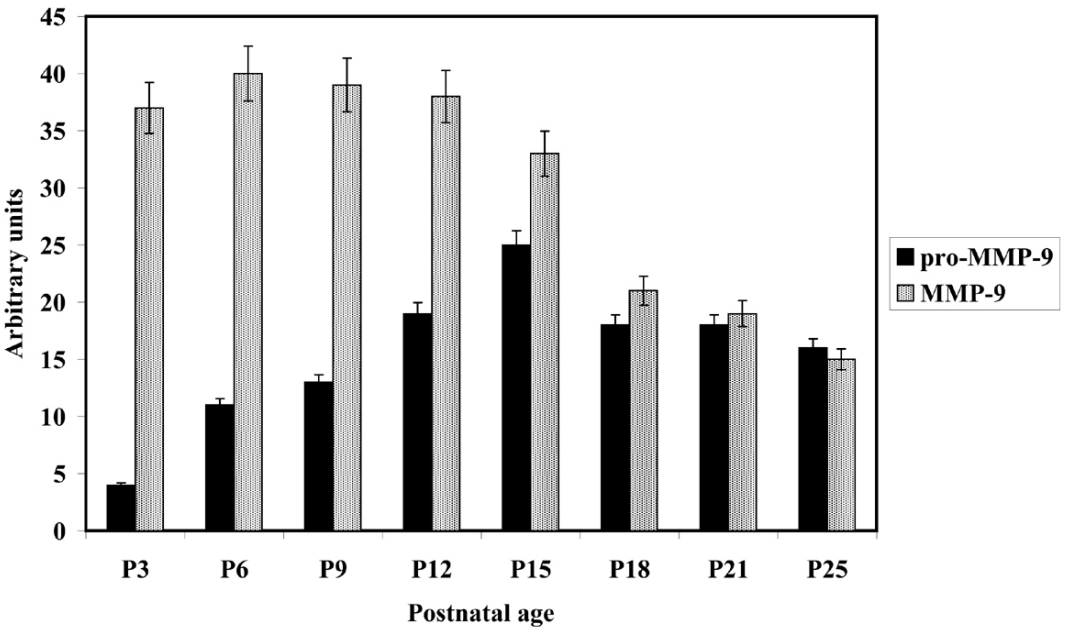


Densitometric analysis for TIMP-2

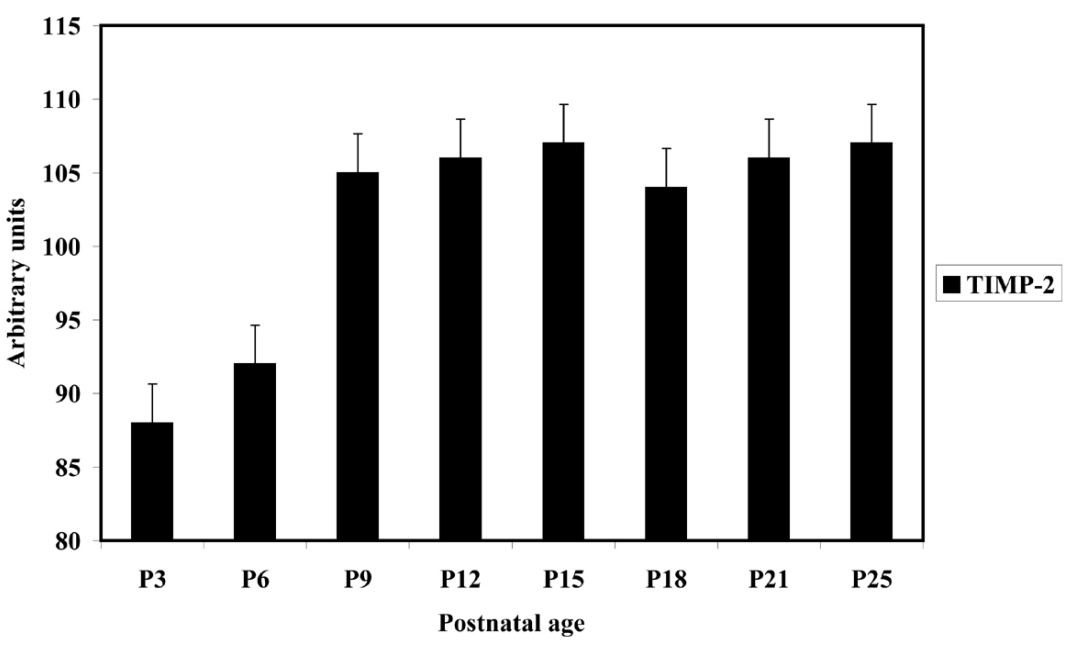


Figure 3.3 In situ Zymography in the developing cerebellum. Frozen tissue sections were incubated with Gelatin-FITC as a substrate (see methods). The digested gelatin fluoresces on tissue sections. (A) Gelatinase activity was present in the EGL and the Purkinje cell layer from P3 to P12. The activity increased in the IGL between P6 and $\mathrm{P} 12$. By P15 the activity decreased significantly in the cerebellum but was still detectable in the hippocampal formation in the same sections (scale: $800 \mu \mathrm{m}$ ). Inset shows gelatinase activity in the EGL, the Purkinje cell layer, and the IGL. Cells scattered in the WM also showed gelatinase activity, but the identity of these cells is not known (scale: $250 \mu \mathrm{m}$ ). Panel (B) shows serial sections treated with $20 \mathrm{mM}$ EDTA and 4\% formaldehyde, which abolish gelatinase activity, and an adjacent untreated section processed for in situ zymography. Reaction product was detectable only in the untreated section. Pictures were taken with the same optical settings. 


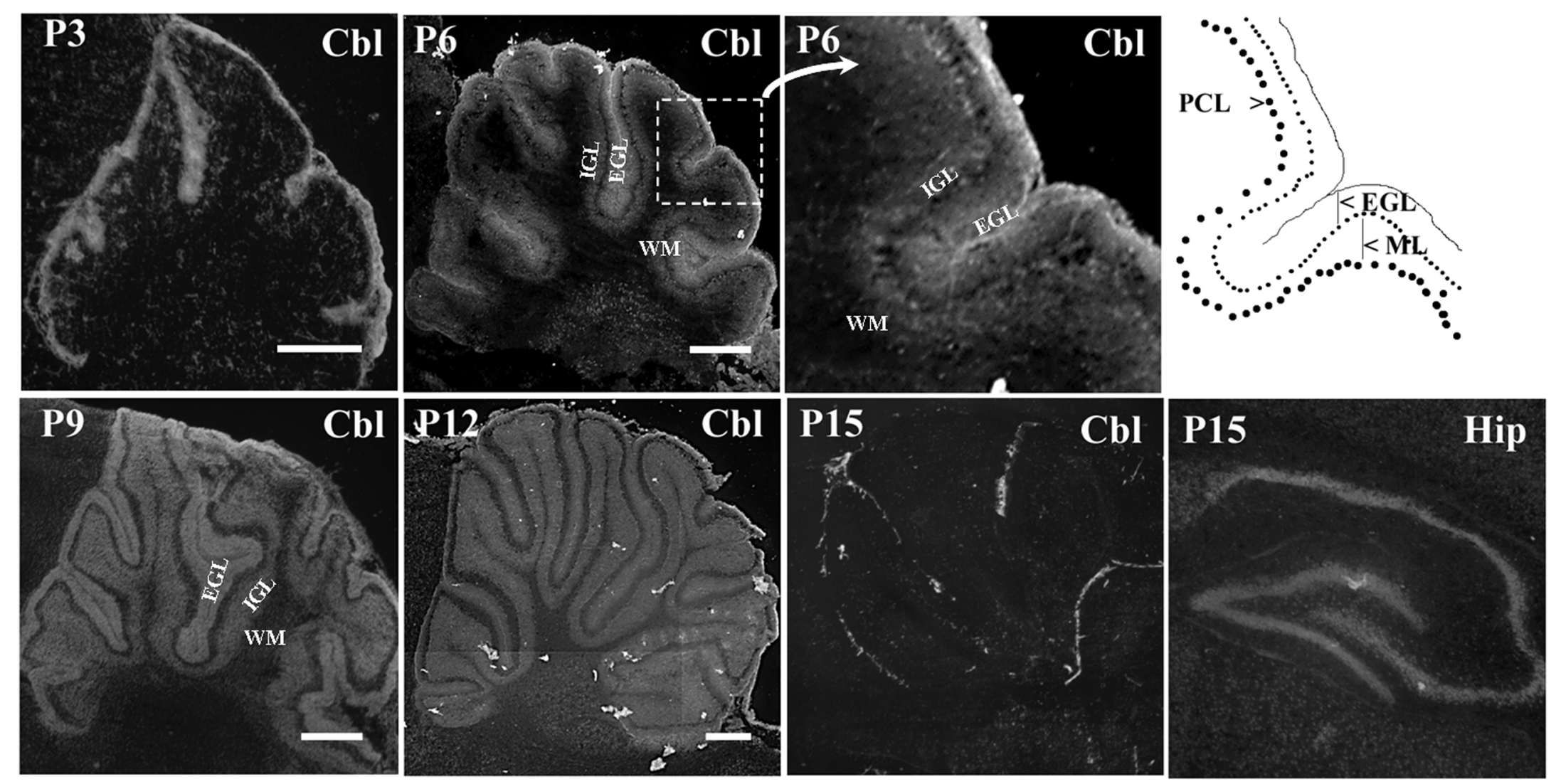


P6 (FITC-Gelatin ${ }^{\circledR}$ )

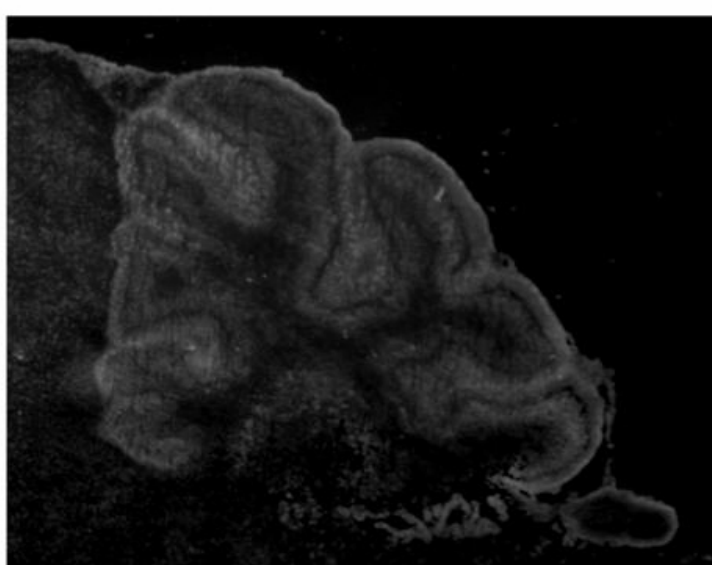

P6 (20mM EDTA / FITC-Gelatin $\left.{ }^{\circledR}\right)$

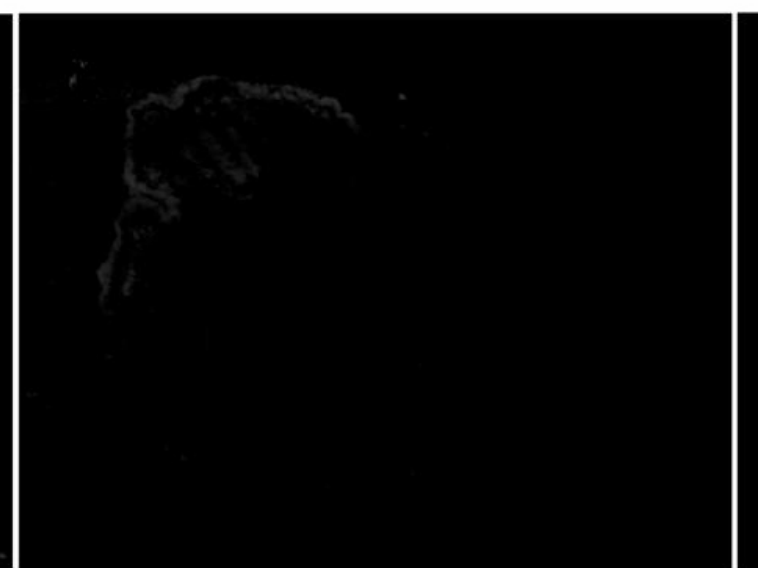

P6 (4\% Formaldehyde/ FITC-Gelatin $\left.{ }^{\circledR}\right)$

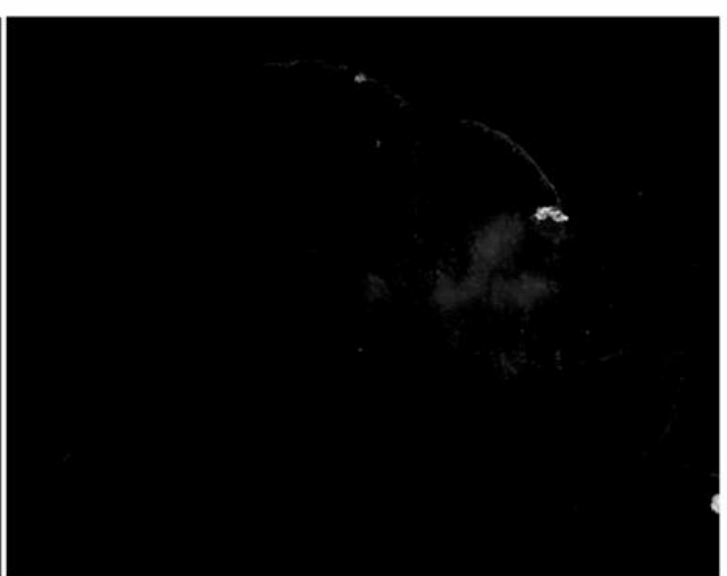


Figure 3.4 Immunohistochemical expression of MMP-2 and MMP-9. Panels showing representative sections from P6, P9, P12, P15, and P21 stained using anti-MMP-2, antiMMP-9, GFAP, and Calbindin D28k. All antibodies were detected with FITC-tagged secondary antibody (in green). In red is the nucleic-acid counterstain TOTO-3. (see results section for details). (EGL: external granule layer; ML: molecular layer; IGL: internal granule layer; PCL Purkinje cell layer; and WM: white matter; scale: $50 \mu \mathrm{m}$ ). 
P6

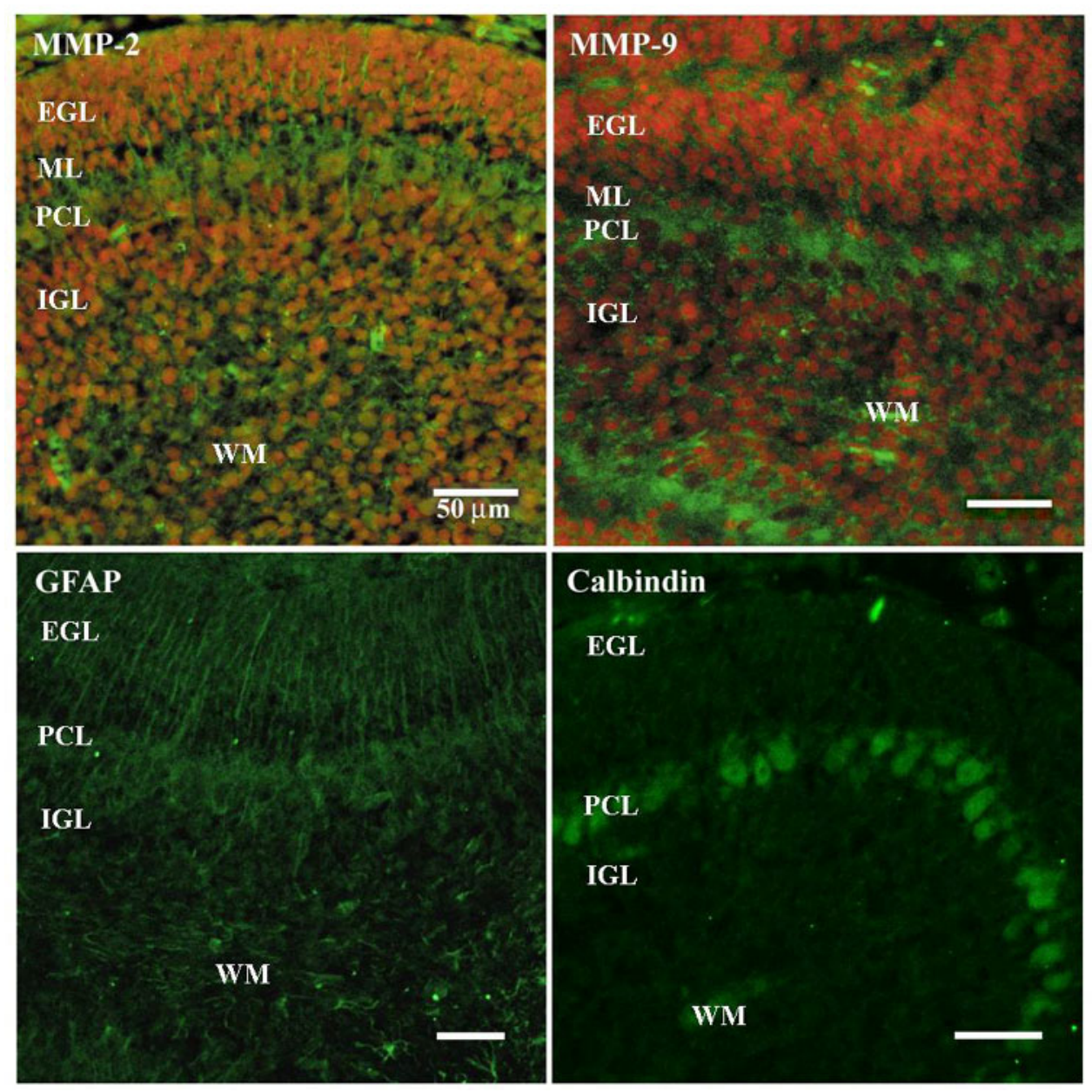


P9

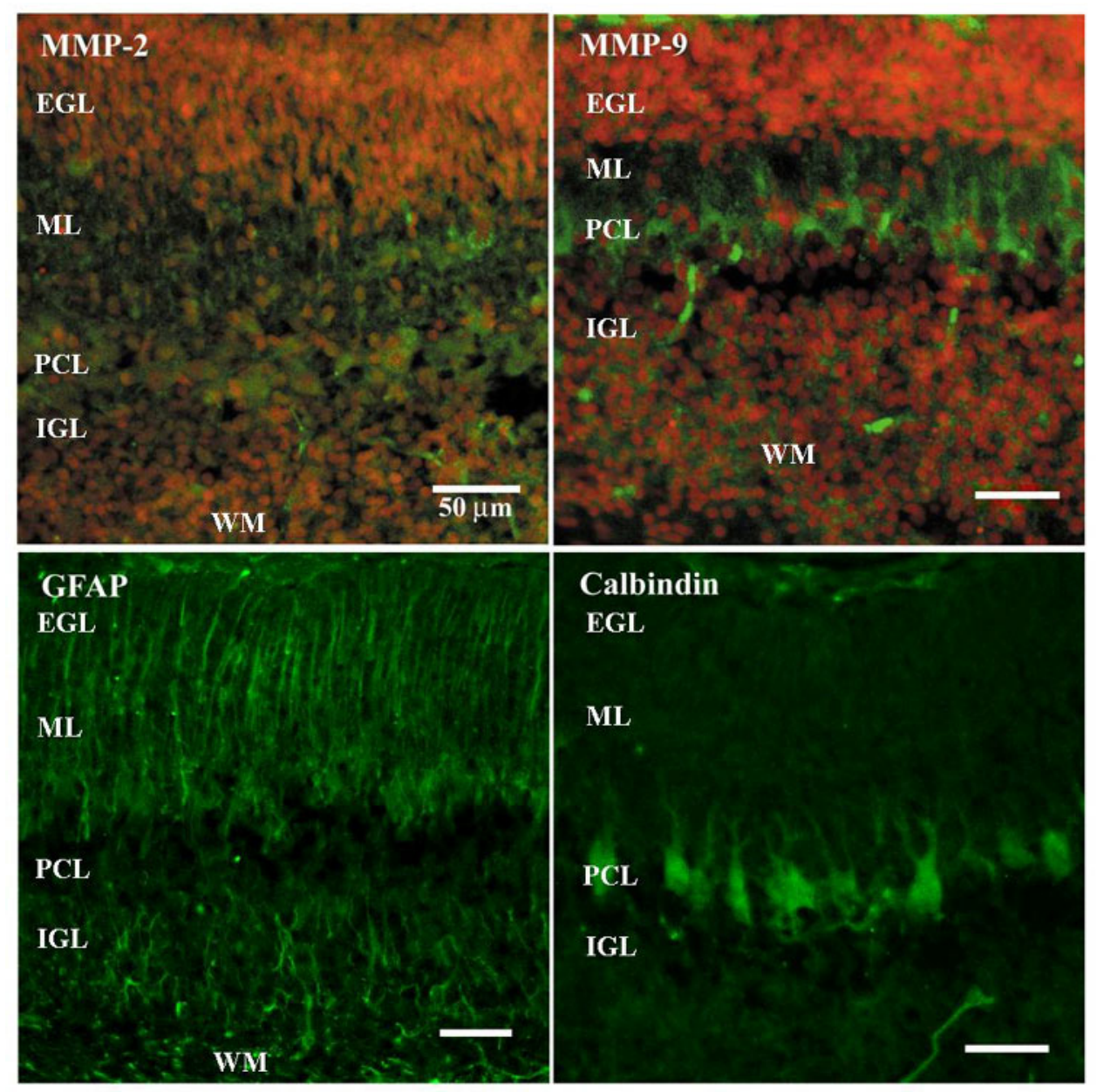


P12

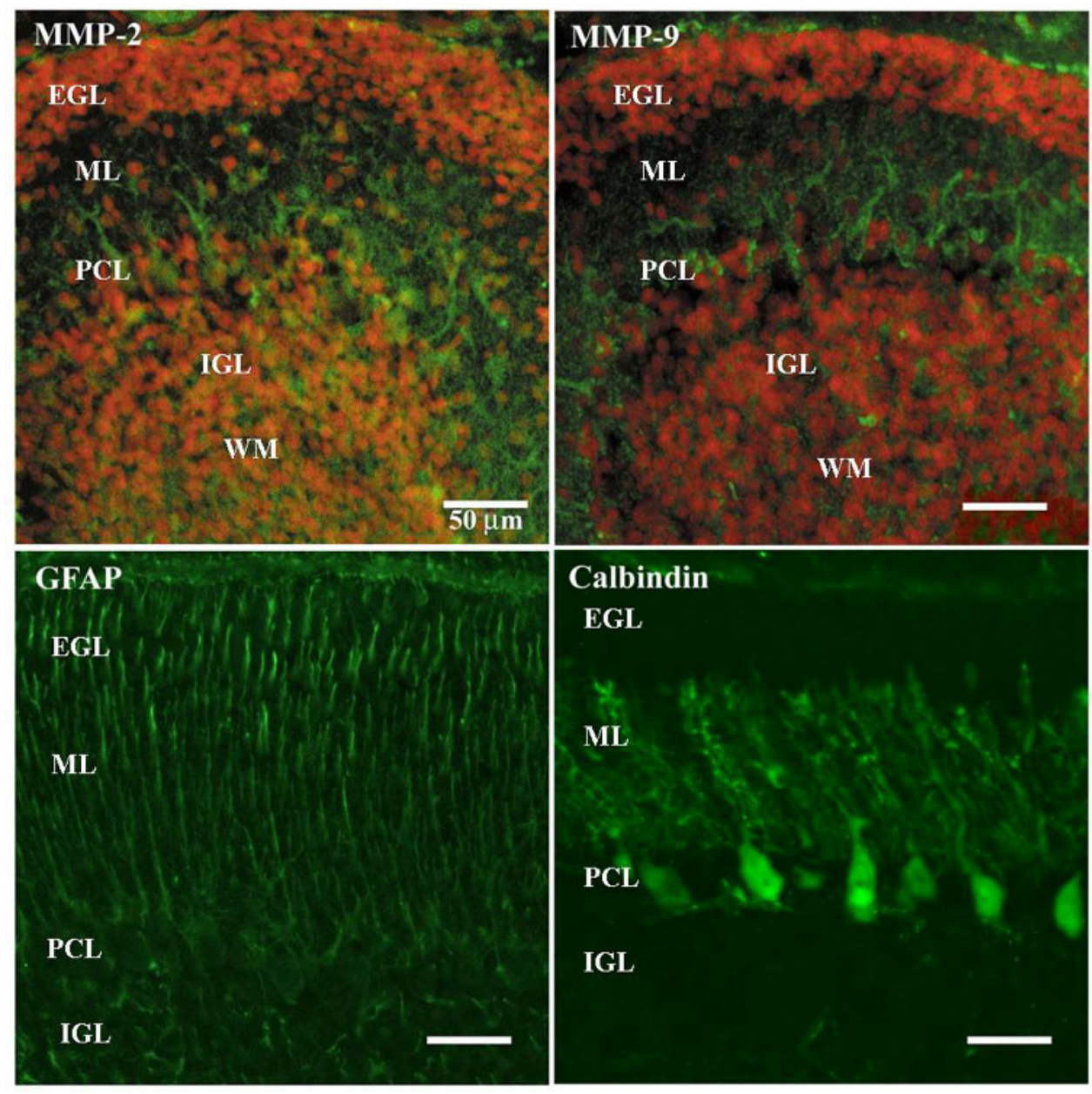


P15

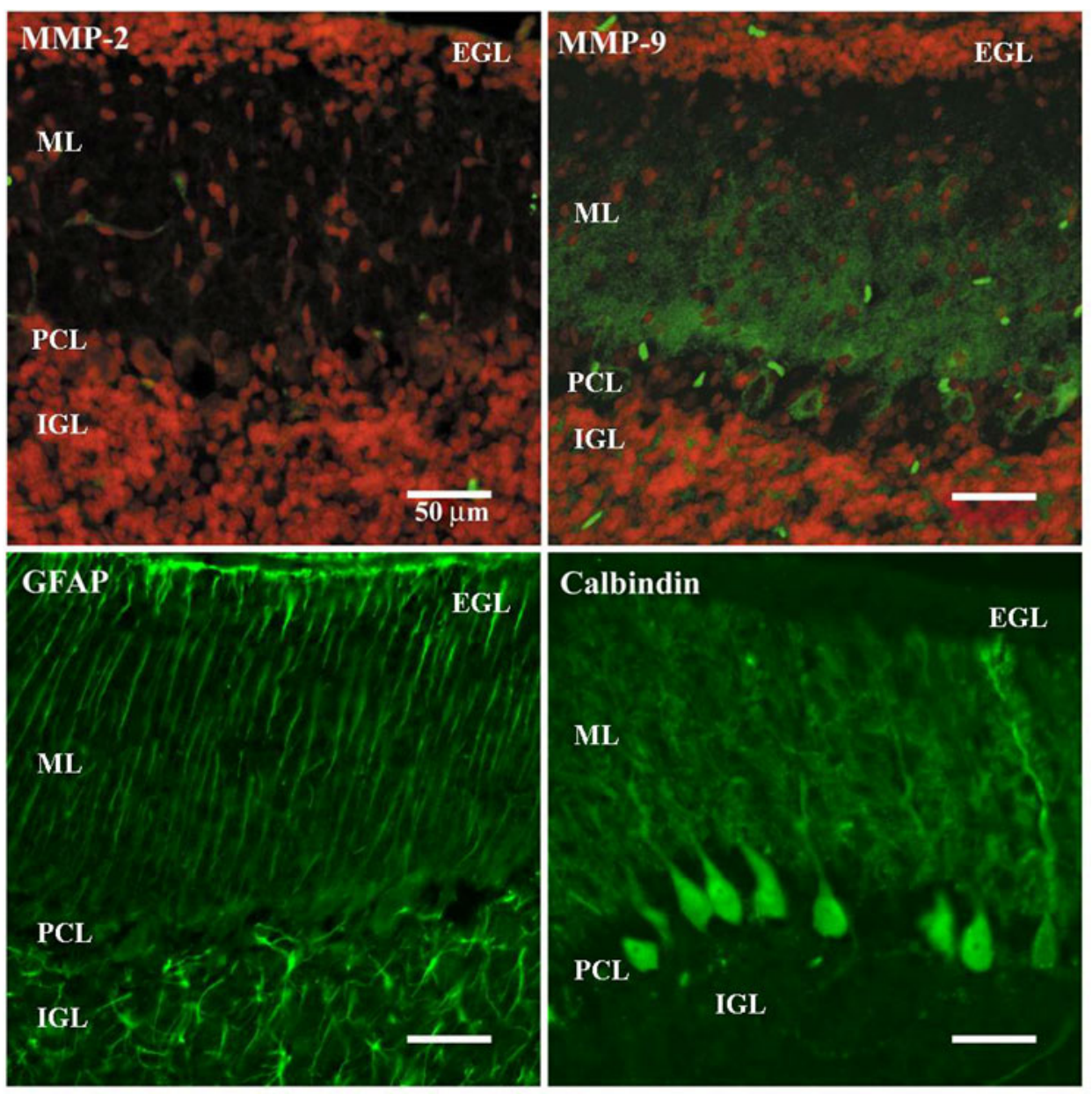


P21

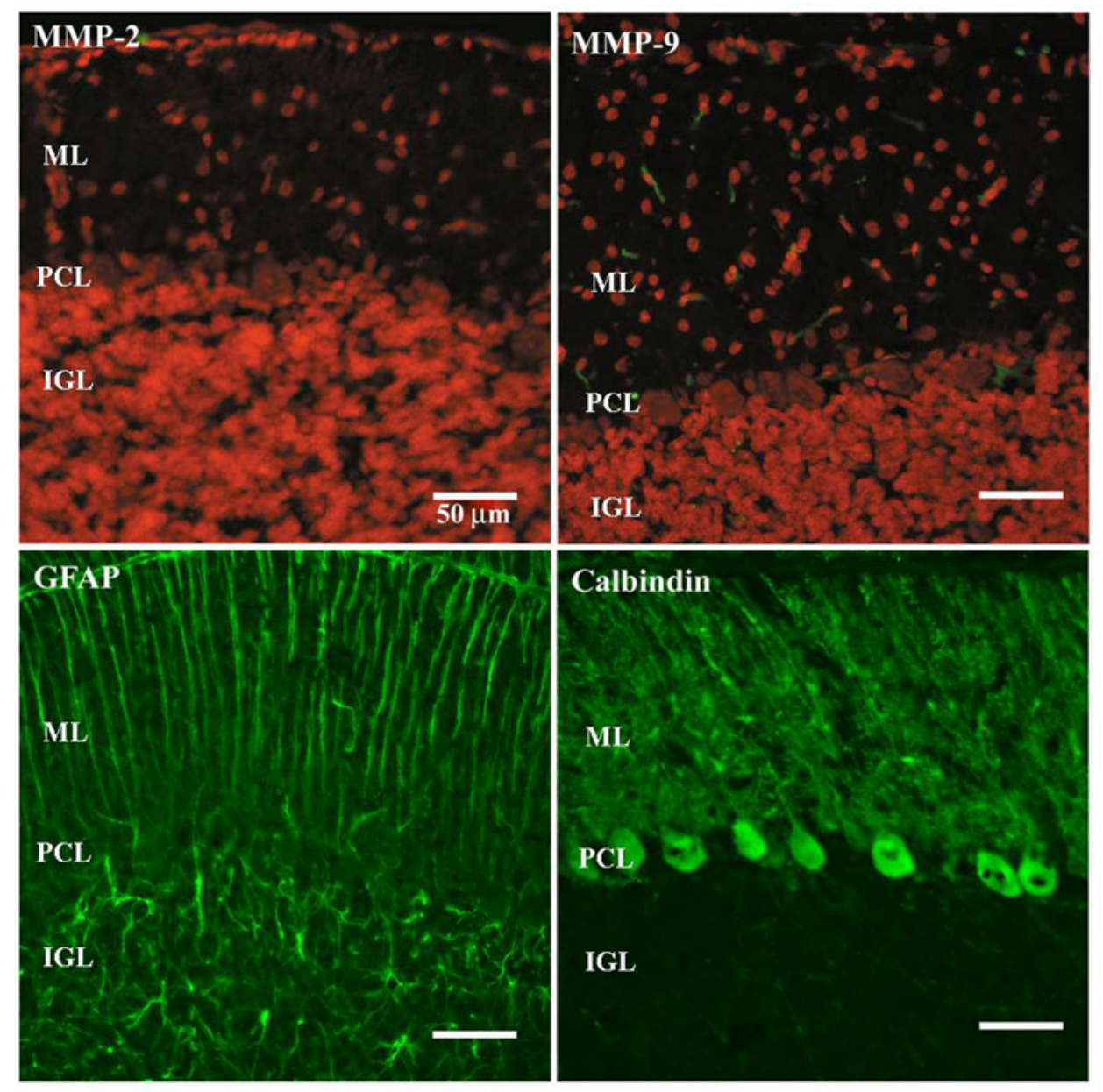


Figure 3.5 Detailed view of MMP-2 IHC. Sample images from P6 and P9 stained for MMP-2 (scale: $50 \mu \mathrm{m}$ ). Insets show from P6 and P9-MMP-2 at higher magnification in combined 2 channel images (FITC-TOTO3), and single channel images (Green = FITC). White arrows point to Bergmann glial fibers (see results section for details; scale: $20 \mu \mathrm{m}$; EGL: external granule layer, PC: Purkinje neuron). 


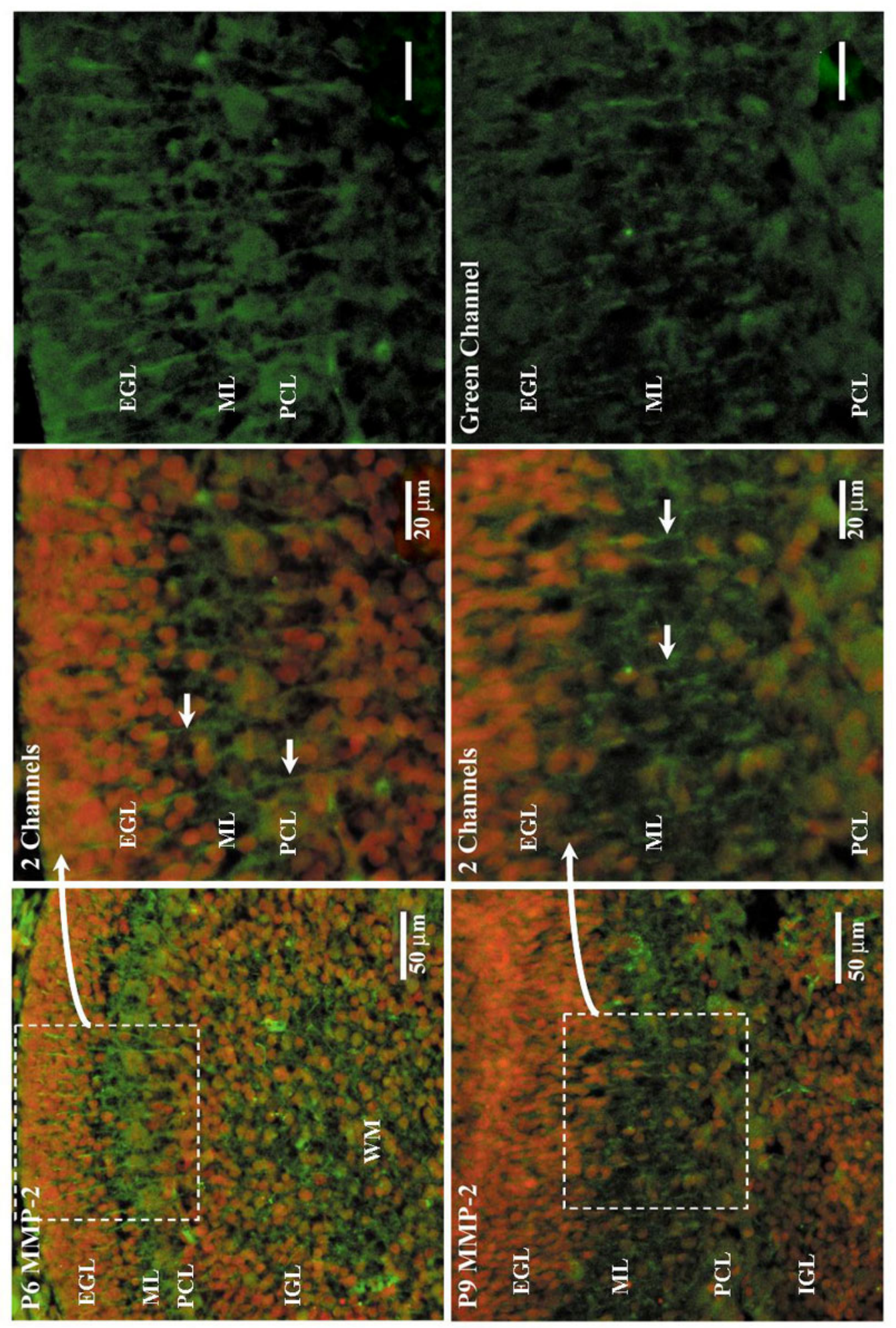


Figure 3.6 Detailed view of MMP-9 IHC. Sample images from P9 and P12 stained for MMP-9; scale: $50 \mu \mathrm{m})$. Insets show from P9 and P12-MMP-9 at higher magnification in combined 2 channel images (FITC-TOTO3), and single channel images (Green = FITC). White arrows point to Purkinje dendrites (see results section for details; scale: $20 \mu \mathrm{m}$; EGL: external granule layer, PC: Purkinje neuron). 


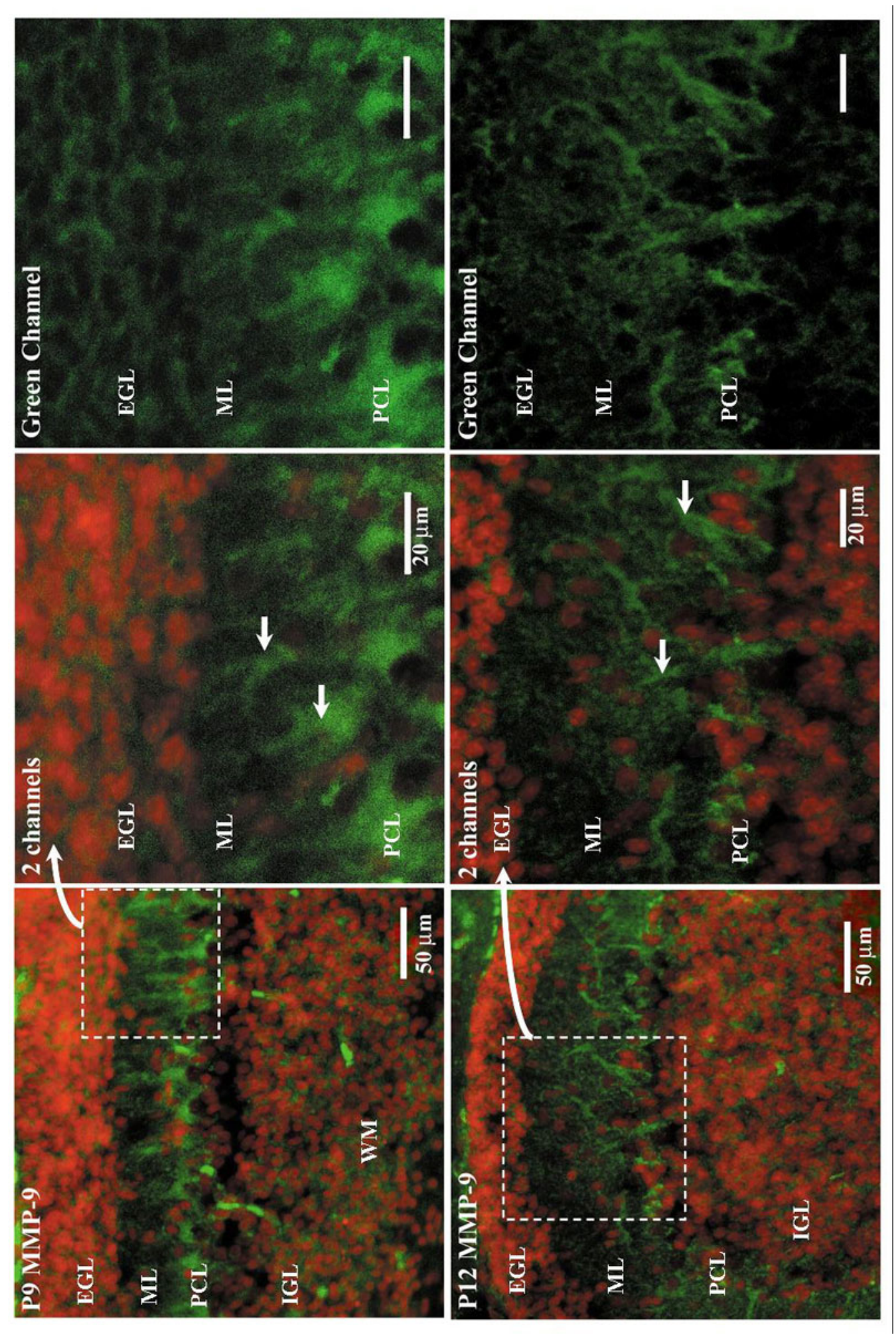



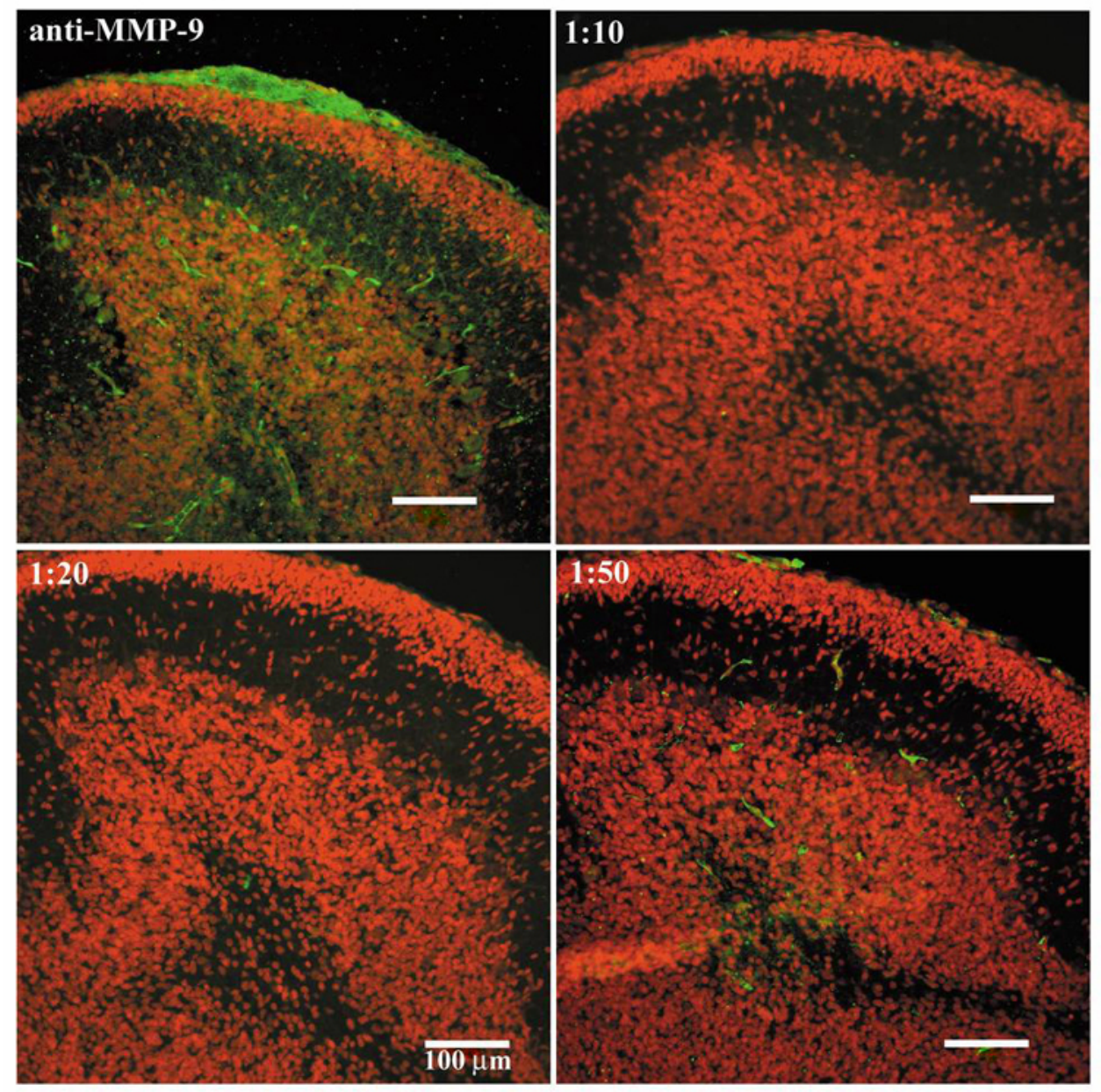

Figure 3.7 Control sections for MMP-9 IHC from P15 rat cerebellum. To determine the specificity of the antibodies used, serial sections were stained with the primary antibody pre-absorbed with an antibody-specific blocking peptide (see methods). Sample sections were incubated with the anti-MMP-9 alone $(0: 1)$ or with increasing dilution of the anti-MMP-9 blocking peptide (1:10, 1:20, and 1:50). As the concentration of the blocking peptide was reduced, the immunoreactivity of MMP-9 increased. Similar controls were done for MMP-2 (not shown; Mag bar: $100 \mu \mathrm{m}$ ). 
Figure 3.8 Expression and activity of MMP-2 and MMP-9 in organotypic slice cultures. Sample sections from a control slice at 7 DIV stained with anti-MMP-9 (A), anti-MMP-2 (B), anti-Calbindin D28k (C), and anti-GFAP (D) then counterstained with the TOTO-3 (red; scale: $50 \mu \mathrm{m}$ ). MMP-2 and MMP-9 immunoreactivity in organotypic slices was similar to that observed in vivo. We performed in situ zymography on organotypic slices treated with a selective MMP2/MMP9 inhibitor. (E) Control section cultured for 7DIV without inhibitors. (F) Sample section from an adjacent slice to (E) and treated with $3.2 \mu \mathrm{M}$ inhibitor for 7DIV shows reduced and aberrant gelatinase activity (scale: $1 \mathrm{~mm}$ ). 

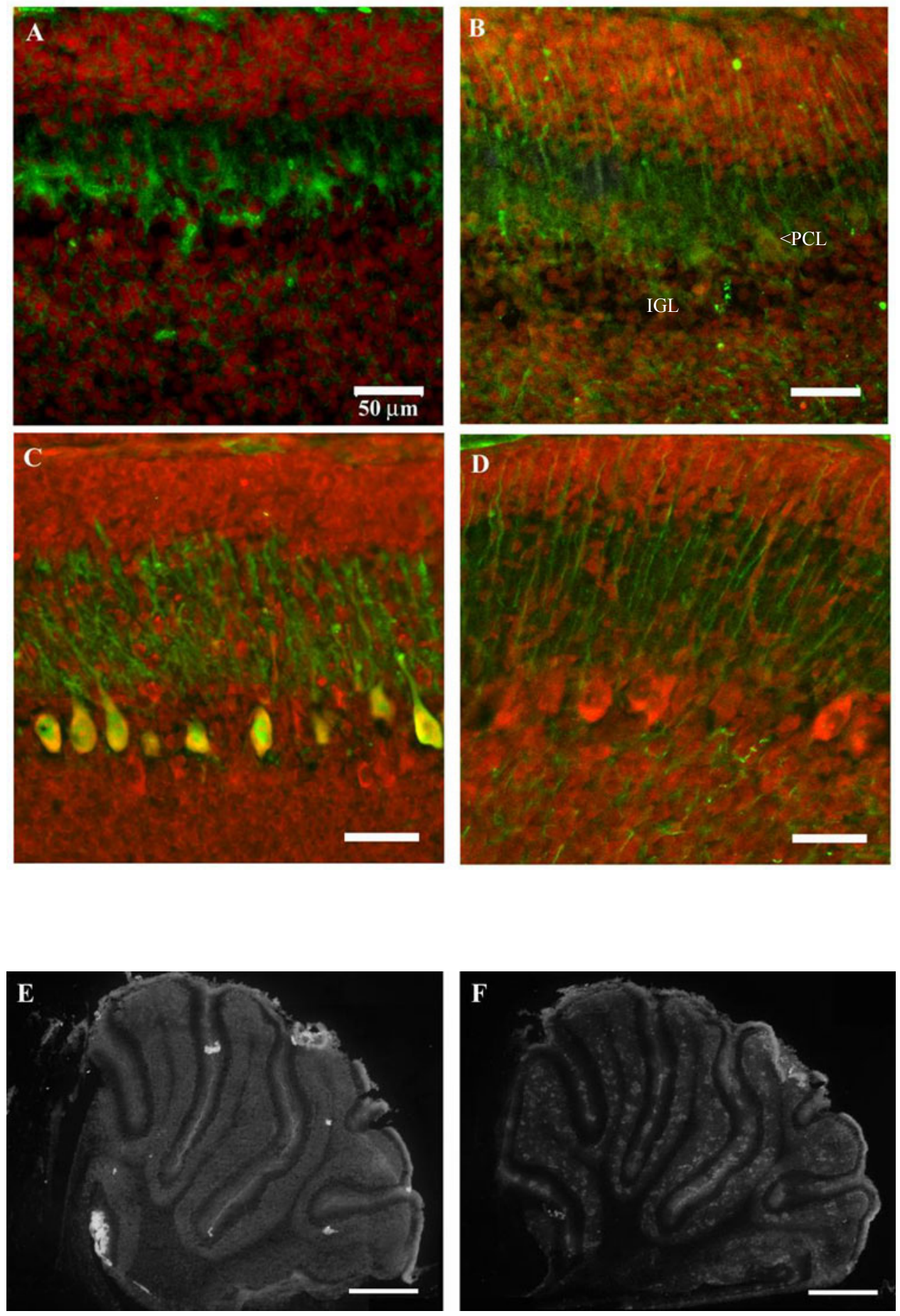
Figure 3.9 The effect of inhibitor treatment on the gelatinase activitity of MMP-2 and MMP9 in vitro. Slices in culture were exposed to SB-3CT for 24hrs, and the conditioned media was collected and assayed for MMP activity. (A) Shows the gelatinase activity in control slices. (B) Shows the gelatinase activity in treated slices from 1DIV, 4DIV, 7DIV and 10DIV. (C-G) show densitometric analysis for zymographic gels for 1DIV, 4DIV, 7DIV, and 10DIV (densitometry in arbitrary units; bars: \pm SEM) 
A

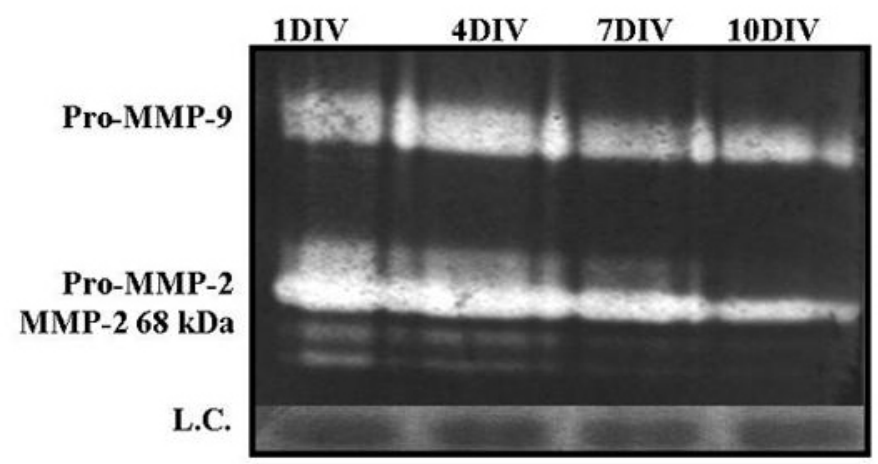

B
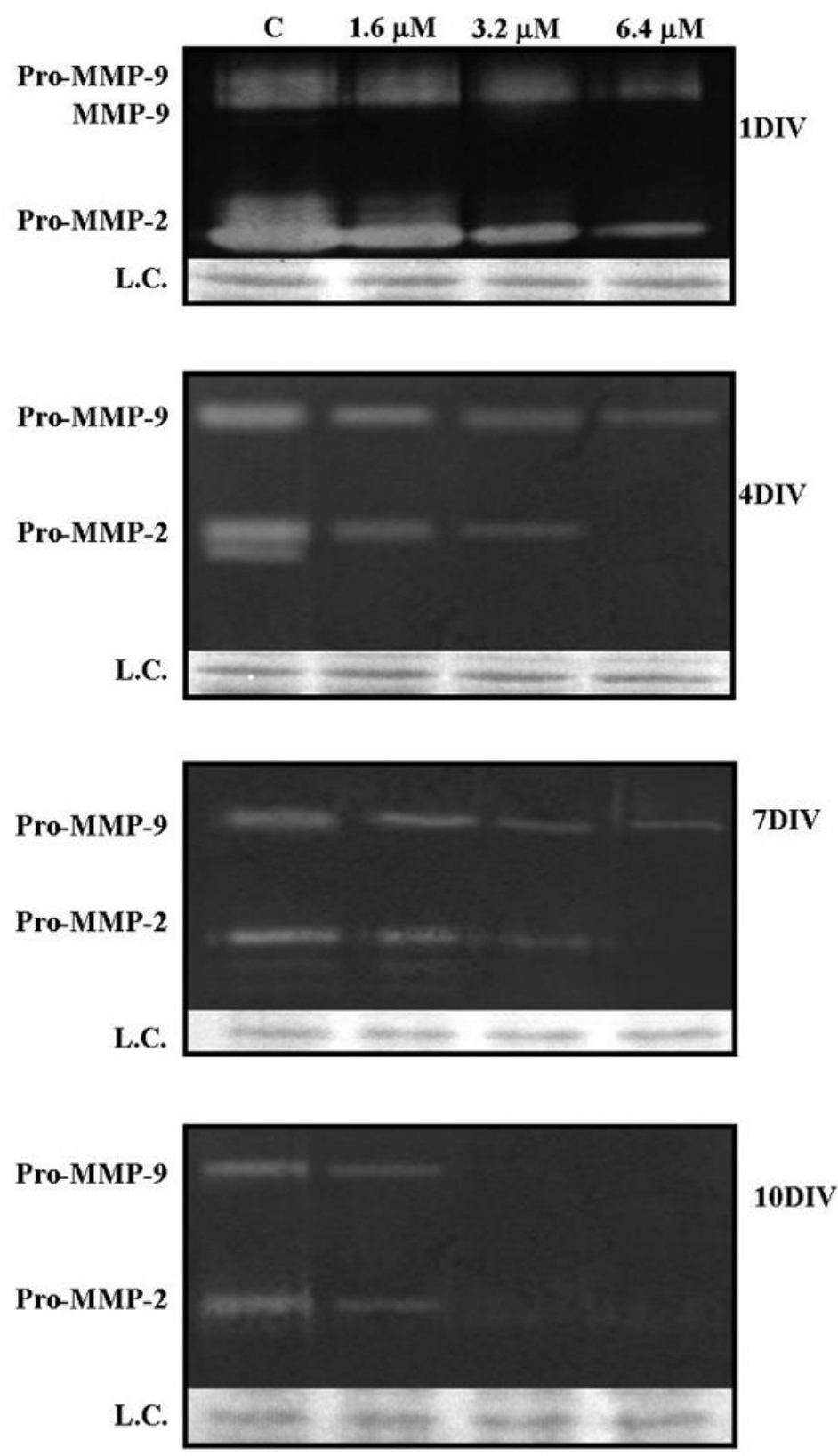
$\mathrm{C}$

Densitometric analysis for control slices

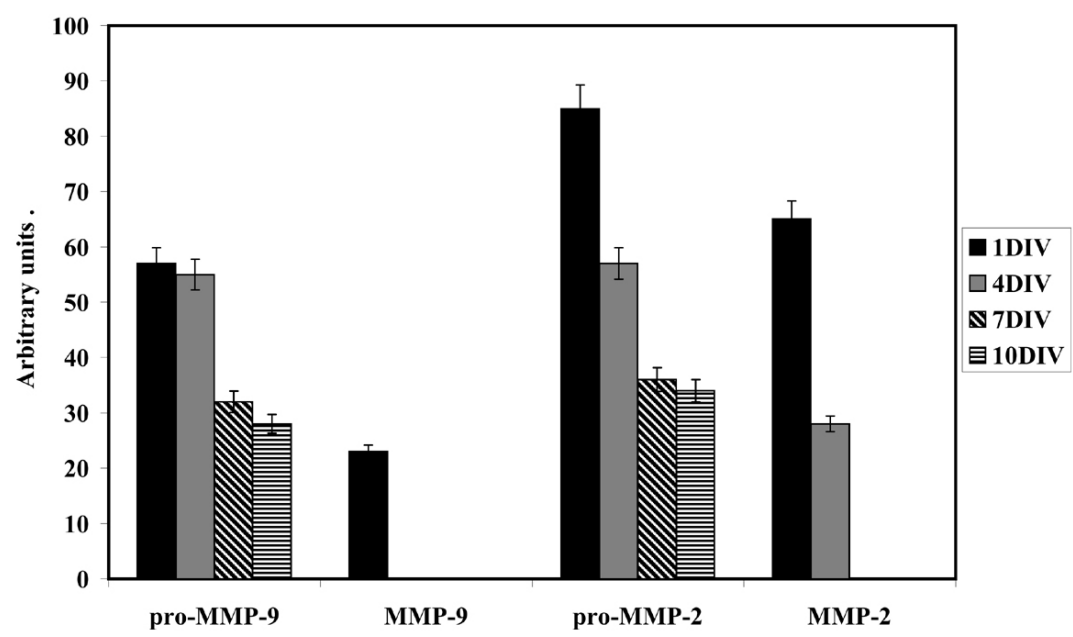

D

Densitometric analysis for 1DIV

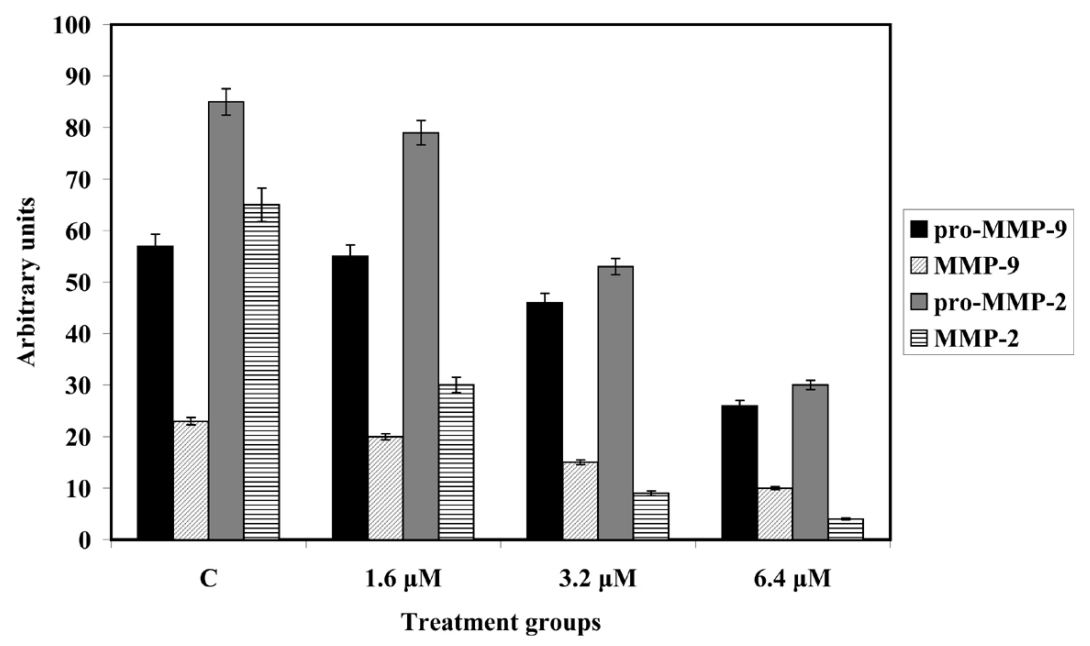


Densitometric analysis for $4 \mathrm{DIV}$

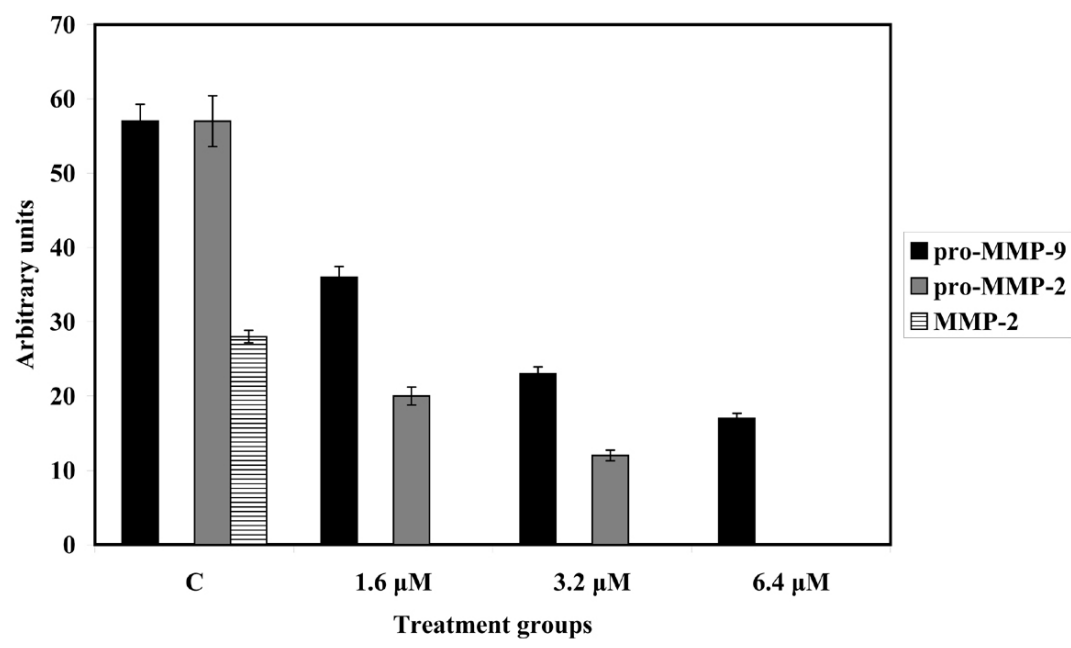

F

Densitometric Analysis for 7DIV

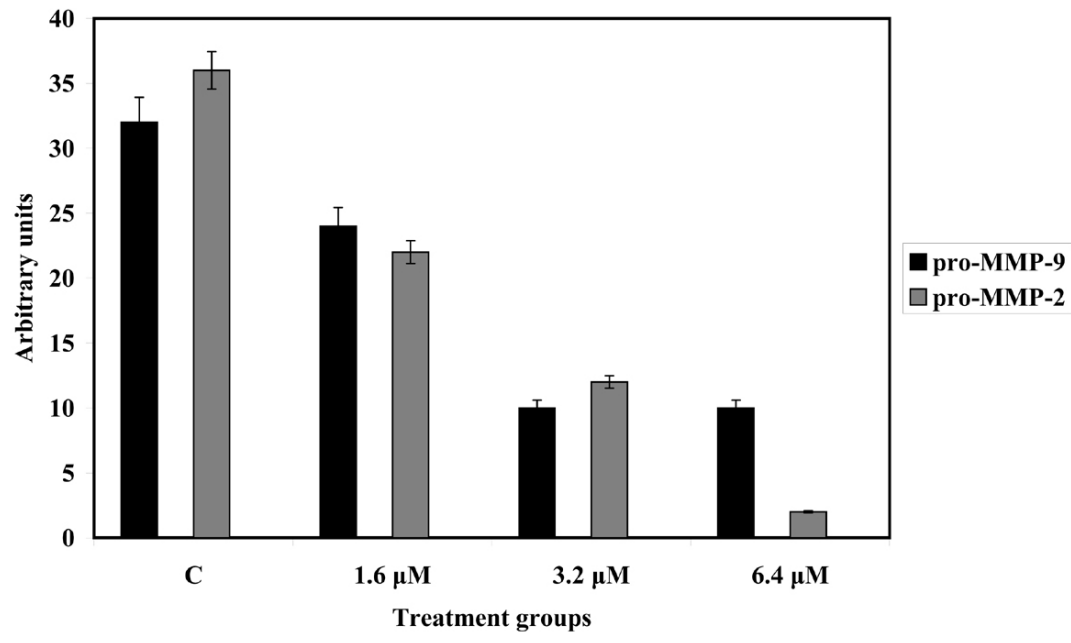


G

Densitometric analysis for 10DIV

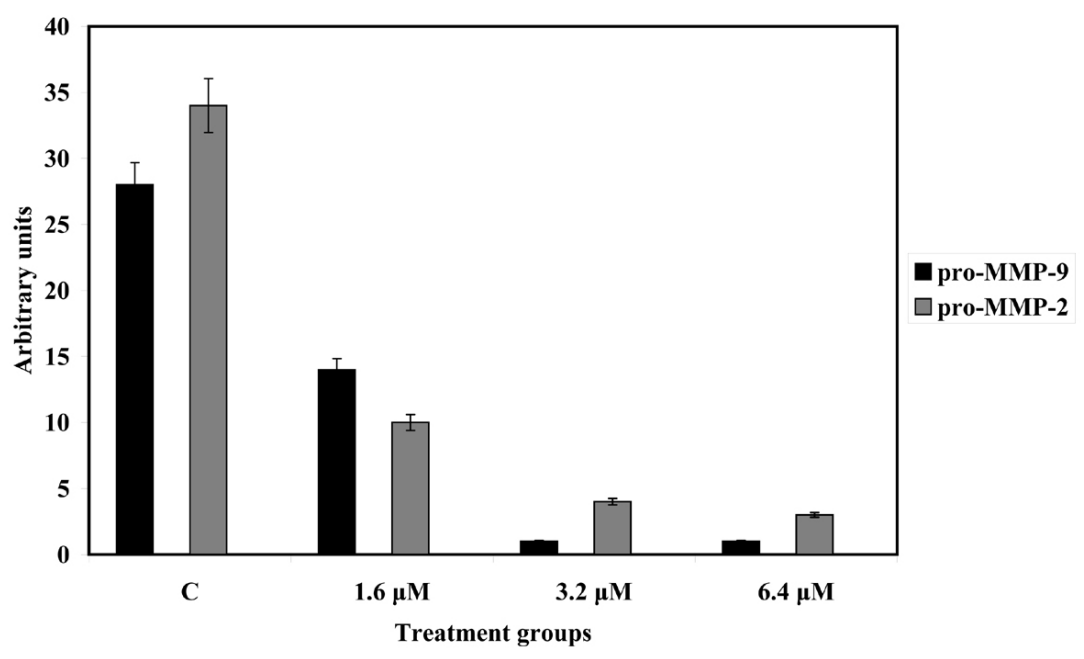




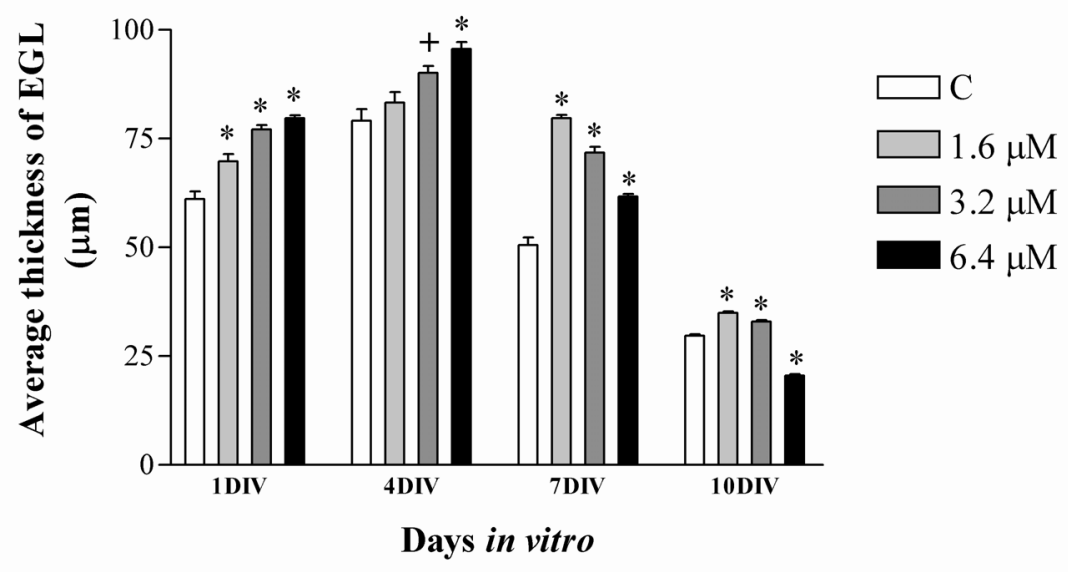

$\mathrm{B}$

Average number of migrating cells

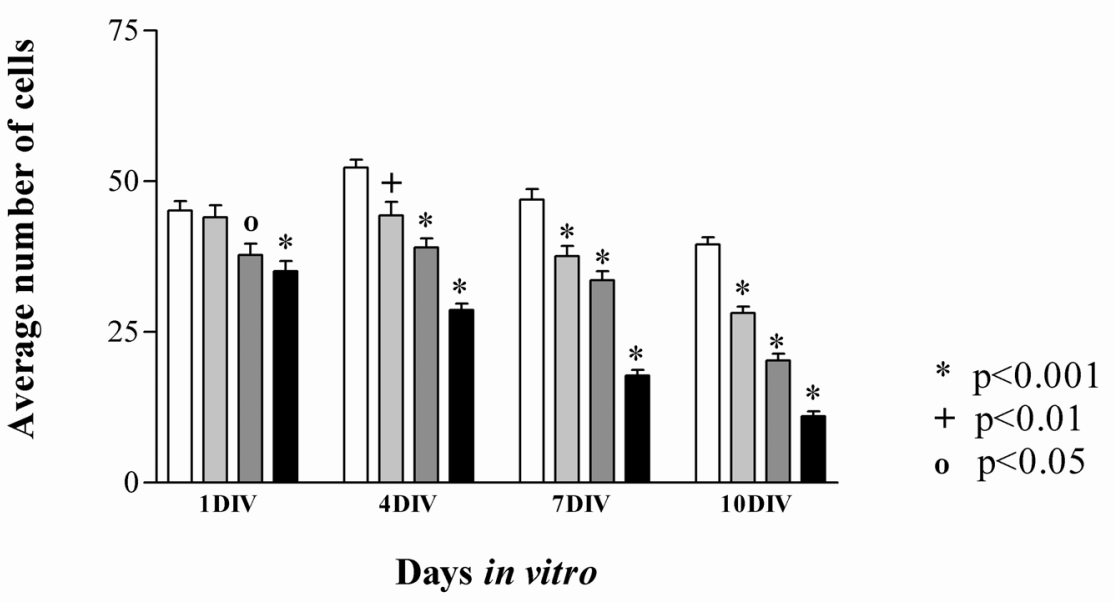

Figure 3.10 The effect of treatment with MMP-2/MMP-9 inhibitor on cerebellar corticogenesis. (A) Treatment with inhibitor caused an initial increase (1DIV and 4DIV), followed by a reduction in the thickness of the EGL. (B) The inhibitor reduced the number of migrating cells in the molecular layer in a dose-dependent manner. $(n=3 ; p$ values denote statistical difference from control samples). 


\section{Reference List}

Adams NC, Tomoda T, Cooper M, Dietz G, Hatten ME (2002) Mice that lack astrotactin have slowed neuronal migration. Development 129: 965-972.

Addison WH (1911) The development of the Purkinje cells and of the cortical layers in the cerebellum of the albino rat. J Comp Neurol 459-485.

Agapova OA, Ricard CS, Salvador-Silva M, Hernandez MR (2001) Expression of matrix metalloproteinases and tissue inhibitors of metalloproteinases in human optic nerve head astrocytes. Glia 33: 205-216.

Albo D, Shinohara T, Tuszynski GP (2002) Up-regulation of matrix metalloproteinase 9 by thrombospondin 1 in gastric cancer. J Surg Res 108: 51-60.

Alder J, Lee KJ, Jessell TM, Hatten ME (1999) Generation of cerebellar granule neurons in vivo by transplantation of BMP-treated neural progenitor cells. Nat Neurosci 2: 535540 .

Allan JA, Hembry RM, Angal S, Reynolds JJ, Murphy G (1991) Binding of latent and high $\mathrm{Mr}$ active forms of stromelysin to collagen is mediated by the $\mathrm{C}$-terminal domain. $\mathrm{J}$ Cell Sci 99: 789-795.

Altman J (1972a) Postnatal development of the cerebellar cortex in the rat. 3. Maturation of the components of the granular layer. J Comp Neurol 145: 465-513.

Altman J (1972b) Postnatal development of the cerebellar cortex in the rat. I. The external germinal layer and the transitional molecular layer. J Comp Neurol 145: 353397.

Altman J, Anderson WJ (1972) Experimental reorganization of the cerebellar cortex. I. Morphological effects of elimination of all microneurons with prolonged x-irradiation started at birth. J Comp Neurol 146: 355-406.

Altman J, Anderson WJ, Wright K (1969a) Reconstitution of the external granular layer of the cerebellar cortex in infant rats after low-level x-irradiation. Anat Rec 163: 453471.

Altman J, Anderson WJ, Wright KA (1969b) Early effects of x-irradiation of the cerebellum in infant rats: decimation and reconstitution of the external granular layer. Exp Neurol 24: 196-216.

Altman J, Bayer SA (1985) Embryonic development of the rat cerebellum. I. Delineation of the cerebellar primordium and early cell movements. J Comp Neurol 231: 1-26. 
Altman J, Bayer SA (1997) In: Development of the cerebellar system in relation to its evolution, structure, and function pp 2-66. New York: CRC Press.

Amenta F, Cavalotta D, Del Valle ME, Mancini M, Sabbatini M, Torres JM, Vega JA (1994) Calbindin D-28k immunoreactivity in the rat cerebellar cortex: age-related changes. Neurosci Lett 178: 131-134.

Angley C, Kumar M, Dinsio KJ, Hall AK, Siegel RE (2003) Signaling by bone morphogenetic proteins and Smad1 modulates the postnatal differentiation of cerebellar cells. J Neurosci 23: 260-268.

Antonio MT, Lopez N, Leret ML (2002) Pb and Cd poisoning during development alters cerebellar and striatal function in rats. Toxicology 176: 59-66.

Arber S, Caroni P (1995) Thrombospondin-4, an extracellular matrix protein expressed in the developing and adult nervous system promotes neurite outgrowth. J Cell Biol 131: 1083-1094.

Asahi M, Asahi K, Jung JC, del Zoppo GJ, Fini ME, Lo EH (2000) Role for matrix metalloproteinase 9 after focal cerebral ischemia: effects of gene knockout and enzyme inhibition with BB-94. J Cereb Blood Flow Metab 20: 1681-1689.

Asahi M, Wang X, Mori T, Sumii T, Jung JC, Moskowitz MA, Fini ME, Lo EH (2001) Effects of matrix metalloproteinase- 9 gene knock-out on the proteolysis of blood-brain barrier and white matter components after cerebral ischemia. J Neurosci 21: 7724-7732.

Asahina M, Yoshiyama Y, Hattori T (2001) Expression of matrix metalloproteinase-9 and urinary-type plasminogen activator in Alzheimer's disease brain. Clin Neuropathol 20: 60-63.

Aspberg A, Binkert C, Ruoslahti E (1995) The versican C-type lectin domain recognizes the adhesion protein tenascin-R. Proc Natl Acad Sci U S A 92: 10590-10594.

Athias (1897) Recherches sur l'histogénèse de l'écorce du cervelet. J Anat Physiol Norm Pathol 398.

Azeh I, Mader M, Smirnov A, Beuche W, Nau R, Weber F (1998) Experimental pneumococcal meningitis in rabbits: the increase of matrix metalloproteinase- 9 in cerebrospinal fluid correlates with leucocyte invasion. Neurosci Lett 256: 127-130.

Backstrom JR, Lim GP, Cullen MJ, Tokes ZA (1996) Matrix metalloproteinase-9 (MMP9) is synthesized in neurons of the human hippocampus and is capable of degrading the amyloid-beta peptide (1-40). J Neurosci 16: 7910-7919.

Bandtlow CE, Zimmermann DR (2000) Proteoglycans in the developing brain: new conceptual insights for old proteins. Physiol Rev 80: 1267-1290. 
Banyai L, Tordai H, Patthy L (1994) The gelatin-binding site of human $72 \mathrm{kDa}$ type IV collagenase (gelatinase A). Biochem J 298: 403-407.

Bartsch S, Bartsch U, Dorries U, Faissner A, Weller A, Ekblom P, Schachner M (1992) Expression of tenascin in the developing and adult cerebellar cortex. J Neurosci 12: 736749.

Baumgart E, Lenk SV, Loening SA, Jung K (2002) Tissue inhibitors of metalloproteinases 1 and 2 in human seminal plasma and their association with spermatozoa. Int J Androl 25: 369-371.

Becker JW, Marcy AI, Rokosz LL, Axel MG, Burbaum JJ, Fitzgerald PM, Cameron PM, Esser CK, Hagmann WK, Hermes JD, . (1995) Stromelysin-1: three-dimensional structure of the inhibited catalytic domain and of the C-truncated proenzyme. Protein Sci 4: 1966-1976.

Beliveau R, Delbecchi L, Beaulieu E, Mousseau N, Kachra Z, Berthelet F, Moumdjian R, Del Maestro R (1999) Expression of matrix metalloproteinases and their inhibitors in human brain tumors. Ann N Y Acad Sci 886: 236-239.

Bendszus M, Weijers HG, Wiesbeck G, Warmuth-Metz M, Bartsch AJ, Engels S, Boning J, Solymosi L (2001) Sequential MR imaging and proton MR spectroscopy in patients who underwent recent detoxification for chronic alcoholism: correlation with clinical and neuropsychological data. AJNR Am J Neuroradiol 22: 1926-1932.

Bignami A, Dahl D (1974) The development of Bergmann glia in mutant mice with cerebellar malformations: reeler, staggerer and weaver. Immunofluorescence study with antibodies to the glial fibrillary acidic protein. J Comp Neurol 155: 219-229.

Bignami A, Hosley M, Dahl D (1993a) Hyaluronic acid and hyaluronic acid-binding proteins in brain extracellular matrix. Anat Embryol (Berl) 188: 419-433.

Bignami A, Perides G, Rahemtulla F (1993b) Versican, a hyaluronate-binding proteoglycan of embryonal precartilaginous mesenchyma, is mainly expressed postnatally in rat brain. J Neurosci Res 34: 97-106.

Birkedal-Hansen H, Taylor RE (1982) Detergent-activation of latent collagenase and resolution of its component molecules. Biochem Biophys Res Commun 107: 1173-1178.

Bischof P, Meisser A, Campana A (2002) Control of MMP-9 expression at the maternalfetal interface. J Reprod Immunol 55: 3-10.

Bode W, Gomis-Ruth FX, Stockler W (1993) Astacins, serralysins, snake venom and matrix metalloproteinases exhibit identical zinc-binding environments

(HEXXHXXGXXH and Met-turn) and topologies and should be grouped into a common family, the 'metzincins'. FEBS Lett 331: 134-140. 
Bode W, Reinemer P, Huber R, Kleine T, Schnierer S, Tschesche H (1994) The X-ray crystal structure of the catalytic domain of human neutrophil collagenase inhibited by a substrate analogue reveals the essentials for catalysis and specificity. EMBO J 13: 12631269.

Bonthius DJ, Goodlett CR, West JR (1988) Blood alcohol concentration and severity of microencephaly in neonatal rats depend on the pattern of alcohol administration. Alcohol 5: 209-214.

Bonthius DJ, Karacay B, Dai D, Pantazis NJ (2003) FGF-2, NGF and IGF-1, but not BDNF, utilize a nitric oxide pathway to signal neurotrophic and neuroprotective effects against alcohol toxicity in cerebellar granule cell cultures. Brain Res Dev Brain Res 140: $15-28$.

Bonthius DJ, West JR (1988) Blood alcohol concentration and microencephaly: a doseresponse study in the neonatal rat. Teratology 37: 223-231.

Bord S, Horner A, Beeton CA, Hembry RM, Compston JE (1999) Tissue inhibitor of matrix metalloproteinase-1 (TIMP-1) distribution in normal and pathological human bone. Bone 24: 229-235.

Borghesani PR, Peyrin JM, Klein R, Rubin J, Carter AR, Schwartz PM, Luster A, Corfas G, Segal RA (2002) BDNF stimulates migration of cerebellar granule cells. Development 129: $1435-1442$.

Boutonnat J, Barbier M, Ronot X, Seigneurin D (2000) Nucleus labeling or membrane labeling for studying the proliferation of drug treated cells? Morphologie 84: 11-15.

Bradley P, Berry M (1978) The Purkinje cell dendritic tree in mutant mouse cerebellum. A quantitative Golgi study of Weaver and Staggerer mice. Brain Res 142: 135-141.

Brodie MS (2002) Increased ethanol excitation of dopaminergic neurons of the ventral tegmental area after chronic ethanol treatment. Alcohol Clin Exp Res 26: 1024-1030.

Brown S, Bernardo MM, Zhi-Hong L, Kotra LP, Tanaka Y, Fridman R, Mobashery S (2000) Potent and selective mechanism-based inhibition of gelatinases. J Am Chem Soc 122: 6799-6800.

Bruckner G, Grosche J (2001) Perineuronal nets show intrinsic patterns of extracellular matrix differentiation in organotypic slice cultures. Exp Brain Res 137: 83-93.

Buchman-Shaked O, Kraiem Z, Gonen Y, Goldman S (2002) Presence of matrix metalloproteinases and tissue inhibitor of matrix metalloproteinase in human sperm. J Androl 23: 702-708.

Buttery PC, ffrench-Constant C (2001) Process extension and myelin sheet formation in maturing oligodendrocytes. Prog Brain Res 132: 115-130. 
Cajal SR (1911) Histologie du system nerveux de l'homme et des vertebres. Vol 2: 66-86. Reprinted by Consejo Superior de Investigaciones Cientificas. Paris: Maloine.

Canete SR, Gui YH, Linask KK, Muschel RJ (1995) MMP-9 (gelatinase B) mRNA is expressed during mouse neurogenesis and may be associated with vascularization. Brain Res Dev Brain Res 88: 37-52.

Cao J, Drews M, Lee HM, Conner C, Bahou WF, Zucker S (1998) The propeptide domain of membrane type 1 matrix metalloproteinase is required for binding of tissue inhibitor of metalloproteinases and for activation of pro-gelatinase A. J Biol Chem 273: 34745-34752.

Carpenter MB (1991) The Cerebellum. In: Core Text of Neuroanatomy pp 224-249. Baltimore, MD: Williams \& Wilkins.

Carter AR, Chen C, Schwartz PM, Segal RA (2002) Brain-derived neurotrophic factor modulates cerebellar plasticity and synaptic ultrastructure. J Neurosci 22: 1316-1327.

Casasco A, Casasco M, Reguzzoni M, Calligaro A, Tateo S, Stetler-Stevenson WG, Liotta LA (1995) Occurrence and distribution of matrix metalloproteinase-2immunoreactivity in human embryonic tissues. Eur J Histochem 39: 31-38.

Castejon OJ (1990) Surface and membrane morphology of Bergmann glial cells and their topographic relationships in the cerebellar molecular layer. J Submicrosc Cytol Pathol 22: 123-134.

Castellanos M, Leira R, Serena J, Pumar JM, Lizasoain I, Castillo J, Davalos A (2003) Plasma metalloproteinase-9 concentration predicts hemorrhagic transformation in acute ischemic stroke. Stroke 34: 40-46.

Caviness VS, Jr., Rakic P (1978) Mechanisms of cortical development: a view from mutations in mice. Annu Rev Neurosci 1:297-326.

Chambaut-Guerin AM, Herigault S, Rouet-Benzineb P, Rouher C, Lafuma C (2000) Induction of matrix metalloproteinase MMP-9 (92-kDa gelatinase) by retinoic acid in human neuroblastoma SKNBE cells: relevance to neuronal differentiation. J Neurochem 74: 508-517.

Chandler S, Miller KM, Clements JM, Lury J, Corkill D, Anthony DC, Adams SE, Gearing AJ (1997) Matrix metalloproteinases, tumor necrosis factor and multiple sclerosis: an overview. J Neuroimmunol 72: 155-161.

Chen MS, Bermingham-McDonogh O, Danehy FT, Jr., Nolan C, Scherer SS, Lucas J, Gwynne D, Marchionni MA (1994) Expression of multiple neuregulin transcripts in postnatal rat brains. J Comp Neurol 349: 389-400. 
Chuong CM, Crossin KL, Edelman GM (1987) Sequential expression and differential function of multiple adhesion molecules during the formation of cerebellar cortical layers. J Cell Biol 104: 331-342.

Clark AW, Krekoski CA, Bou SS, Chapman KR, Edwards DR (1997) Increased gelatinase A (MMP-2) and gelatinase B (MMP-9) activities in human brain after focal ischemia. Neurosci Lett 238: 53-56.

Clark IM, Cawston TE (1989) Fragments of human fibroblast collagenase. Purification and characterization. Biochem J 263: 201-206.

Conant K, McArthur JC, Griffin DE, Sjulson L, Wahl LM, Irani DN (1999)

Cerebrospinal fluid levels of MMP-2, 7, and 9 are elevated in association with human immunodeficiency virus dementia. Ann Neurol 46: 391-398.

Condorelli DF, Dell'Albani P, Timmusk T, Mudo G, Belluardo N (1998) Differential regulation of BDNF and NT-3 mRNA levels in primary cultures of rat cerebellar neurons. Neurochem Int 32: 87-91.

Conradi NG (1985) Cerebellar foliation in rats. 1. Cortical changes preceding the formation of a fissure. Acta Pathol Microbiol Immunol Scand [A] 93: 385-389.

Costa S, Planchenault T, Charriere-Bertrand C, Mouchel Y, Fages C, Juliano S, Lefrancois T, Barlovatz-Meimon G, Tardy M (2002) Astroglial permissivity for neuritic outgrowth in neuron-astrocyte cocultures depends on regulation of laminin bioavailability. Glia 37: 105-113.

Crabbe T, Ioannou C, Docherty AJ (1993) Human progelatinase A can be activated by autolysis at a rate that is concentration-dependent and enhanced by heparin bound to the C-terminal domain. Eur J Biochem 218: 431-438.

Cragg B, Phillips S (1985) Natural loss of Purkinje cells during development and increased loss with alcohol. Brain Res 325: 151-160.

D'Arcangelo G, Nakajima K, Miyata T, Ogawa M, Mikoshiba K, Curran T (1997) Reelin is a secreted glycoprotein recognized by the CR-50 monoclonal antibody. J Neurosci 17: 23-31.

D'Mello SR, Galli C, Ciotti T, Calissano P (1993) Induction of apoptosis in cerebellar granule neurons by low potassium: inhibition of death by insulin-like growth factor I and cAMP. Proc Natl Acad Sci U S A 90: 10989-10993.

Dahl D, Bignami A (1973) Immunochemical and immunofluorescence studies of the glial fibrillary acidic protein in vertebrates. Brain Res 61:279-93.

Dahmane N, Altaba A (1999) Sonic hedgehog regulates the growth and patterning of the cerebellum. Development 126: 3089-3100. 
Damsky CH, Werb Z (1992) Signal transduction by integrin receptors for extracellular matrix: cooperative processing of extracellular information. Curr Opin Cell Biol 4: 772781.

Das GD (1976) Differentiation of Bergmann glia cells in the cerebellum: a golgi study. Brain Res 110: 199-213.

Das GD, Lammert GL, McAllister JP (1974) Contact guidance and migratory cells in the developing cerebellum. Brain Res 69: 13-29.

de Souza AP, Gerlach RF, Line SR (2000) Inhibition of human gingival gelatinases (MMP-2 and MMP-9) by metal salts. Dent Mater 16: 103-108.

DeFreitas MF, Yoshida CK, Frazier WA, Mendrick DL, Kypta RM, Reichardt LF (1995) Identification of integrin alpha 3 beta 1 as a neuronal thrombospondin receptor mediating neurite outgrowth. Neuron 15: 333-343.

Del Bigio MR, Tchelingerian JL, Jacque CM (1999) Expression of extracellular matrix degrading enzymes during migration of xenografted brain cells. Neuropathol Appl Neurobiol 25: 54-62.

Dhanaraj V, Ye QZ, Johnson LL, Hupe DJ, Ortwine DF, Dunbar JB, Jr., Rubin JR, Pavlovsky A, Humblet C, Blundell TL (1996) X-ray structure of a hydroxamate inhibitor complex of stromelysin catalytic domain and its comparison with members of the zinc metalloproteinase superfamily. Structure 4: 375-386.

Dieni S, Rees S (2002) Distribution of brain-derived neurotrophic factor and TrkB receptor proteins in the fetal and postnatal hippocampus and cerebellum of the guinea pig. J Comp Neurol 454: 229-240.

Dillon LS, Atkins DL (1970) Two unique features of the anterior cerebellum in the higher primates, including man. Anat Rec 168: 415-431.

Dino MR, Nunzi MG, Anelli R, Mugnaini E (2000a) Unipolar brush cells of the vestibulocerebellum: afferents and targets. Prog Brain Res 124:123-37.

Dino MR, Schuerger RJ, Liu Y, Slater NT, Mugnaini E (2000b) Unipolar brush cell: a potential feedforward excitatory interneuron of the cerebellum. Neuroscience 98: 625636.

Doughty ML, Delhaye-Bouchaud N, Mariani J (1998) Quantitative analysis of cerebellar lobulation in normal and agranular rats. J Comp Neurol 399: 306-320.

Dvergsten CL, Fosmire GJ, Ollerich DA, Sandstead HH (1983) Alterations in the postnatal development of the cerebellar cortex due to zinc deficiency. I. Impaired acquisition of granule cells. Brain Res 271: 217-226. 
Eberhardt W, Schulze M, Engels C, Klasmeier E, Pfeilschifter J (2002) Glucocorticoidmediated suppression of cytokine-induced matrix metalloproteinase-9 expression in rat mesangial cells: involvement of nuclear factor-kappaB and Ets transcription factors. Mol Endocrinol 16: 1752-1766.

Eccles JC (1967) Circuits in the cerebellar control of movement. Proc Natl Acad Sci U S A 58: 336-343.

Eccles JC, Sasaki K, Strata P (1967) A comparison of the inhibitory actions of golgi cells and of basket cells. Exp Brain Res 3: 81-94.

Edmondson JC, Hatten ME (1987) Glial-guided granule neuron migration in vitro: a high-resolution time-lapse video microscopic study. J Neurosci 7: 1928-1934.

Eliceiri BP (2001) Integrin and growth factor receptor crosstalk. Circ Res 89: 1104-1110.

Felici L, Bronzetti E, Amenta F (1989) Enzyme histochemistry of glutamate dehydrogenase in ageing rat cerebellar cortex. Mech Ageing Dev 47: 199-205.

Ferguson SA (1996) Neuroanatomical and functional alterations resulting from early postnatal cerebellar insults in rodents. Pharmacol Biochem Behav 55: 663-671.

Ferguson TA, Muir D (2000) MMP-2 and MMP-9 increase the neurite-promoting potential of schwann cell basal laminae and are upregulated in degenerated nerve. Mol Cell Neurosci 16: 157-167.

Fillmore HL, VanMeter TE, Broaddus WC (2001) Membrane-type matrix metalloproteinases (MT-MMPs): expression and function during glioma invasion. $\mathrm{J}$ Neurooncol 53: 187-202.

Fingleton B (2003) Matrix metalloproteinase inhibitors for cancer therapy:the current situation and future prospects. Expert Opin Ther Targets 7: 385-397.

Fishell G, Hatten ME (1991) Astrotactin provides a receptor system for CNS neuronal migration. Development 113: 755-765.

Fisher KE, Fei Q, Laird ER, Stock JL, Allen MR, Sahagan BG, Strick CA (2002) Engineering autoactivating forms of matrix metalloproteinase- 9 and expression of the active enzyme in cultured cells and transgenic mouse brain. Biochemistry 41: 8289-8297.

Fourie AM, Coles F, Moreno V, Karlsson L (2003) Catalytic activity of ADAM8, ADAM15 and MDC-L (ADAM28) on synthetic peptide substrates, and in ectodomain cleavage of CD23. J Biol Chem 278: 30469-30477.

Freimark BD, Feeser WS, Rosenfeld SA (1994) Multiple sites of the propeptide region of human stromelysin-1 are required for maintaining a latent form of the enzyme. J Biol Chem 269: 26982-26987. 
Fridman R, Toth M, Pena D, Mobashery S (1995) Activation of progelatinase B (MMP9) by gelatinase A (MMP-2). Cancer Res 55: 2548-2555.

Friedberg MH, Glantz MJ, Klempner MS, Cole BF, Perides G (1998) Specific matrix metalloproteinase profiles in the cerebrospinal fluid correlated with the presence of malignant astrocytomas, brain metastases, and carcinomatous meningitis. Cancer 82: 923-930.

Frolichsthal-Schoeller P, Vescovi AL, Krekoski CA, Murphy G, Edwards DR, Forsyth P (1999) Expression and modulation of matrix metalloproteinase-2 and tissue inhibitors of metalloproteinases in human embryonic CNS stem cells. Neuroreport 10: 345-351.

Fujimura M, Gasche Y, Morita-Fujimura Y, Massengale J, Kawase M, Chan PH (1999) Early appearance of activated matrix metalloproteinase- 9 and blood-brain barrier disruption in mice after focal cerebral ischemia and reperfusion. Brain Res 842: 92-100.

Furuya M, Ishikura H, Ogawa Y, Kawarada Y, Shibata M, Fujimoto S, Yoshiki T (2000) Analyses of matrix metalloproteinases and their inhibitors in cyst fluid of serous ovarian tumors. Pathobiology 68: 239-244.

Ghorpade A, Persidskaia R, Suryadevara R, Che M, Liu XJ, Persidsky Y, Gendelman HE (2001) Mononuclear phagocyte differentiation, activation, and viral infection regulate matrix metalloproteinase expression: implications for human immunodeficiency virus type 1-associated dementia. J Virol 75: 6572-6583.

Gilbertson RJ, Clifford SC, MacMeekin W, Meekin W, Wright C, Perry RH, Kelly P, Pearson AD, Lunec J (1998) Expression of the ErbB-neuregulin signaling network during human cerebellar development: implications for the biology of medulloblastoma. Cancer Res 58: 3932-3941.

Gilthorpe JD, Papantoniou EK, Chedotal A, Lumsden A, Wingate RJ (2002) The migration of cerebellar rhombic lip derivatives. Development 129: 4719-4728.

Glickstein M, Voogd J (1995) Lodewijk Bolk and the comparative anatomy of the cerebellum. Trends Neurosci 18: 206-210.

Goffinet AM (1990) Determinants of nerve cell patterns during development: a review. Eur J Morphol 28: 149-168.

Gokaslan ZL, Chintala SK, York JE, Boyapati V, Jasti S, Sawaya R, Fuller G, Wildrick DM, Nicolson GL, Rao JS (1998) Expression and role of matrix metalloproteinases MMP-2 and MMP-9 in human spinal column tumors. Clin Exp Metastasis 16: 721-728.

Goldberg GI, Strongin A, Collier IE, Genrich LT, Marmer BL (1992) Interaction of 92$\mathrm{kDa}$ type IV collagenase with the tissue inhibitor of metalloproteinases prevents dimerization, complex formation with interstitial collagenase, and activation of the proenzyme with stromelysin. J Biol Chem 267: 4583-4591. 
Goldowitz D, Hamre K (1998) The cells and molecules that make a cerebellum. Trends Neurosci 21: 375-382.

Gregory WA, Edmondson JC, Hatten ME, Mason CA (1988) Cytology and neuron-glial apposition of migrating cerebellar granule cells in vitro. J Neurosci 8: 1728-1738.

Grumet M, Hoffman S, Crossin KL, Edelman GM (1985) Cytotactin, an extracellular matrix protein of neural and non-neural tissues that mediates glia-neuron interaction. Proc Natl Acad Sci U S A 82: 8075-8079.

Gveric D, Hanemaaijer R, Newcombe J, van Lent NA, Sier CF, Cuzner ML (2001) Plasminogen activators in multiple sclerosis lesions: implications for the inflammatory response and axonal damage. Brain 124: 1978-1988.

Hackethal H (1971) [Simple structures in the cerebellar corpus of placental mammals]. J Hirnforsch 13: 279-290.

Hager G, Dodt HU, Zieglgansberger W, Liesi P (1995) Novel forms of neuronal migration in the rat cerebellum. J Neurosci Res 40: 207-219.

Hah N, Lee ST (2003) An absolute role of the PKC-dependent NF-kappaB activation for induction of MMP-9 in hepatocellular carcinoma cells. Biochem Biophys Res Commun 305: 428-433.

Hall MC, Young DA, Waters JG, Rowan AD, Chantry A, Edwards DR, Clark IM (2003) The comparative role of activator protein 1 and Smad factors in the regulation of Timp-1 and MMP-1 gene expression by transforming growth factor-beta 1. J Biol Chem 278: 10304-10313.

Hamano K, Takeya T, Iwasaki N, Nakayama J, Ohto T, Okada Y (1998) A quantitative study of the progress of myelination in the rat central nervous system, using the immunohistochemical method for proteolipid protein. Brain Res Dev Brain Res 108: 287293.

Han VZ, Bell CC (2002) Cell morphology and local circuitry of the central lobes of the mormyrid cerebellum. Ann N Y Acad Sci 978: 515-516.

Han YP, Tuan TL, Hughes M, Wu H, Garner WL (2001) Transforming growth factorbeta - and tumor necrosis factor-alpha -mediated induction and proteolytic activation of MMP-9 in human skin. J Biol Chem 276: 22341-22350.

Hanaway J (1967) Formation and differentiation of the external granule layer of the cerebellum. J Comp Neurol 1-14.

Hatten M (1990) Riding the glial monorail: a common mechanism for glial-guided neuronal migration in different regions of the developing brain. Trends Neurosci 179184. 
Hatten ME (1984) Embryonic cerebellar astroglia in vitro. Brain Res 315: 309-313.

Hausmann B, Mangold U, Sievers J, Berry M (1985) Derivation of cerebellar Golgi neurons from the external granular layer: evidence from explantation of external granule cells in vivo. J Comp Neurol 232: 511-522.

Hausmann B, Sievers J (1985) Cerebellar external granule cells are attached to the basal lamina from the onset of migration up to the end of their proliferative activity. J Comp Neurol 241: 50-62.

Hayashita-Kinoh H, Kinoh H, Okada A, Komori K, Itoh Y, Chiba T, Kajita M, Yana I, Seiki M (2001) Membrane-type 5 matrix metalloproteinase is expressed in differentiated neurons and regulates axonal growth. Cell Growth Differ 12: 573-580.

Haydar TF, Bambrick LL, Krueger BK, Rakic P (1999) Organotypic slice cultures for analysis of proliferation, cell death, and migration in the embryonic neocortex. Brain Res Brain Res Protoc 4: 425-437.

Hayle TH (1973) A comparative study of spinocerebellar systems in three classes of poikilothermic vertebrates. J Comp Neurol 149: 477-496.

Heckroth JA, Goldowitz D, Eisenman LM (1989) Purkinje cell reduction in the reeler mutant mouse: a quantitative immunohistochemical study. J Comp Neurol 279: 546-555.

Heo JH, Lucero J, Abumiya T, Koziol JA, Copeland BR, del Zoppo GJ (1999) Matrix metalloproteinases increase very early during experimental focal cerebral ischemia. $\mathrm{J}$ Cereb Blood Flow Metab 19: 624-633.

Hoffman S, Crossin KL, Edelman GM (1988) Molecular forms, binding functions, and developmental expression patterns of cytotactin and cytotactin-binding proteoglycan, an interactive pair of extracellular matrix molecules. J Cell Biol 106: 519-532.

Hofmann UB, Westphal JR, Van Kraats AA, Ruiter DJ, Van Muijen GN (2000a) Expression of integrin alpha(v)beta(3) correlates with activation of membrane-type matrix metalloproteinase-1 (MT1-MMP) and matrix metalloproteinase-2 (MMP-2) in human melanoma cells in vitro and in vivo. Int J Cancer 87: 12-19.

Hofmann UB, Westphal JR, Waas ET, Becker JC, Ruiter DJ, Van Muijen GN (2000b) Coexpression of integrin alpha(v)beta3 and matrix metalloproteinase-2 (MMP-2) coincides with MMP-2 activation: correlation with melanoma progression. J Invest Dermatol 115: 625-632.

Hopker VH, Shewan D, Tessier-Lavigne M, Poo M, Holt C (1999) Growth-cone attraction to netrin-1 is converted to repulsion by laminin-1. Nature 401: 69-73.

Howard JD, Mottet NK (1986) Effects of methylmercury on the morphogenesis of the rat cerebellum. Teratology 34: 89-95. 
Howell BW, Hawkes R, Soriano P, Cooper JA (1997) Neuronal position in the developing brain is regulated by mouse disabled-1. Nature 389: 733-737.

Huang X, Huang P, Robinson MK, Stern MJ, Jin Y (2003) UNC-71, a disintegrin and metalloprotease (ADAM) protein, regulates motor axon guidance and sex myoblast migration in C. elegans. Development 130: 3147-3161.

Hughes PM, Wells GM, Perry VH, Brown MC, Miller KM (2002) Comparison of matrix metalloproteinase expression during Wallerian degeneration in the central and peripheral nervous systems. Neuroscience 113: 273-287.

Hunter DJ, Spector TD (2003) The role of bone metabolism in osteoarthritis. Curr Rheumatol Rep 5: 15-19.

Huppertz B, Kertschanska S, Demir AY, Frank HG, Kaufmann P (1998) Immunohistochemistry of matrix metalloproteinases (MMP), their substrates, and their inhibitors (TIMP) during trophoblast invasion in the human placenta. Cell Tissue Res 291: 133-148.

Hussain S, Assender JW, Bond M, Wong LF, Murphy D, Newby AC (2002) Activation of protein kinase Czeta is essential for cytokine-induced metalloproteinase-1, -3, and -9 secretion from rabbit smooth muscle cells and inhibits proliferation. J Biol Chem 277: $27345-27352$.

Iino M, Goto K, Kakegawa W, Okado H, Sudo M, Ishiuchi S, Miwa A, Takayasu Y, Saito I, Tsuzuki K, Ozawa S (2001) Glia-synapse interaction through Ca2+-permeable AMPA receptors in Bergmann glia. Science 292: 926-929.

Illman SA, Keski-Oja J, Lohi J (2001) Promoter characterization of the human and mouse epilysin (MMP-28) genes. Gene 275: 185-194.

Imai K, Yokohama Y, Nakanishi I, Ohuchi E, Fujii Y, Nakai N, Okada Y (1995) Matrix metalloproteinase 7 (matrilysin) from human rectal carcinoma cells. Activation of the precursor, interaction with other matrix metalloproteinases and enzymic properties. J Biol Chem 270: 6691-6697.

Ito M (1968) The neuronal mechanism of the cerebellar efferent system. Proc Aust Assoc Neurol 5: 13-18.

Itoh Y, Nagase H (1995) Preferential inactivation of tissue inhibitor of metalloproteinases-1 that is bound to the precursor of matrix metalloproteinase 9 (progelatinase B) by human neutrophil elastase. J Biol Chem 270: 16518-16521.

Jacobson M (1991) Histogenesis and Morphogenesis of Cortical Structures. In: Developmental Neurobiology Plenum Pub Corp.

Jansen J (1972) Features of cerebellar morphology and organization. Acta Neurol Scand Suppl 51: 197-217. 
Jiang A, Lehti K, Wang X, Weiss SJ, Keski-Oja J, Pei D (2001) Regulation of membrane-type matrix metalloproteinase 1 activity by dynamin-mediated endocytosis. Proc Natl Acad Sci U S A 98: 13693-13698.

Jin X, Mathers PH, Szabo G, Katarova Z, Agmon A (2001) Vertical bias in dendritic trees of non-pyramidal neocortical neurons expressing GAD67-GFP in vitro. Cereb Cortex 11: 666-678.

Kanan CV (1973) The external configuration of the cerebral hemispheres of the camel (Camelus dromedarius). Acta Anat (Basel) 85: 145-152.

Kandel ER, Schwartz JH, Jessel TM (2000) The Cerebellum. In: Principles of Neural Science (Kandel ER, Schwartz JH, Jessel TM, eds), pp 832-852. McGraw-Hill/Appleton \& Lange.

Kanwar YS, Ota K, Yang Q, Wada J, Kashihara N, Tian Y, Wallner EI (1999) Role of membrane-type matrix metalloproteinase 1 (MT-1-MMP), MMP-2, and its inhibitor in nephrogenesis. Am J Physiol 277: F934-F947.

Katsuhiko M, Hideyuki O, Yasuzo T (1984) [Development of the cerebellum and its abnormalities]. Tanpakushitsu Kakusan Koso 29: 1633-1658.

Khuth ST, Akaoka H, Pagenstecher A, Verlaeten O, Belin MF, Giraudon P, Bernard A (2001) Morbillivirus infection of the mouse central nervous system induces regionspecific upregulation of MMPs and TIMPs correlated to inflammatory cytokine expression. J Virol 75: 8268-8282.

Kleifeld O, Kotra LP, Gervasi DC, Brown S, Bernardo MM, Fridman R, Mobashery S, Sagi I (2001) X-ray absorption studies of human matrix metalloproteinase-2 (MMP-2) bound to a highly selective mechanism-based inhibitor. comparison with the latent and active forms of the enzyme. J Biol Chem 276: 17125-17131.

Knauper V, Smith B, Lopez-Otin C, Murphy G (1997) Activation of progelatinase B (proMMP-9) by active collagenase-3 (MMP-13). Eur J Biochem 248: 369-373.

Komuro H, Rakic P (1995) Dynamics of granule cell migration: a confocal microscopic study in acute cerebellar slice preparations. J Neurosci 15: 1110-1120.

Komuro H, Rakic P (1998) Distinct modes of neuronal migration in different domains of developing cerebellar cortex. J Neurosci 18: 1478-1490.

Komuro H, Yacubova E, Yacubova E, Rakic P (2001) Mode and tempo of tangential cell migration in the cerebellar external granular layer. J Neurosci 21: 527-540.

Korneliussen HK (1967) Cerebellar corticogenesis in Cetaca, with special reference to regional variations. J Hirnforsch 9: 151-185. 
Korneliussen HK (1968) On the morphology and subdivision of the cerebellar nuclei of the rat. J Hirnforsch 10: 109-122.

Kunimoto M, Suzuki T (1997) Migration of granule neurons in cerebellar organotypic cultures is impaired by methylmercury. Neurosci Lett 226: 183-186.

Laine J, Axelrad H (1998) Lugaro cells target basket and stellate cells in the cerebellar cortex. Neuroreport 9: 2399-2403.

Lampert K, Machein U, Machein MR, Conca W, Peter HH, Volk B (1998) Expression of matrix metalloproteinases and their tissue inhibitors in human brain tumors. Am J Pathol 153: 429-437.

Landis DM, Landis SC (1978) Several mutations in mice that affect the cerebellum. Adv Neurol 21: 85-105.

Lange W (1971) [Comparative studies on the cerebellum of man, the elephant and certain toothed whales]. Verh Anat Ges 65: 137-138.

Lange W (1972) [Regional differences in cytoarchitectonics of the cerebellar cortex in man, rhesus monkey and cat]. Z Anat Entwicklungsgesch 138: 329-346.

Lapchak PA, Chapman DF, Zivin JA (2000) Metalloproteinase inhibition reduces thrombolytic (tissue plasminogen activator)-induced hemorrhage after thromboembolic stroke. Stroke 31: 3034-3040.

Leake A, Morris CM, Whateley J (2000) Brain matrix metalloproteinase 1 levels are elevated in Alzheimer's disease. Neurosci Lett 291: 201-203.

Lee MA, Palace J, Stabler G, Ford J, Gearing A, Miller K (1999) Serum gelatinase B, TIMP-1 and TIMP-2 levels in multiple sclerosis. A longitudinal clinical and MRI study. Brain 122 ( Pt 2): 191-197.

Leib SL, Leppert D, Clements J, Tauber MG (2000) Matrix metalloproteinases contribute to brain damage in experimental pneumococcal meningitis. Infect Immun 68: 615-620.

Letourneau PC, Condic ML, Snow DM (1992) Extracellular matrix and neurite outgrowth. Curr Opin Genet Dev 2: 625-634.

Levitt P, Rakic P (1980) Immunoperoxidase localization of glial fibrillary acidic protein in radial glial cells and astrocytes of the developing rhesus monkey brain. J Comp Neurol 193: 815-840.

Li J, Brick P, O'Hare MC, Skarzynski T, Lloyd LF, Curry VA, Clark IM, Bigg HF, Hazleman BL, Cawston TE, . (1995) Structure of full-length porcine synovial collagenase reveals a $\mathrm{C}$-terminal domain containing a calcium-linked, four-bladed beta-propeller. Structure 3: 541-549. 
Li Z, Lin H, Zhu Y, Wang M, Luo J (2001) Disruption of cell cycle kinetics and cyclindependent kinase system by ethanol in cultured cerebellar granule progenitors. Brain Res Dev Brain Res 132: 47-58.

Libson AM, Gittis AG, Collier IE, Marmer BL, Goldberg GI, Lattman EE (1995) Crystal structure of the haemopexin-like C-terminal domain of gelatinase A. Nat Struct Biol 2: 938-942.

Liesi P, Hager G, Dodt HU, Seppala I, Zieglgansberger W (1995) Domain-specific antibodies against the $\mathrm{B} 2$ chain of laminin inhibit neuronal migration in the neonatal rat cerebellum. J Neurosci Res 40: 199-206.

Lim GP, Russell MJ, Cullen MJ, Tokes ZA (1997) Matrix metalloproteinases in dog brains exhibiting Alzheimer-like characteristics. J Neurochem 68: 1606-1611.

Limb GA, Daniels JT, Pleass R, Charteris DG, Luthert PJ, Khaw PT (2002) Differential expression of matrix metalloproteinases 2 and 9 by glial Muller cells: response to soluble and extracellular matrix-bound tumor necrosis factor-alpha. Am J Pathol 160: 1847-1855.

Liuzzi GM, Mastroianni CM, Santacroce MP, Fanelli M, D'Agostino C, Vullo V, Riccio $P$ (2000) Increased activity of matrix metalloproteinases in the cerebrospinal fluid of patients with HIV-associated neurological diseases. J Neurovirol 6: 156-163.

Llano E, Pendas AM, Aza-Blanc P, Kornberg TB, Lopez-Otin C (2000) Dm1-MMP, a matrix metalloproteinase from Drosophila with a potential role in extracellular matrix remodeling during neural development. J Biol Chem 275: 35978-35985.

Llano E, Pendas AM, Freije JP, Nakano A, Knauper V, Murphy G, Lopez-Otin C (1999) Identification and characterization of human MT5-MMP, a new membrane-bound activator of progelatinase a overexpressed in brain tumors. Cancer Res 59: 2570-2576.

Llinas R, Hillman DE, Precht W (1973) Neuronal circuit reorganization in mammalian agranular cerebellar cortex. J Neurobiol 4: 69-94.

Loeb JA, Fischbach GD (1995) ARIA can be released from extracellular matrix through cleavage of a heparin-binding domain. J Cell Biol 130: 127-135.

Lorton D, Anderson WJ (1986) The effects of postnatal lead toxicity on the development of cerebellum in rats. Neurobehav Toxicol Teratol 8: 51-59.

Lowry CL, McGeehan G, LeVine H, III (1992) Metal ion stabilization of the conformation of a recombinant 19-kDa catalytic fragment of human fibroblast collagenase. Proteins 12: 42-48.

Luo J, Lindstrom CL, Donahue A, Miller MW (2001) Differential effects of ethanol on the expression of cyclo-oxygenase in cultured cortical astrocytes and neurons. $\mathrm{J}$

Neurochem 76: 1354-1363. 
Lyon G, Raymond G, Mogami K, Gadisseux JF, Della GE (1993) Disorder of cerebellar foliation in Walker's lissencephaly and neu-laxova syndrome. J Neuropathol Exp Neurol 52: 633-639.

Maisonpierre PC, Belluscio L, Friedman B, Alderson RF, Wiegand SJ, Furth ME, Lindsay RM, Yancopoulos GD (1990) NT-3, BDNF, and NGF in the developing rat nervous system: parallel as well as reciprocal patterns of expression. Neuron 5: 501-509.

Makowski GS, Ramsby ML (1998) Binding of latent matrix metalloproteinase 9 to fibrin: activation via a plasmin-dependent pathway. Inflammation 22: 287-305.

Maquoi E, Frankenne F, Baramova E, Munaut C, Sounni NE, Remacle A, Noel A, Murphy G, Foidart JM (2000) Membrane type 1 matrix metalloproteinase-associated degradation of tissue inhibitor of metalloproteinase 2 in human tumor cell lines. J Biol Chem 275: 11368-11378.

Maquoi E, Munaut C, Colige A, Lambert C, Frankenne F, Noel A, Grams F, Krell HW, Foidart JM (2002) Stimulation of matrix metalloproteinase-9 expression in human fibrosarcoma cells by synthetic matrix metalloproteinase inhibitors. Exp Cell Res 275: $110-121$.

Marchenko GN, Ratnikov BI, Rozanov DV, Godzik A, Deryugina EI, Strongin AY (2001) Characterization of matrix metalloproteinase-26, a novel metalloproteinase widely expressed in cancer cells of epithelial origin. Biochem J 356: 705-718.

Marder G, Greenwald RA (2003) Potential applications of matrix metalloproteinase inhibitors in geriatric practice. Isr Med Assoc J 5: 361-364.

Martin KH, Slack JK, Boerner SA, Martin CC, Parsons JT (2002) Integrin connections map: to infinity and beyond. Science 296: 1652-1653.

Matsuura E, Umehara F, Hashiguchi T, Fujimoto N, Okada Y, Osame M (2000) Marked increase of matrix metalloproteinase 9 in cerebrospinal fluid of patients with fungal or tuberculous meningoencephalitis. J Neurol Sci 173: 45-52.

Melik-Musyan AB, Fanardzhyan VV (1998) Histological identification of Lugaro cells in the cat cerebellum. Neurosci Behav Physiol 28: 486-489.

Mendis DB, Shahin S, Gurd JW, Brown IR (1994) Developmental expression in the rat cerebellum of $\mathrm{SC}$, a putative brain extracellular matrix glycoprotein related to SPARC. Brain Res 633: 197-205.

Miale I, Sidman R (1961) An autoradiographic analysis of histogenesis in the mouse cerebellum. Exp Neurol 227-296.

Milev P, Meyer-Puttlitz B, Margolis RK, Margolis RU (1995) Complex-type asparaginelinked oligosaccharides on phosphacan and protein-tyrosine phosphatase-zeta/beta 
mediate their binding to neural cell adhesion molecules and tenascin. J Biol Chem 270: 24650-24653.

Millen KJ, Millonig JH, Wingate RJ, Alder J, Hatten ME (1999) Neurogenetics of the cerebellar system. J Child Neurol 14: 574-581.

Mills J, Digicaylioglu M, Legg AT, Young CE, Young SS, Barr AM, Fletcher L, O'Connor TP, Dedhar S (2003) Role of integrin-linked kinase in nerve growth factorstimulated neurite outgrowth. J Neurosci 23: 1638-1648.

Ming JE, Elkan M, Tang K, Golden JA (2002) Type I bone morphogenetic protein receptors are expressed on cerebellar granular neurons and a constitutively active form of the type IA receptor induces cerebellar abnormalities. Neuroscience 114: 849-857.

Monea S, Lehti K, Keski-Oja J, Mignatti P (2002) Plasmin activates pro-matrix metalloproteinase-2 with a membrane-type 1 matrix metalloproteinase-dependent mechanism. J Cell Physiol 192: 160-170.

Montaner J, Alvarez-Sabin J, Molina CA, Angles A, Abilleira S, Arenillas J, Monasterio $\mathrm{J}$ (2001) Matrix metalloproteinase expression is related to hemorrhagic transformation after cardioembolic stroke. Stroke 32: 2762-2767.

Mook OR, Van Overbeek C, Ackema EG, Van Maldegem F, Frederiks WM (2003) In situ localization of gelatinolytic activity in the extracellular matrix of metastases of colon cancer in rat liver using quenched fluorogenic DQ-gelatin. J Histochem Cytochem 51: 821-829.

Morodomi T, Ogata Y, Sasaguri Y, Morimatsu M, Nagase H (1992) Purification and characterization of matrix metalloproteinase 9 from U937 monocytic leukaemia and HT1080 fibrosarcoma cells. Biochem J 285: 603-611.

Moss ML, Lambert MH (2002) Shedding of membrane proteins by ADAM family proteases. Essays Biochem 38:141-53.

Mugnaini E, Forstronen PF (1967) Ultrastructural studies on the cerebellar histogenesis. I. Differentiation of granule cells and development of glomeruli in the chick embryo. Z Zellforsch Mikrosk Anat 77: 115-143.

Muir EM, Adcock KH, Morgenstern DA, Clayton R, von Stillfried N, Rhodes K, Ellis C, Fawcett JW, Rogers JH (2002) Matrix metalloproteases and their inhibitors are produced by overlapping populations of activated astrocytes. Brain Res Mol Brain Res 100: 103117.

Murphy G, Stanton H, Cowell S, Butler G, Knauper V, Atkinson S, Gavrilovic J (1999) Mechanisms for pro matrix metalloproteinase activation. APMIS 107: 38-44.

Nagase H (1997) Activation mechanisms of matrix metalloproteinases. Biol Chem 378: 151-160. 
Nakamura H, Fujii Y, Ohuchi E, Yamamoto E, Okada Y (1998) Activation of the precursor of human stromelysin 2 and its interactions with other matrix metalloproteinases. Eur J Biochem 253: 67-75.

Nielsen BS, Lam HR, Ladefoged O (2003) Developmental neurotoxicity of toluene in rats as measured by L-ornithine decarboxylase in cerebellum. Pharmacol Toxicol 92: 5154.

Nieuwenhuys R (1967) Comparative anatomy of the cerebellum. Prog Brain Res 25:1-93.

O'Leary JL, Petty J, Smith JM, O'Leary M, Inukai J (1968) Cerebellar cortex of rat and other animals. A structural and ultrastructural study. J Comp Neurol 134: 401-432.

O'Shea KS, Rheinheimer JS, Dixit VM (1990) Deposition and role of thrombospondin in the histogenesis of the cerebellar cortex. J Cell Biol 110: 1275-1283.

Obersteiner H (1883) Der feinere Bau der Kleinhirnrinde beim Menschen und bei Tieren. Biol Zentralbl 145-155.

Ogata Y, Enghild JJ, Nagase H (1992) Matrix metalloproteinase 3 (stromelysin) activates the precursor for the human matrix metalloproteinase 9. J Biol Chem 267: 3581-3584.

Oh LY, Larsen PH, Krekoski CA, Edwards DR, Donovan F, Werb Z, Yong VW (1999) Matrix metalloproteinase-9/gelatinase $\mathrm{B}$ is required for process outgrowth by oligodendrocytes. J Neurosci 19: 8464-8475.

Oh LY, Yong VW (1996) Astrocytes promote process outgrowth by adult human oligodendrocytes in vitro through interaction between bFGF and astrocyte extracellular matrix. Glia 17: 237-253.

Ohmori H, Ogura H, Yasuda M, Nakamura S, Hatta T, Kawano K, Michikawa T, Yamashita K, Mikoshiba K (1999) Developmental neurotoxicity of phenytoin on granule cells and Purkinje cells in mouse cerebellum. J Neurochem 72: 1497-1506.

Ohshima T, Ogawa M, Veeranna, Hirasawa M, Longenecker G, Ishiguro K, Pant HC, Brady RO, Kulkarni AB, Mikoshiba K (2001) Synergistic contributions of cyclindependant kinase 5/p35 and Reelin/Dab1 to the positioning of cortical neurons in the developing mouse brain. Proc Natl Acad Sci U S A 98: 2764-2769.

Ohtsuka A, Taguchi T, Sayed R, Murakami T (2000) The spatial relationship between the perineuronal proteoglycan network and the synaptic boutons as visualized by double staining with cationic colloidal iron method and anti-calbindin-D-28K immunohistochemistry in rat cerebellar nuclei. Arch Histol Cytol 63: 313-318.

Okada Y, Gonoji Y, Naka K, Tomita K, Nakanishi I, Iwata K, Yamashita K, Hayakawa T (1992) Matrix metalloproteinase 9 (92-kDa gelatinase/type IV collagenase) from HT 1080 human fibrosarcoma cells. Purification and activation of the precursor and enzymic properties. J Biol Chem 267: 21712-21719. 
Okumura Y, Sato H, Seiki M, Kido H (1997) Proteolytic activation of the precursor of membrane type 1 matrix metalloproteinase by human plasmin. A possible cell surface activator. FEBS Lett 402: 181-184.

Olney JW, Wozniak DF, Farber NB, Jevtovic-Todorovic V, Bittigau P, Ikonomidou C (2002) The enigma of fetal alcohol neurotoxicity. Ann Med 34: 109-119.

Oohira A (2001) [Proteoglycans in the development, lesion, and aging of the brain]. Seikagaku 73: 471-474.

Overall CM (2002) Molecular determinants of metalloproteinase substrate specificity: matrix metalloproteinase substrate binding domains, modules, and exosites. Mol Biotechnol 22: 51-86.

Owens MW, Milligan SA, Jourd'heuil D, Grisham MB (1997) Effects of reactive metabolites of oxygen and nitrogen on gelatinase A activity. Am J Physiol 273: L445L450.

Ozaki M, Kishigami S, Yano R (1998) Expression of receptors for neuregulins, ErbB2, ErbB3 and ErbB4, in developing mouse cerebellum. Neurosci Res 30: 351-354.

Ozaki M, Tohyama K, Kishida H, Buonanno A, Yano R, Hashikawa T (2000) Roles of neuregulin in synaptogenesis between mossy fibers and cerebellar granule cells. J Neurosci Res 59: 612-623.

Padgett LC, Lui GM, Werb Z, LaVail MM (1997) Matrix metalloproteinase-2 and tissue inhibitor of metalloproteinase-1 in the retinal pigment epithelium and interphotoreceptor matrix: vectorial secretion and regulation. Exp Eye Res 64: 927-938.

Palay SL, Chan-Palay V (1974) The design of the cerebellar cortex. In: Cerebellar cortex cytology and organization pp 5. New York: Springer-Verlag.

Parma A (1969) [The size of cell corpuscles of Purkinje cells in the paleocerebellum and neocerebellum of some mammals as compared to man]. Acta Anat Suppl (Basel) 56:33746.

Pavlaki M, Cao J, Hymowitz M, Chen WT, Bahou W, Zucker S (2002) A conserved sequence within the propeptide domain of membrane type 1 matrix metalloproteinase is critical for function as an intramolecular chaperone. J Biol Chem 277: 2740-2749.

Pesheva P, Probstmeier R (2000) The yin and yang of tenascin-R in CNS development and pathology. Prog Neurobiol 61: 465-493.

Pierce DR, Williams DK, Light KE (1999) Purkinje cell vulnerability to developmental ethanol exposure in the. Alcohol Clin Exp Res 23: 1650-1659. 
Pinkas-Kramarski R, Eilam R, Alroy I, Levkowitz G, Lonai P, Yarden Y (1997)

Differential expression of NDF/neuregulin receptors ErbB-3 and ErbB-4 and involvement in inhibition of neuronal differentiation. Oncogene 15: 2803-2815.

Pires Neto MA, Braga-de-Souza S, Lent R (1999) Extracellular matrix molecules play diverse roles in the growth and guidance of central nervous system axons. Braz J Med Biol Res 32: 633-638.

Pittman RN, Williams AG (1989) Neurite penetration into collagen gels requires Ca2+dependent metalloproteinase activity. Dev Neurosci 11: 41-51.

Plagge A, Sendtner-Voelderndorff L, Sirim P, Freigang J, Rader C, Sonderegger P, Brummendorf T (2001) The contactin-related protein FAR-2 defines purkinje cell clusters and labels subpopulations of climbing fibers in the developing cerebellum. Mol Cell Neurosci 18: 91-107.

Planas AM, Sole S, Justicia C (2001) Expression and activation of matrix metalloproteinase-2 and -9 in rat brain after transient focal cerebral ischemia. Neurobiol Dis 8: 834-846.

Planas AM, Sole S, Justicia C, Farre ER (2000) Estimation of gelatinase content in rat brain: effect of focal ischemia. Biochem Biophys Res Commun 278: 803-807.

Platten M, Wick W, Weller M (2001) Malignant glioma biology: role for TGF-beta in growth, motility, angiogenesis, and immune escape. Microsc Res Tech 52: 401-410.

Pons S, Trejo JL, Martinez-Morales JR, Marti E (2001) Vitronectin regulates Sonic hedgehog activity during cerebellum development through CREB phosphorylation. Development 128: 1481-1492.

Pross C, Farooq MM, Angle N, Lane JS, Cerveira JJ, Xavier AE, Freischlag JA, Law RE, Gelabert HA (2002) Dexamethasone inhibits vascular smooth muscle cell migration via modulation of matrix metalloproteinase activity. J Surg Res 102: 57-62.

Qian X, Wang TN, Rothman VL, Nicosia RF, Tuszynski GP (1997) Thrombospondin-1 modulates angiogenesis in vitro by up-regulation of matrix metalloproteinase-9 in endothelial cells. Exp Cell Res 235: 403-412.

Raithatha SA, Muzik H, Muzik H, Rewcastle NB, Johnston RN, Edwards DR, Forsyth PA (2000) Localization of gelatinase-A and gelatinase-B mRNA and protein in human gliomas. Neuro -oncol 2: 145-150.

Rakic P (1971) Neuron-glia relationship during granule cell migration in developing cerebellar cortex. A Golgi and electronmicroscopic study in Macacus Rhesus. J Comp Neurol 141: 283-312.

Rakic P, Sidman RL (1970) Histogenesis of cortical layers in human cerebellum, particularly the lamina dissecans. J Comp Neurol 139: 473-500. 
Ratzinger G, Stoitzner P, Ebner S, Lutz MB, Layton GT, Rainer C, Senior RM, Shipley JM, Fritsch P, Schuler G, Romani N (2002) Matrix metalloproteinases 9 and 2 are necessary for the migration of Langerhans cells and dermal dendritic cells from human and murine skin. J Immunol 168: 4361-4371.

Raval-Fernandes S, Rome LH (1998) Role of axonal components during myelination. Microsc Res Tech 41: 379-392.

Reichenbach A, Siegel A, Rickmann M, Wolff JR, Noone D, Robinson SR (1995) Distribution of Bergmann glial somata and processes: implications for function. J Hirnforsch 36: 509-517.

Rice DS, Sheldon M, D'Arcangelo G, Nakajima K, Goldowitz D, Curran T (1998) Disabled-1 acts downstream of Reelin in a signaling pathway that controls laminar organization in the mammalian brain. Development 125: 3719-3729.

Rio C, Rieff HI, Qi P, Khurana TS, Corfas G (1997) Neuregulin and erbB receptors play a critical role in neuronal migration. Neuron 19: 39-50.

Riquelme R, Miralles CP, de Blas AL (2002) Bergmann glia GABA(A) receptors concentrate on the glial processes that wrap inhibitory synapses. J Neurosci 22: 1072010730 .

Rooprai HK, McCormick D (1997) Proteases and their inhibitors in human brain tumours: a review. Anticancer Res 17: 4151-4162.

Rooprai HK, Van Meter T, Rucklidge GJ, Hudson L, Everall IP, Pilkington GJ (1998) Comparative analysis of matrix metalloproteinases by immunocytochemistry, immunohistochemistry and zymography in human primary brain tumours. Int J Oncol 13: 1153-1157.

Rosenberg GA, Cunningham LA, Wallace J, Alexander S, Estrada EY, Grossetete M, Razhagi A, Miller K, Gearing A (2001) Immunohistochemistry of matrix metalloproteinases in reperfusion injury to rat brain: activation of MMP-9 linked to stromelysin-1 and microglia in cell cultures. Brain Res 893: 104-112.

Rosenberg GA, Dencoff JE, Correa N, Jr., Reiners M, Ford CC (1996) Effect of steroids on CSF matrix metalloproteinases in multiple sclerosis: relation to blood-brain barrier injury. Neurology 46: 1626-1632.

Rosenberg GA, Estrada EY, Dencoff JE (1998) Matrix metalloproteinases and TIMPs are associated with blood-brain barrier opening after reperfusion in rat brain. Stroke 29: 2189-2195.

Rosenblum G, Meroueh SO, Kleifeld O, Brown S, Singson SP, Fridman R, Mobashery S, Sagi I (2003) Structural basis for potent slow binding inhibition of human matrix metalloproteinase-2 (MMP-2). J Biol Chem 278: 27009-27015. 
Rowitch DH, Jacques B, Lee SM, Flax JD, Snyder EY, McMahon AP (1999) Sonic hedgehog regulates proliferation and inhibits differentiation of CNS precursor cells. $\mathrm{J}$ Neurosci 19: 8954-8965.

Rubin JB, Choi Y, Segal RA (2002) Cerebellar proteoglycans regulate sonic hedgehog responses during development. Development 129: 2223-2232.

Ryder EF, Cepko CL (1994) Migration patterns of clonally related granule cells and their progenitors in the developing chick cerebellum. Neuron 12: 1011-1028.

Saari H, Suomalainen K, Lindy O, Konttinen YT, Sorsa T (1990) Activation of latent human neutrophil collagenase by reactive oxygen species and serine proteases. Biochem Biophys Res Commun 171: 979-987.

Sager PR, Doherty RA, Rodier PM (1982) Effects of methylmercury on developing mouse cerebellar cortex. Exp Neurol 77: 179-193.

Sameshima T, Nabeshima K, Toole BP, Yokogami K, Okada Y, Goya T, Koono M, Wakisaka S (2000) Expression of emmprin (CD147), a cell surface inducer of matrix metalloproteinases, in normal human brain and gliomas. Int J Cancer 88: 21-27.

Sang QX, Birkedal-Hansen H, Van Wart HE (1995) Proteolytic and non-proteolytic activation of human neutrophil progelatinase B. Biochim Biophys Acta 1251: 99-108.

Santibanez JF, Guerrero J, Quintanilla M, Fabra A, Martinez J (2002) Transforming growth factor-betal modulates matrix metalloproteinase-9 production through the Ras/MAPK signaling pathway in transformed keratinocytes. Biochem Biophys Res Commun 296: 267-273.

Sato H, Kinoshita T, Takino T, Nakayama K, Seiki M (1996) Activation of a recombinant membrane type 1-matrix metalloproteinase (MT1-MMP) by furin and its interaction with tissue inhibitor of metalloproteinases (TIMP)-2. FEBS Lett 393: 101104.

Sato T, Koike L, Miyata Y, Hirata M, Mimaki Y, Sashida Y, Yano M, Ito A (2002) Inhibition of activator protein-1 binding activity and phosphatidylinositol 3-kinase pathway by nobiletin, a polymethoxy flavonoid, results in augmentation of tissue inhibitor of metalloproteinases-1 production and suppression of production of matrix metalloproteinases-1 and -9 in human fibrosarcoma HT-1080 cells. Cancer Res 62: 10251029.

Scappaticci FA (2003) The therapeutic potential of novel antiangiogenic therapies. Expert Opin Investig Drugs 12: 923-932.

Schleifenbaum C (1973) [The postnatal development of the brain of poodles and wolves (author's transl)]. Z Anat Entwicklungsgesch 141: 179-205. 
Schutz A, Schneidenbach D, Aust G, Tannapfel A, Steinert M, Wittekind C (2002) Differential Expression and Activity Status of MMP-1, MMP-2 and MMP-9 in Tumor and Stromal Cells of Squamous Cell Carcinomas of the Lung. Tumour Biol 23: 179-184.

Schwartz MA (2001) Integrin signaling revisited. Trends Cell Biol 11: 466-470.

Seabold GK, Luo J, Miller MW (1998) Effect of ethanol on neurotrophin-mediated cell survival and receptor expression in cultures of cortical neurons. Brain Res Dev Brain Res 108: 139-145.

Seil FJ (2001) Interactions between cerebellar Purkinje cells and their associated astrocytes. Histol Histopathol 16: 955-968.

Sekine-Aizawa Y, Hama E, Watanabe K, Tsubuki S, Kanai-Azuma M, Kanai Y, Arai H, Aizawa H, Iwata N, Saido TC (2001) Matrix metalloproteinase (MMP) system in brain: identification and characterization of brain-specific MMP highly expressed in cerebellum. Eur J Neurosci 13: 935-948.

Shafranova VP (1969) [Characteristics of the arteria blood supply of the molecular layer of the cerebellar cortex in cats, dogs and monkeys]. Arkh Anat Gistol Embriol 56: 72-77.

Shapiro SD (1997) Mighty mice: transgenic technology "knocks out" questions of matrix metalloproteinase function. Matrix Biol 15: 527-533.

Shapiro SD (1998) Matrix metalloproteinase degradation of extracellular matrix: biological consequences. Curr Opin Cell Biol 10: 602-608.

Sheffield JB, Krasnopolsky V, Dehlinger E (1994) Inhibition of retinal growth cone activity by specific metalloproteinase inhibitors in vitro. Dev Dyn 200: 79-88.

Shiga T, Ichikawa M, Hirata Y (1983) A Golgi study of Bergmann glial cells in developing rat cerebellum. Anat Embryol (Berl) 167: 191-201.

Shrimali RK, Reddy KV (2000) Integrins and disintegrins: the candidate molecular players in sperm-egg interaction. Indian J Exp Biol 38: 415-424.

Sidman RL (1983) Experimental neurogenetics. Res Publ Assoc Res Nerv Ment Dis 60:19-46.

Sidman RL, Rakic P (1973) Neuronal migration, with special reference to developing human brain: a review. Brain Res 62: 1-35.

Sobel RA (2001) The extracellular matrix in multiple sclerosis: an update. Braz J Med Biol Res 34: 603-609.

Sobel RA, Ahmed AS (2001) White matter extracellular matrix chondroitin sulfate/dermatan sulfate proteoglycans in multiple sclerosis. J Neuropathol Exp Neurol 60: 1198-1207. 
Sopata I, Wize J (1979) A latent gelatin specific proteinase of human leucocytes and its activation. Biochim Biophys Acta 571: 305-312.

Sotelo C (1990) Cerebellar synaptogenesis: what we can learn from mutant mice. J Exp Biol 153:225-49.

Spacek J (1985) Three-dimensional analysis of dendritic spines. III. Glial sheath. Anat Embryol (Berl) 171: 245-252.

Springman EB, Angleton EL, Birkedal-Hansen H, Van Wart HE (1990) Multiple modes of activation of latent human fibroblast collagenase: evidence for the role of a Cys 73 active-site zinc complex in latency and a "cysteine switch" mechanism for activation. Proc Natl Acad Sci U S A 87: 364-368.

Stoltenburg-Didinger G, Altenkirch H, Wagner M (1990) Neurotoxicity of organic solvent mixtures: embryotoxicity and fetotoxicity. Neurotoxicol Teratol 12: 585-589.

Sumii T, Lo EH (2002) Involvement of matrix metalloproteinase in thrombolysisassociated hemorrhagic transformation after embolic focal ischemia in rats. Stroke 33: 831-836.

Suzuki K, Lees M, Newlands GF, Nagase H, Woolley DE (1995) Activation of precursors for matrix metalloproteinases 1 (interstitial collagenase) and 3 (stromelysin) by rat mast-cell proteinases I and II. Biochem J 305: 301-306.

Suzuki T, Fujikura K, Higashiyama T, Takata K (1997) DNA staining for fluorescence and laser confocal microscopy. J Histochem Cytochem 45: 49-53.

Szklarczyk A, Lapinska J, Rylski M, McKay RD, Kaczmarek L (2002) Matrix metalloproteinase-9 undergoes expression and activation during dendritic remodeling in adult hippocampus. J Neurosci 22: 920-930.

Tagliaferro P, Vega MD, Evrard SG, Ramos AJ, Brusco A (2002) Alcohol exposure during adulthood induces neuronal and astroglial alterations in the hippocampal CA-1 area. Ann N Y Acad Sci 965: 334-342.

Taishi P, Sanchez C, Wang Y, Fang J, Harding JW, Krueger JM (2001) Conditions that affect sleep alter the expression of molecules associated with synaptic plasticity. Am J Physiol Regul Integr Comp Physiol 281: R839-R845.

Takacs J, Metzger F (2002) Morphological study of organotypic cerebellar cultures. Acta Biol Hung 53: 187-204.

Tanaka M, Tomita A, Yoshida S, Yano M, Shimizu H (1994) Observation of the highly organized development of granule cells in rat cerebellar organotypic cultures. Brain Res 641: 319-327. 
Tang BL (2001) ADAMTS: a novel family of extracellular matrix proteases. Int J Biochem Cell Biol 33: 33-44.

Tanney DC, Feng L, Pollock AS, Lovett DH (1998) Regulated expression of matrix metalloproteinases and TIMP in nephrogenesis. Dev Dyn 213: 121-129.

Terashima T, Inoue K, Inoue Y, Mikoshiba K, Tsukada Y (1985) Observations on Golgi epithelial cells and granule cells in the cerebellum of the reeler mutant mouse. Brain Res 350: $103-112$.

Thelen K, Kedar V, Panicker AK, Schmid RS, Midkiff BR, Maness PF (2002) The neural cell adhesion molecule $\mathrm{L} 1$ potentiates integrin-dependent cell migration to extracellular matrix proteins. J Neurosci 22: 4918-4931.

Tissir F, Lambert dR, Goffinet AM (2002) The role of reelin in the development and evolution of the cerebral cortex. Braz J Med Biol Res 35: 1473-1484.

Tokuraku M, Sato H, Murakami S, Okada Y, Watanabe Y, Seiki M (1995) Activation of the precursor of gelatinase $\mathrm{A} / 72 \mathrm{kDa}$ type IV collagenase/MMP-2 in lung carcinomas correlates with the expression of membrane-type matrix metalloproteinase (MT-MMP) and with lymph node metastasis. Int J Cancer 64: 355-359.

Trenkner E, Smith D, Segil N (1984) Is cerebellar granule cell migration regulated by an internal clock? J Neurosci 4: 2850-2855.

Troeberg L, Nagase H (2003) Measurement of matrix metalloproteinase activities in the medium of cultured synoviocytes using zymography. Methods Mol Biol 225: 77-87.

Trommsdorff M, Gotthardt M, Hiesberger T, Shelton J, Stockinger W, Nimpf J, Hammer RE, Richardson JA, Herz J (1999) Reeler/Disabled-like disruption of neuronal migration in knockout mice lacking the VLDL receptor and ApoE receptor 2. Cell 97: 689-701.

Tucker RP, Brunso-Bechtold JK, Jenrath DA, Khan NA, Poss PM, Sweatt AJ, Xu Y (1994) Cellular origins of tenascin in the developing nervous system. Perspect Dev Neurobiol 2: 89-99.

Uhm JH, Dooley NP, Oh LY, Yong VW (1998) Oligodendrocytes utilize a matrix metalloproteinase, MMP-9, to extend processes along an astrocyte extracellular matrix. Glia 22: 53-63.

Uhm JH, Dooley NP, Villemure JG, Yong VW (1996) Glioma invasion in vitro: regulation by matrix metalloprotease-2 and protein kinase C. Clin Exp Metastasis 14: 421-433.

Vaillant C, Didier-Bazes M, Hutter A, Belin MF, Thomasset N (1999) Spatiotemporal expression patterns of metalloproteinases and their inhibitors in the postnatal developing rat cerebellum. J Neurosci 19: 4994-5004. 
Vallee BL, Auld DS (1990) Zinc coordination, function, and structure of zinc enzymes and other proteins. Biochemistry 29: 5647-5659.

Van Wart HE, Birkedal-Hansen H (1990) The cysteine switch: a principle of regulation of metalloproteinase activity with potential applicability to the entire matrix metalloproteinase gene family. Proc Natl Acad Sci U S A 87: 5578-5582.

VanMeter TE, Rooprai HK, Kibble MM, Fillmore HL, Broaddus WC, Pilkington GJ (2001) The role of matrix metalloproteinase genes in glioma invasion: co-dependent and interactive proteolysis. J Neurooncol 53: 213-235.

Vaudry D, Falluel-Morel A, Leuillet S, Vaudry H, Gonzalez BJ (2003) Regulators of cerebellar granule cell development act through specific signaling pathways. Science 300: 1532-1534.

Vecil GG, Larsen PH, Corley SM, Herx LM, Besson A, Goodyer CG, Yong VW (2000) Interleukin-1 is a key regulator of matrix metalloproteinase-9 expression in human neurons in culture and following mouse brain trauma in vivo. J Neurosci Res 61: 212224.

Vince GH, Wagner S, Pietsch T, Klein R, Goldbrunner RH, Roosen K, Tonn JC (1999) Heterogeneous regional expression patterns of matrix metalloproteinases in human malignant gliomas. Int J Dev Neurosci 17: 437-445.

Vliagoftis H, Schwingshackl A, Milne CD, Duszyk M, Hollenberg MD, Wallace JL, Befus AD, Moqbel R (2000) Proteinase-activated receptor-2-mediated matrix metalloproteinase-9 release from airway epithelial cells. J Allergy Clin Immunol 106: 537-545.

Vu TH, Werb Z (2000) Matrix metalloproteinases: effectors of development and normal physiology. Genes Dev 14: 2123-2133.

Wagner S, Coerper S, Fricke J., Hunt KT, Hussain Z, Elmlinger MW, Mueller E, Becker HD (2003) Comparison of inflammatory and systemic sources of growth factors in acute and chronic human wounds. Wound Repair and Regeneration 11: 253-260.

Wallace VA (1999) Purkinje-cell-derived Sonic hedgehog regulates granule neuron precursor cell proliferation in the developing mouse cerebellum. Curr Biol 9: 445-448.

Wang X, Jung J, Asahi M, Chwang W, Russo L, Moskowitz MA, Dixon CE, Fini ME, Lo EH (2000) Effects of matrix metalloproteinase-9 gene knock-out on morphological and motor outcomes after traumatic brain injury. J Neurosci 20: 7037-7042.

Wang X, Mori T, Jung JC, Fini ME, Lo EH (2002) Secretion of matrix metalloproteinase-2 and -9 after mechanical trauma injury in rat cortical cultures and involvement of MAP kinase. J Neurotrauma 19: 615-625. 
Wechsler-Reya RJ (2001) Caught in the matrix: how vitronectin controls neuronal differentiation. Trends Neurosci 24: 680-682.

Werz W, Schachner M (1988) Adhesion of neural cells to extracellular matrix constituents. Involvement of glycosaminoglycans and cell adhesion molecules. Brain Res 471: 225-234.

White AM, Matthews DB, Best PJ (2000a) Ethanol, memory, and hippocampal function: a review of recent findings. Hippocampus 10: 88-93.

White LA, Mitchell TI, Brinckerhoff CE (2000b) Transforming growth factor beta inhibitory element in the rabbit matrix metalloproteinase-1 (collagenase-1) gene functions as a repressor of constitutive transcription. Biochim Biophys Acta 1490: 259268.

Whiting BA, Barton RA (2003) The evolution of the cortico-cerebellar complex in primates: anatomical connections predict patterns of correlated evolution. J Hum Evol 44: $3-10$.

Wiggins RC (1986) Myelination: a critical stage in development. Neurotoxicology 7: 103-120.

Willenbrock F, Murphy G, Phillips IR, Brocklehurst K (1995) The second zinc atom in the matrix metalloproteinase catalytic domain is absent in the full-length enzymes: a possible role for the C-terminal domain. FEBS Lett 358: 189-192.

Windsor LJ, Bodden MK, Birkedal-Hansen B, Engler JA, Birkedal-Hansen H (1994) Mutational analysis of residues in and around the active site of human fibroblast-type collagenase. J Biol Chem 269: 26201-26207.

Wood KA, Dipasquale B, Youle RJ (1993) In situ labeling of granule cells for apoptosisassociated DNA fragmentation reveals different mechanisms of cell loss in developing cerebellum. Neuron 11: 621-632.

Woodworth A, Fiete D, Baenziger JU (2002) Spatial and temporal regulation of tenascinR glycosylation in the cerebellum. J Biol Chem 277: 50941-50947.

Wu WB, Peng HC, Huang TF (2003) Disintegrin causes proteolysis of beta-catenin and apoptosis of endothelial cells. Involvement of cell-cell and cell-ECM interactions in regulating cell viability. Exp Cell Res 286: 115-127.

Yabe T, Samuels I, Schwartz JP (2002) Bone morphogenetic proteins BMP-6 and BMP-7 have differential effects on survival and neurite outgrowth of cerebellar granule cell neurons. J Neurosci Res 68: 161-168.

Yachnis AT, Rorke LB (1999) Cerebellar and brainstem development: an overview in relation to Joubert syndrome. J Child Neurol 14: 570-573. 
Yacubova E, Komuro H (2002) Intrinsic program for migration of cerebellar granule cells in vitro. J Neurosci 22: 5966-5981.

Yacubova E, Komuro H (2003) Cellular and molecular mechanisms of cerebellar granule cell migration. Cell Biochem Biophys 37: 213-234.

Yamada K, Fukaya M, Shibata T, Kurihara H, Tanaka K, Inoue Y, Watanabe M (2000) Dynamic transformation of Bergmann glial fibers proceeds in correlation with dendritic outgrowth and synapse formation of cerebellar Purkinje cells. J Comp Neurol 418: 106120.

Yamada K, Watanabe M (2002) Cytodifferentiation of Bergmann glia and its relationship with Purkinje cells. Anat Sci Int 77: 94-108.

Yamasaki M, Yamada K, Furuya S, Mitoma J, Hirabayashi Y, Watanabe M (2001) 3Phosphoglycerate dehydrogenase, a key enzyme for l-serine biosynthesis, is preferentially expressed in the radial glia/astrocyte lineage and olfactory ensheathing glia in the mouse brain. J Neurosci 21: 7691-7704.

Yong VW, Krekoski CA, Forsyth PA, Bell R, Edwards DR (1998) Matrix metalloproteinases and diseases of the CNS. Trends Neurosci 21: 75-80.

Yong VW, Power C, Forsyth P, Edwards DR (2001) Metalloproteinases in biology and pathology of the nervous system. Nat Rev Neurosci 2: 502-511.

Yoshiyama Y, Asahina M, Hattori T (2000) Selective distribution of matrix metalloproteinase-3 (MMP-3) in Alzheimer's disease brain. Acta Neuropathol (Berl) 99: 91-95.

Yuasa S (1996) Bergmann glial development in the mouse cerebellum as revealed by tenascin expression. Anat Embryol (Berl) 194: 223-234.

Yuasa S, Kawamura K, Kuwano R, Ono K (1996) Neuron-glia interrelations during migration of Purkinje cells in the mouse embryonic cerebellum. Int J Dev Neurosci 14: 429-438.

Yuasa S, Kawamura K, Ono K, Yamakuni T, Takahashi Y (1991) Development and migration of Purkinje cells in the mouse cerebellar primordium. Anat Embryol (Berl) 184: $195-212$.

Yuasa S, Kitoh J, Oda S, Kawamura K (1993) Obstructed migration of Purkinje cells in the developing cerebellum of the reeler mutant mouse. Anat Embryol (Berl) 188: 317 329.

Yushchenko M, Weber F, Mader M, Scholl U, Maliszewska M, Tumani H, Felgenhauer K, Beuche W (2000) Matrix metalloproteinase-9 (MMP-9) in human cerebrospinal fluid (CSF): elevated levels are primarily related to CSF cell count. J Neuroimmunol 110: 244251. 
Zagon IS, McLaughlin PJ, Rogers WE (1985) Neuronal migration independent of glial guidance: light and electron microscopic studies in the cerebellar cortex of neonatal rats. Acta Anat (Basel) 122: 77-86.

Zecevic N, Rakic P (1976) Differentiation of Purkinje cells and their relationship to other components of developing cerebellar cortex in man. J Comp Neurol 167: 27-47.

Zechel J, Gohil H, Lust WD, Cohen A (2002) Alterations in matrix metalloproteinase-9 levels and tissue inhibitor of matrix metalloproteinases-1 expression in a transforming growth factor-beta transgenic model of hydrocephalus. J Neurosci Res 69: 662-668.

Zhang JW, Deb S, Gottschall PE (1998) Regional and differential expression of gelatinases in rat brain after systemic kainic acid or bicuculline administration. Eur $\mathrm{J}$ Neurosci 10: 3358-3368.

Zhang L, Goldman JE (1996a) Developmental fates and migratory pathways of dividing progenitors in the postnatal rat cerebellum. J Comp Neurol 370: 536-550.

Zhang L, Goldman JE (1996b) Generation of cerebellar interneurons from dividing progenitors in white matter. Neuron 16: 47-54.

Zheng C, Heintz N, Hatten ME (1996) CNS gene encoding astrotactin, which supports neuronal migration along glial fibers. Science 272: 417-419.

Zheng Z, Lee JE, Yenari MA (2003) Stroke: molecular mechanisms and potential targets for treatment. Curr Mol Med 3: 361-372.

Zuo J, Ferguson TA, Hernandez YJ, Stetler-Stevenson WG, Muir D (1998) Neuronal matrix metalloproteinase-2 degrades and inactivates a neurite-inhibiting chondroitin sulfate proteoglycan. J Neurosci 18: 5203-5211. 


\section{Appendix 1: Detailed experimental protocols}

\section{A1. Animal surgeries}

1. Prepare, clean and sterilize surgery tools.

2. Sterilize work area with $5 \%$ Chlorox, then with $75 \% \mathrm{EtOH}$

3. Anesthetize pups on ice (P3 and P6) or with $120 \mathrm{mg} / \mathrm{kg}$ injection of pentobarbital (P9 and older)

4. Decapitate the pup and gently make a midline incision and deflect the scalp. Do not cut too deep, this will damage underlying neural tissue. Also do not apply pressure because it will cause the soft brain tissue to ooze out of the foramen magnum.

5. Gently score the cranium with a scalpel and remove it with a pair of small forceps.

6. Do the following step over a dish full of cold PBS. Turn the head upside down and sever the cranial nerves. The brain will drop into the PBS.

N.B: $\quad$ For biochemical processing experiments, use $\mathrm{ddH}_{2} \mathrm{O}$ instead of PBS. Separate cerebellum from cerebrum and freeze tissue liquid nitrogen. Label tube $(\mathrm{Cbl}=$ cerebellum; $\mathrm{Ctx}=$ cerebral cortex; plus age $)$ and store at $-80^{\circ} \mathrm{C}$.

7. Very carefully remove remaining meningies and place the brain in fixative.

N.B: $\quad$ For in situ zymography experiments, do not use fixative.

8. Cut a small cork and place it in a small embedding cube. Label the cube $(\mathrm{IHC}$ Px $=$ immunohistochemistry + postnatal day; ISZ Px: in situ zymography + postnatal day). Cover the cork with tissue freezing compound 
(O.C.T.), place brain on its side and cover entirely with O.C.T. Place the cube in powdered dry ice and cover with a thin layer of dry ice.

9. Store cubes in $-80^{\circ} \mathrm{C}$ freezer until sectioning.

10. Important: use superfrost plus (Fisher 12-550-15) glass slides or coated ( $2 \%$ saline or gelatin) slides. Tissue will detach easily from regular slides.

\section{A2. Immunohistochemistry}

1. Store cryostat sections, $12 \mu \mathrm{m}$ thick, in plastic slide boxes wrapped with plastic wrap at $-20^{\circ} \mathrm{C}$.

2. Slides are inserted in plastic slide container (4 each; leave one slot empty for negative control) and placed on shaker for all subsequent steps. Need to prepare $12 \mathrm{ml}$ of solutions to submerge the sections. Never let slides dry out between steps.

3. Rinse slides in $25 \%$ ethanol in $\mathrm{ddH}_{2} \mathrm{O}$ for $15 \mathrm{~min}$ to remove all O.C.T. compound residues.

4. Rinse slides in PBS-TX (0.1M PBS + 0.1\% Triton-X 100) for $30 \mathrm{~min}$.

5. Incubate slides in primary $\mathrm{Ab}$ solution for $24 \mathrm{hrs}$ at $4^{\circ} \mathrm{C}$ on shaker. Dissolve goat-anti-MMP-9 and goat-anti-MMP-2 in PBS (1:1000). Dissolve mouseanti-Calbindin D28k (1:3000) and mouse-anti-GFAP (1:1000) in PBS/ PBSTX (1:1).

6. Transfer antibody solutions individually into $50 \mathrm{ml}$ conical tubes, label the tubes, and store them at $4^{\circ} \mathrm{C}$. Antibody solutions are good for a maximum of 
1 month and can be reused 2 to 3 times.

7. Rinse slides 3 times in PBS for a total of $30 \mathrm{~min}$. During this time prepare secondary antibodies. For MMP-2 and MMP-9, dissolve anti-goat-FITC (1:300) and TOTO-3 (1:500) in PBS. For Calbindin D28k and GFAP, dissolve anti-mouse-FITC (1:300) and TOTO-3 (1:500) in PBS. Protect working solutions of secondary antibody from light by wrapping the tube with aluminum foil. Working solutions of secondary antibody can be reused 2-3 times if stored at $4^{\circ} \mathrm{C}$. Remember to rinse the Control section in $25 \%$ ethanol for $15 \mathrm{~min}$, followed by $30 \mathrm{~min}$ in PBS. Add control section to slide container and incubate all slides with secondary antibody

8. Incubate slides in secondary antibody solution for $2 \mathrm{hrs}$ at room temperature. Wrap the slide container with aluminum foil to prevent bleaching of seconday antibodies.

9. $\quad$ Rinse slides 3 times in PBS for a total of 30 minutes.

10. Gently blot excess fluid from around the sections (do not let them dry), add 2-3 drops of mounting media (PBS-Glycerol 1:1 or Vectashield) and coverslip. Blot excess fluid from around the coverslips and seal the edges with a coat of clear and fast-drying nail polish.

11. Store slides in a slide box at $4^{\circ} \mathrm{C}$.

\section{A3. In situ zymography}

1. Brains are dissected, embedded in O.C.T. compound and frozen without 
fixation

2. Section brains and store sections in slide box at $-20^{\circ} \mathrm{C}$

3. Prepare reaction buffer: $0.05 \mathrm{M}$ Tris- $\mathrm{HCl}, 0.15 \mathrm{M} \mathrm{NaCl}, 5 \mathrm{mM} \mathrm{CaCl}_{2}, 0.2$ $\mathrm{mM} \mathrm{NaN}\left(\mathrm{pH}\right.$ 7.6). Dissolve $\mathrm{DQ}^{\mathrm{TM}}$ gelatin-FITC (40 $\mu \mathrm{g} / \mathrm{ml} ; \mathrm{D}-12054$; Molecular Probes Inc., Eugene, OR) in reaction buffer in $50 \mathrm{ml}$ conical tube. Place tube in warm water bath and shake for $30 \mathrm{sec}$ or until the gelatin dissolves completely.

4. Add staining solution to slide container and wrap it with aluminum foil. Place slide container on a shaker at $37^{\circ} \mathrm{C}$ for 24 hours.

5. Retrieve slides and blot excess fluid from around the sections. Don't let the slides dry out. Add few drops of wet mounting media over the sections and coverslip the slides. Blot excess fluid from around the coverslips and seal the edges with fast-drying nail polish.

6. $\quad$ Store slides at $4^{\circ} \mathrm{C}$.

\section{A4. Cerebellar cell culture}

Cerebellar granule neuron cell culture protocol:

1. Dissect the cerebellum out and put the fresh tissue in a small tube of $1 \mathrm{H}$ solution

2. When finished, finely chop all tissue with a razor blade on a glass slide

3. Move chopped tissue to a $50 \mathrm{ml}$ conical tube and add solution A. lock tube well, shake several times, then incubate/shake at $37^{\circ} \mathrm{C}$ for $15 \mathrm{~min}$. 
4. Then, add solution C directly to the tube, shake and centrifuge for $15 \mathrm{sec}$ at $500 \mathrm{rpm}$

5. Remove supernatant, add $5 \mathrm{ml}$ solution $\mathrm{B}$, swirl and mix well and let sit for $5 \mathrm{~min}$.

6. Transfer supernatant to a $15 \mathrm{ml}$ tube; gently add solution $\mathrm{D}$ to about $12 \mathrm{ml}$

7. Then spin down for $3 \mathrm{~min}$ at $2000 \mathrm{rpm}$

8. Remove supernatant, keep pellet and add $5 \mathrm{ml}$ of culture media and divide over dishes

9. For glial culture, transfer supernatant to a flat culture bottle and add $10 \mathrm{ml}$ DMEM and incubate. Change media every 3 days

\section{Stock solutions:}

1. $\quad$ trypsin: $25 \mathrm{mg} / \mathrm{ml}$ (T8003, sigma)

2. trypsin inhibitor: $4 \mathrm{mg} / \mathrm{ml}$ soybean trypsin inhibitor (T9003, sigma)

3. DNase: $200 \mathrm{U} / \mathrm{ml}$ DNAse I (D-4527, sigma)

4. $\quad \mathrm{MgSO}_{4}, 7 \mathrm{H}_{2} \mathrm{O}: 3.82 \%(\mathrm{w} / \mathrm{v})$

N.B: prepare all solutions in $\mathrm{dd} H 2 \mathrm{O}$

$1 \mathrm{H}$ buffer $(50 \mathrm{ml}): 50 \mathrm{ml}$ EBSS $+0.125 \mathrm{~g}$ Glucose $+0.15 \mathrm{~g} \mathrm{BSA}+0.5 \mathrm{ml} \mathrm{MgSO}_{4}$ stock

A buffer $(10 \mathrm{ml}): 0.1 \mathrm{ml}$ trypsin stock $+9.9 \mathrm{ml} 1 \mathrm{H}$ buffer

B buffer $(10 \mathrm{ml}): 8.6 \mathrm{ml} \mathrm{1H}+1 \mathrm{ml}$ trypsin inhibitor Stock $+0.2 \mathrm{ml}$ DNAse stock +0.2 $\mathrm{ml} \mathrm{MgSO} 4$ stock

C buffer (10 ml): $8.4 \mathrm{ml} \mathrm{1H}+1.6 \mathrm{ml} \mathrm{B}$ buffer

D buffer $(10 \mathrm{ml}): 9.8 \mathrm{ml} 1 \mathrm{H}+400 \mathrm{mg} \mathrm{BSA}+0.2 \mathrm{ml} \mathrm{MgSO}_{4}$ stock

Culture media stock solutions: 


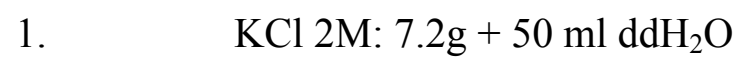

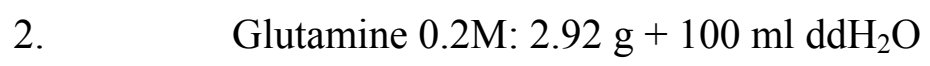

3. Glucose 1.33M (24\%): $12 \mathrm{~g}+50 \mathrm{ml}$

4. Poly-D-Lysine $50 \mu \mathrm{g} / \mathrm{ml}$ in $\mathrm{ddH}_{2} \mathrm{O}$ (for coating slides and cover slips)

For $100 \mathrm{ml}$ medium: $1 \mathrm{ml} \mathrm{KCl}+1 \mathrm{ml}$ Glutamine stock $+2.5 \mathrm{ml}$ Glucose stock $+10 \mathrm{ml}$ FBS

$+1 \mathrm{ml} \mathrm{Pen} /$ Strep $(0.12 \mathrm{ml}$ gentamicin $)+85 \mathrm{ml}$ EMEM

\section{A5. Protein extraction}

(Monolayer cell culture)

1. Remove culture medium with care. (Some cells easily detach from plate)

2. Add $0.5 \mathrm{ml}$ (the amount of buffer added may be increased if the cell culture is too dense) of RIPA buffer with freshly added inhibitors to cell culture plate.

3. Scrap with a cell scraper and $1 \mathrm{ml}$ pipetter up and down several times to shear membranes. Incubate on ice for $10 \mathrm{~min}$.

4. Spin down at $10,000 \mathrm{~g}$ for $10 \mathrm{~min}$ at $4^{\circ} \mathrm{C}$.

5. Transfer the supernatant fluid, which is the total cell lysate, to clean eppendorf tubes and freeze at $-20^{\circ} \mathrm{C}$ or run lowly assay to check protein concentration.

RIPA buffer:

$1 \times$ PBS 
$1 \%$ P-40

$0.5 \%$ sodium deoxycholate

$0.1 \%$ SDS

$\underline{\text { RIPA buffer with inhibitors (make fresh): }}$

$10 \mathrm{mg} / \mathrm{ml}$ PMSF at $10 \mathrm{ml} / \mathrm{ml}$ RIPA

Aprotinin (Sigma \#A6279 as liquid) at $30 \mu \mathrm{l} / \mathrm{ml}$ RIPA

$100 \mathrm{mM}$ sodium orthovanadate at $10 \mathrm{ml} / \mathrm{ml} \mathrm{RIPA}$

Lowly assay (for microplate assay) 40:

1. Make A': Add $20 \mathrm{ml}$ of A to $1 \mathrm{ml}$ of S.

2. Prepare 5 dilution of protein standard (BSA) from $0.0875,0.175,0.35,0.7$, $1.4 \mathrm{mg} / \mathrm{ml}$. Standard curve should be prepared each time the assay is performed.

N.B: prepare all samples and standards in triplicates

3. Add $5 \mu \mathrm{l}$ of standard and samples into a clean microtiter plate.

4. $\quad$ Add $25 \mu l$ of $A^{\prime}$ into each well.

5. $\quad$ Add $200 \mu \mathrm{l}$ of B into each well; gently agitate the plate to mix the reagents. (Avoid air bubbles)

6. Incubate at room temperature for $15 \mathrm{~min}$ and read absorbance at $750 \mathrm{~nm}$ (program 33)

7. Calculate average protein concentration in $\mu \mathrm{g} / \mu \mathrm{l}$.

8. Maximum volume to load in a gel with $0.75 \mathrm{~mm}$ wells is $25 \mu \mathrm{l}$ and $60 \mu \mathrm{l}$ in a gel with $1.5 \mathrm{~mm}$ wells. 
9. Prepare aliquots with $16 \mu$ l (protein + RIPA buffer) $+5 \mu$ l sample buffer minutes before loading in the gel

\begin{tabular}{|c|c|c|c|c|c|}
\hline Tissue & Age & Ave. Conc. $(\mu \mathrm{g} / \mu \mathrm{l})$ & Protein $(\mu \mathrm{g})$ & Protein $(\mu \mathrm{l})$ & RIPA buffer $(\mu \mathrm{l})$ \\
\hline \multirow{9}{*}{$\begin{array}{l}\text { Cerebellar } \\
\text { Cortex }\end{array}$} & P3 & 34.13 & 853.25 & 5.9 & 10.1 \\
\hline & $\mathrm{P} 6$ & 30.82 & 770.5 & 6.5 & 9.5 \\
\hline & $\mathrm{P9}$ & 45.57 & 1139.25 & 4.4 & 11.6 \\
\hline & P12 & 49.46 & 1236.5 & 4 & 12 \\
\hline & $\mathrm{P} 15$ & 36.46 & 911.5 & 5.5 & 10.5 \\
\hline & P18 & 40.37 & 1009.25 & 4.9 & 11.1 \\
\hline & P21 & 44.6 & 1115 & 4.5 & 11.5 \\
\hline & P25 & 34.13 & 853.25 & 5.9 & 10.1 \\
\hline & P30 & 35.62 & 915.5 & 5.5 & 10.5 \\
\hline \multirow{9}{*}{$\begin{array}{l}\text { Cerebral } \\
\text { Cortex }\end{array}$} & $\mathrm{P} 3$ & 25.89 & 647.25 & 7.7 & 8.3 \\
\hline & $\mathrm{P} 6$ & 29.38 & 734.5 & 6.8 & 9.2 \\
\hline & P9 & 29.27 & 731.75 & 6.8 & 9.2 \\
\hline & $\mathrm{P} 12$ & 33.64 & 841 & 6 & 10 \\
\hline & P15 & 37.47 & 936.75 & 5.3 & 10.7 \\
\hline & $\mathrm{P} 18$ & 36.74 & 918.5 & 5.4 & 10.6 \\
\hline & P21 & 21.7 & 542.5 & 9.2 & 6.8 \\
\hline & $\mathrm{P} 25$ & 19.38 & 484.5 & 10.3 & 5.7 \\
\hline & P30 & 37.78 & 944.5 & 5.3 & 10.7 \\
\hline
\end{tabular}

Table 1. Protein concentration for gelatinase assay. Example from Tuesday, Nov. 272001

\section{A6. Gelatinase assay}

Note: Zymographic analysis $=$ Gelatinase assay

Gelatinolytic activity $=$ Gelatin degrading activity

10\% Separating Gel: $15 \mathrm{ml}$

Dissolve $15 \mathrm{mg}$ gelatin in $7.5 \mathrm{ml} \mathrm{ddH}_{2} \mathrm{O}$ by heating in stir plate.

Add $3.75 \mathrm{ml}$ 4X separating buffer after cooling to RT

Add $3.75 \mathrm{ml} \mathrm{40 \%} \mathrm{37.5:1} \mathrm{acrylamine/Bisacrylamine}$ 
Add $100 \mu 1$ 10\% APS, mix well

Add $20 \mu$ TEMED

Stacking Gel:

37.5:1 Acrylamine/Bisacrylamine $1 \mathrm{ml}$

4X stacking buffer $\quad 2.5 \mathrm{ml}$

$\mathrm{dd}_{2} \mathrm{O} \quad 6.5 \mathrm{ml}$

$10 \%$ APS $\quad 50 \mu 1$

TEMED $\quad 10 \mu 1$

Samples preparation and electrophoresis:

1. Prepare samples in $4 \mathrm{X}$ sample buffer (non-reducing, $40 \mathrm{mM}$ Tris-HCL $\mathrm{pH} 8$, $80 \%$ Glycerin, $8 \%$ SDS, $0.4 \%$ Bromophenol blue). Do not heat samples before loading.

2. Fill the container with Protein Running Buffer. Load samples in the electrophoretic gel. Max load: $25 \mu \mathrm{l}$ in $0.75 \mathrm{~mm}$ plate.

3. Attach the gel container to the power supply and adjust the current intensity to $0.32 \mathrm{~mA}$. Let the gel run for 2 to 3 hours (until the blue dye starts to run down).

4. Wash gel in $2.5 \%$ Triton-100 for $30 \mathrm{~min}$

5. Switch to $50 \mathrm{mM}$ Tris-HCL $\mathrm{pH} 7.4,0.1 \mathrm{M} \mathrm{NaCl}, 2.5 \%$ Triton-100 for additional $60 \mathrm{~min}$

6. Incubate in reaction buffer $\left(50 \mathrm{mM}\right.$ Tris-HCL $\left.\mathrm{pH} 7.4,10 \mathrm{mM} \mathrm{CaCl}_{2}\right)$ overnight at $37^{\circ} \mathrm{C}$.

7. Stain the gel with $0.5 \%$ coomassie blueR in $45 \% \mathrm{MeOH}, 10 \%$ acetic acid for 
$30 \mathrm{~min}$ at room temperature on shaker.

8. De-stain the gel in destaining solution $(10 \% \mathrm{MeOH}, 10 \%$ acetic acid)

9. Take picture of gel on the Eaglesight ${ }^{\circledR}$ workstation.

\section{A7. Reverse zymography assay}

Gel preparation:

Separating Gel (12\%):

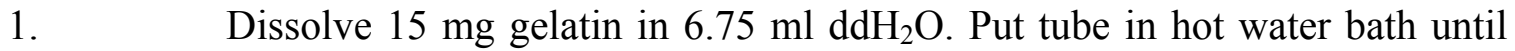
gelatin dissolves.

2. $\quad 4.5 \mathrm{ml}$ of $40 \% 37.5: 1$ Acrylamine/Bisacrylamine

3. $\quad 3.75 \mathrm{ml} 4 \mathrm{X}$ Separating Buffer

4. $15 \mu \mathrm{l}$ of $0.2 \mu \mathrm{g} / \mathrm{ml}$ pro-MMP2 (Calbiochem 444213)

5. $\quad 75 \mu 110 \%$ APS

6. $\quad 15 \mu 1$ TEMED

Overlay gel with ddH2O

Stacking Gel:

1. $\quad 1 \mathrm{ml}$ of $40 \% 37.5: 1$ Acrylamine/Bisacrylamine

2. $2.5 \mathrm{ml}$ Stacking Buffer

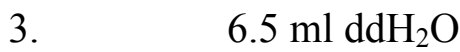

4. $\quad 50 \mu 110 \%$ APS

5. $\quad 10 \mu 1$ TEMED 
Let the gel run for 2 hours

N.B: sample preparation, incubation time and staining are the same as in Gelatinase Assay

\section{A8. Organotypic slice culture}

\section{Solutions:}

1. Culture media: $46 \%$ Eagle's basal medium $+25 \%$ Earl's balanced salt solution $+25 \%$ horse serum $+1 \%$ penicillin-streptomycin-glutamine (penicillin $10^{5}$ units $/ \mathrm{ml}$; streptomycin $10 \mathrm{mg} / \mathrm{ml} ; 29.2 \mathrm{mg} \cdot \mathrm{ml}^{-1}$ ) $+6.5 \mathrm{mg} / \mathrm{ml}$ glucose. Adjust $\mathrm{pH}$ to 7.2. Store culture media in an autoclaved bottle at $4^{\circ} \mathrm{C}$ until use.

2. ACSF: $126.0 \mathrm{mM} \mathrm{NaCl}+3.0 \mathrm{mM} \mathrm{KCl}+1.3 \mathrm{mM} \mathrm{MgSO}_{4}+2.5 \mathrm{mM} \mathrm{CaCl}_{2}$ $+1.2 \mathrm{mM} \mathrm{NaH}_{2} \mathrm{PO}_{4}+26 \mathrm{mM} \mathrm{NaHCO} 3+20 \mathrm{mM}$ dextrose. Keep ACSF at $4^{\circ} \mathrm{C}$. Bubble ACSF in $\mathrm{O}_{2}: \mathrm{CO}_{2}$ gas mixture (95\%:5\%) for 15 min before use.

3. Autoclave all paper towels, surgery tools and glassware

4. Perform all steps under sterile conditions in a laminar flow hood. Clean space with a mixture of $25 \%$ ethanol and $2 \%$ chlorox before use.

Procedure:

5. Prepare six plates. Put $1 \mathrm{ml}$ of culture medium in the well. Place Millicell membrane-inserts (Cat\# PICMORG50, Millipore, Bedford, MA) over the culture media and try to avoid air bubbles.

6. Anesthesize rat pups (P5) by cooling on ice. Rub head with $75 \%$ ethanol.

7. Decapitate pups and quickly dissect the hind brain including, the cerebellum, out. 
7. Place the cerebellum in a Petri dish filled with ice cold ACSF.

8. Under magnifying glass, make a cut behind the inferior colliculus and gently separate the cerebellum from the pons. Make a sagittal cut $2 \mathrm{~mm}$ lateral to the vermis.

9. Glue flat surface down on the stage of vibraslicer (WPI, Sarasota, FL), and immerse in ACSF.

10. Sections the cerebellum at $500 \mu \mathrm{m}$ thickness. Collect slices from the vermal region and few millimeters around it.

11. Gently transfer slices to the millicel membrane. Arrange only 2 slices over every membrane and place $20 \mu 1$ of culture media on top of the slices. Use only 4 wells from the six-well culture plate. One well is for control slices, while the other three are for treatment groups.

12. Incubate culture plates at $35^{\circ} \mathrm{C}$ with $5 \% \mathrm{CO}_{2}$ atmosphere.

13. Replace culture media every 2 days. Warm the culture media to $35^{\circ} \mathrm{C}$ before adding to the culture plate.

\section{A9. MMP inhibitor treatment}

1. Dilute the gelatinase inhibitor (SB-3CT) in culture media to a final concentration of $1.6 \mu \mathrm{M}, 3.2 \mu \mathrm{M}$, and $6.4 \mu \mathrm{M}$. Prepare inhibitor solution from aliquots $30 \mathrm{~min}$ before treatment and allow the solution to warm up to $37^{\circ} \mathrm{C}$.

2. Start treat slices with the inhibitor $6 \mathrm{hrs}$ after the beginning of the slice culture. 
3. For 1DIV, harvest the slices $24 \mathrm{hrs}$ after the initial treatment. Place metal block in $-80^{\circ} \mathrm{C}$ freezer the night before. Place glass slides on the metal block and place few drops of O.C.T. compound on them. Sandwich the O.C.T. compound between two cold glass slides and let it freeze (Figure1, a-c). The O.C.T. compound should freeze flat like a coin. Detach the glass slides from the frozen O.C.T. coin by rubbing the surface lightly with your finger. Place the frozen O.C.T. coin flat on the metal block. Cover a tissue slice with O.C.T. compound and gently place it on the frozen O.C.T. coin using a paint brush (Figure 1d). Cover the slice with powdered dry ice and let it freeze (Figure 1e).

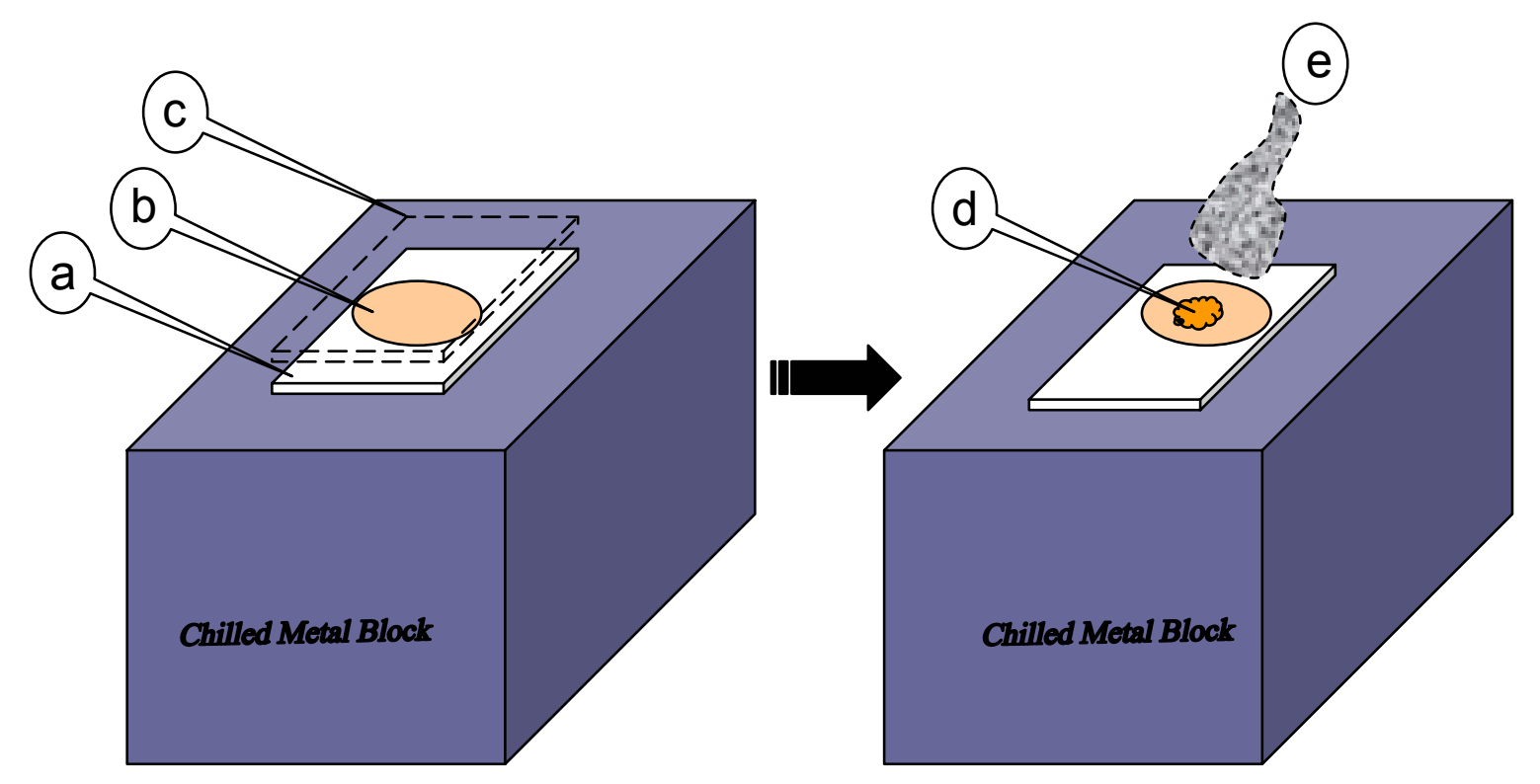

Figure 1. Freezing slices for IHC and ISZ. Refer to text for details.

4. Pipette out the culture media from the culture plate and place in pre-labeled eppendorf tubes. Store tubes at $-20^{\circ} \mathrm{C}$. 
5. For the remaining treatment groups, replace the culture media with the inhibitor every two days or $24 \mathrm{hrs}$ before collecting the slices, and repeat the procedure in (3).

\section{A10. Morphometric analysis}

1. Sampling frames were chosen by systematic random sampling. All frames are of equal size using a 20x objective. Fame size $=325.7 \times 325.7$

2. Using the LSM510 software, choose "Overlay" from the menue and pick the following: line thickness, color (white), ruler, and curved line.

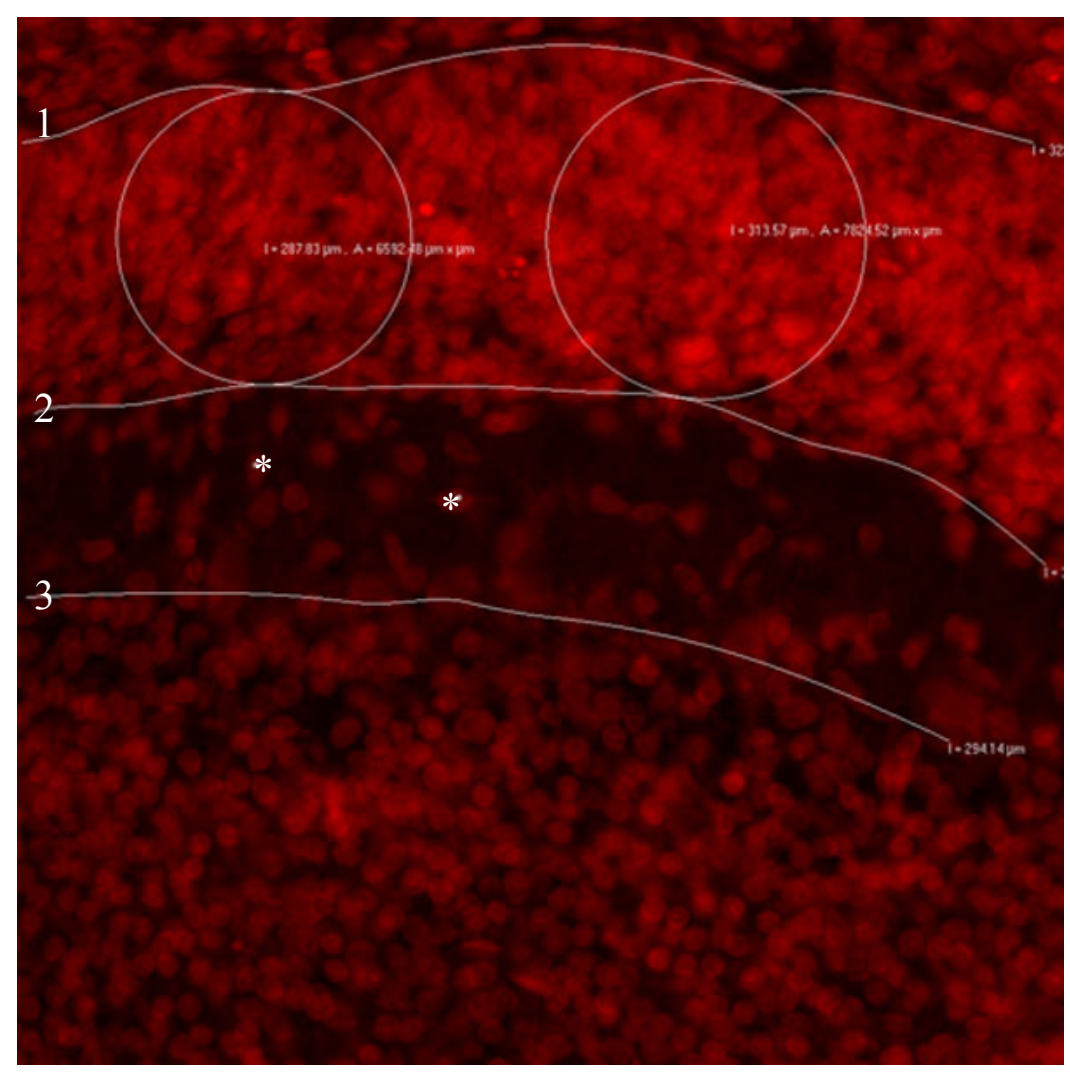

Figure 2. Morphometric analysis in cerebellar sections. Sample frame from 4DIV 1.6 $\mu \mathrm{M}$ section. We measured the thickness of the EGL and the number of migrating cells in the ML. (*: migrating cells) 
3. Draw 3 lines: line 1 borders the EGL-pia, line 2 borders the EGL-ML, and line 3 through the nuclei of Purkinje cell (Figure 2).

4. Draw 2 circles between line 1 and line 2 . The circles have to touch the lines at 2 points, one point on each line. Record the area (A) of each circle

5. To determine the distance (D) between the lines, apply the following

formula in Excel: $\quad \mathrm{D}=2 * \operatorname{SQRT}(\mathrm{A} / \mathrm{Pi}())$

6. Count the cells between line 2 and 3 . Choose only clearly visible cells with ovoid nuclei, not exceeding $8 \mu \mathrm{m}$ in diameter 


\title{
Curriculum vitae
}

\author{
Albert E. Ayoub
}

\begin{tabular}{|c|c|}
\hline \multicolumn{2}{|c|}{ Present Position and Address } \\
\hline \multirow[t]{3}{*}{ Postdoctoral Associate } & Department of Neurobiology \\
\hline & Yale University School of Medicine \\
\hline & Mentor: Dr. Pasko Rakic \\
\hline \multirow[t]{3}{*}{ Office Address } & Department of Neurobiology \\
\hline & 333 Cedar Street, SHM C302 \\
\hline & New Haven, CT 06520-8001 \\
\hline Phone & (203) 785-6172 \\
\hline Fax & (203) 785-5263 \\
\hline Email & albert.ayoub@yale.edu \\
\hline
\end{tabular}

\section{Biography}

Date of Birth $\quad$ May 7, 1973

Citizenship Lebanon

\section{Education}

2003

Ph.D., Neurobiology and Anatomy Department of Neurobiology and Anatomy WVU School of Medicine, Morgantown WV 26506

1998 (Dec.) B.A. Biology (minor in Physics). Summa cum laude Department of Biology

West Virginia University, Morgantown WV 26506

\section{Honors and Awards}

2002

2000

$1999-2000$

1998

1998

1998
Doctoral student travel fellowship (award: \$1,400)

Doctoral student travel fellowship (award: $\$ 1,200$ )

Swiger doctoral student fellowship (award: \$ 1,000/yr)

Summer research fellowship (award: \$2,200)

Graduated with High Honors, WVU Eberly College of Arts and Science

Dean's Award for Scholarly Achievements, Eberly College of Arts and Sciences 


\section{Professional Membership}

1999-

2000-

$2000-$

$2000-$

$2001-$
American Association for the Advancement of Science (AAAS)

Society for Neuroscience

American Association of Anatomists

FASEB

Bioinformatics.Org

\section{Academic and University Committees}

2003

2001- 2003

2001-
Admissions committee for the Biomedical Science Graduate Training Program

Graduate student representative, Department of Neurobiology and Anatomy Student Leadership Committee, WVU School of Medicine

\section{Teaching Experience}

Spring 2003

Spring 2002

Spring 2002

Spring 2001

Spring 2000
Medical Neurobiology (CCMD 775)

Medical Neurobiology (CCMD 775)

Continuing Education for Psychiatry Residents at Chestnut Ridge Hospital (Internal structures of the CNS)

Medical Neurobiology (CCMD 775)

Medical Microanatomy (ANAT 723)

\section{Seminar Presentations}

2003

2003

2002

2001

2000

1999
The matrix metalloproteinases 2 and 9 are expressed in the developing cerebellar cortex and are disrupted by ethanol exposure, Van Liere Research Symposium. Contribution of MMP-2 and MMP-9 to the postnatal development of the rat cerebellar cortex, Dept. of Neurobiology at Yale University School of Medcicine. Contribution of MMP-2 and MMP-9 to the development of the cerebellar cortex and the effect of ethanol exposure, Dept. of Neurobiology and Anatomy.

Structural Plasticity of Microglia in the hypothalamic SON, Dept. of Neurobiology and Anatomy.

Microglial plasticity in the Supraoptic Nucleus, Van Liere Research Symposium. Neurobiology of Neurotrophins (A Review), Dept. of Neurobiology and Anatomy. 


\section{Research Activities}

2001-2003

Contribution of MMPs to the development of the cerebellar granule neurons and the effect of ethanol exposure. Advisor: J. Luo, Ph.D.

2001

2000

1999

1998

1998
Developmental neurobiology of oligodendrocyte progenitors.

Research Rotation; Laboratory of R. C. Wiggins, Ph.D.

Plasticity of Microglia in the hypothalamic SON

Research Rotation; Laboratory of A. K. Salm, Ph.D.

Molecular aspects of ROS-induced oligodendrocyte injury.

Research Rotation; Laboratory of G. W. Konat, Ph.D./L.M.

Structural organization of auditory brain stem (SOC) circuitry.

Research Rotation; Laboratory of A. S. Berrebi, Ph.D.

Glial plasticity in the hypothalamic SON

Summer Research Fellowship; Laboratory of A. K. Salm, Ph.D.

Feeding competition and dominance in the shrimp Palaemonetes vulagris. Co-investigator (33\% effort). Undergraduate Research Honors Project; Department of Biology.

\section{Publications}

Ayoub A. E. and Luo J. (2003) On the Contribution of MMP-2 and MMP-9 to the Postnatal Cerebellar Corticogenesis (in preparation)

Ayoub A. E. and Salm A. K. (2003) Increased morphological diversity of microglia in the activated hypothalamic supraoptic nucleus. J Neurosci 23(21):7759-66

Salm A.K., Ayoub A. E., Lally B. E. (2003) Structural plasticity of nonneuronal cells in the hypothalamo-neurohypophyseal system: in the right place at the right time. Advances in Molecular and Cell Biology, Vol. 31:181-199 (in press).

Ayoub A.E., Lin H., Li Z., Ma C., Kaplan R., Cai T., Wiggins R.C., Luo J. Developmental expression of matrix-metalloproteinases in the rat cerebellar cortex: impact of ethanol exposure. Soc. Neurosci. Abstr. 28: 727.102002

Ayoub A.E. and Salm A. K. Morphological plasticity of microglia in the activated supraoptic nucleus. Soc. Neurosci. Abstr. 26: 726.72000 